



\section{PLANTES}

USUELIES

DES BRASILIENS,

PAR M. AUGUSTE DE SAINT-HILAIRE.

\section{PARIS,}

GPIABERT, LIBRAIRE, RUE DE SAVOIE, T० $\mathrm{N}^{\circ}$ A DCCC XXIY. 
836 Saint-Hilaire. Plantes uselles des Brasiliens, plates, 3 parts, Paris, 1824, etc. 


\title{
PLANTES USUELLES
}

\author{
DES
}

BR ASILIENS. 



\title{
PLANTES
}

\author{
USUELLES
}

\section{DES BR ASILIENS,}

\section{PAR M. AUGUSTE DE SAINT-HILAIRE,}

\author{
CORRESPONDANT DE L'ACADÉMIE DES SCIENCES.
}

\section{PARIS,}

GRIMBERT, LIBRAIRE, RUE DE SAVOIE, $\mathbf{x}^{0} \mathbf{1 4}$.

II DCCC XXIV. 


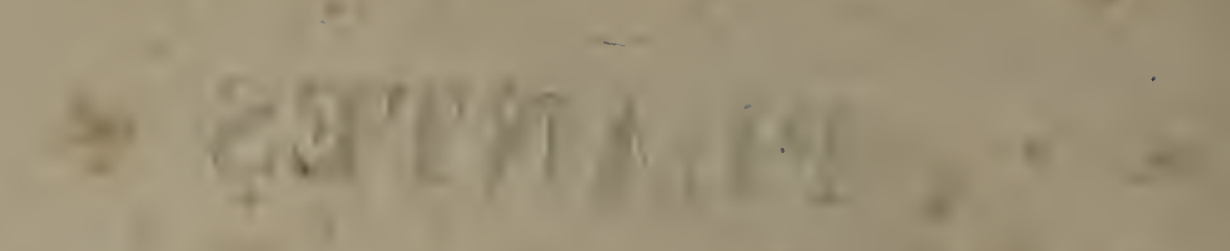

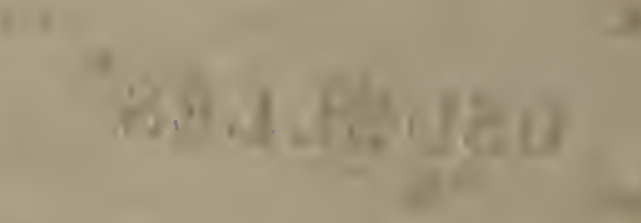
4908 .

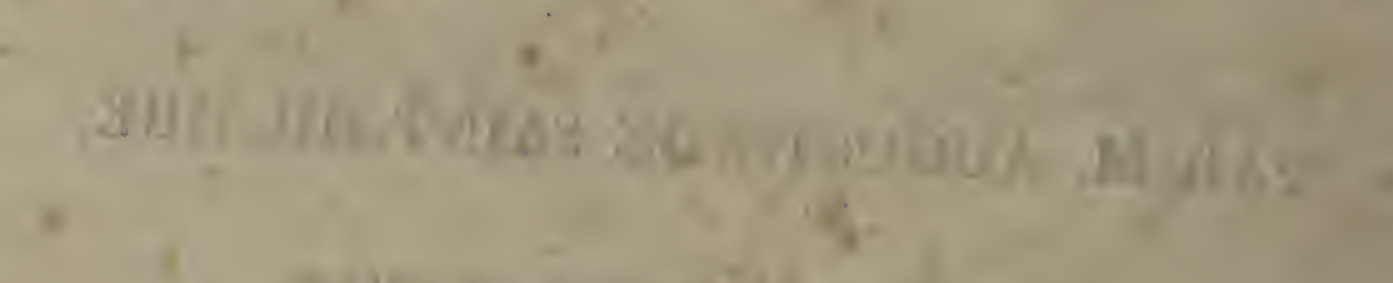




\title{
STRYCHNOS PSEUDOQUINA.
}

\author{
STRYCHNOS FAUX-QUINQUINA.
}

FAMILLE DES A POCINEES.

S. caule inermi, tortuoso; cortice suberoso; foliis ovatis quintuplinerviis, subtus villosis; floribus racemoso-paniculatis, axillaribus, pedunculisque villosis.

Strychnos pseudoquina. Aug. de S. Hil. App. Voy. 34.

Nom vulgaire : Quina do campo.

Description. Arbre d'environ I 2 pieds, rabougri, tortueux, sans épines ; à écorce subéreuse, molle et jaune d'ochre extérieurement, plus compacte, plus dure et plus grise en dessous; à rameaux nombreux et formant une sorte de tête comme le pommier; à ramules tétragones et chargés de poils roux. Feurlues opposées, très-courtement pétiolées, sans stipule, longues de 3 à 4 pouces, ovales, aiguës dans le jeune âge, puis un peu émoussées, entières, dures, cassantes, d'un vert jaunâtre, munies d'un bord calleux, couvertes en dessous d'un duvet roux, glabres ou à peine pubescentes en dessus, relevéeș de cinq nervures dont l'intermédiaire droite, les autres opposées par paire et convergentes : pétiole épais, long de 2 ou 3 lignes, articulé un peu au dessus de sa base, pubescent, presque cylindrique. Grappes axillaires, composées, se rapprochant de la panicule, étalées ou ascendantes, un peu plus longues ou un peu plus courtes que les feuilles, velues et continues avec un court pédoncule qui est chargé à sa base de deux bractées ovales-aiguës, concaves et velues : rameaux de la panicule opposés, étalés, diminuant de longueur de la base au sommet, simples ou presque simples dans le haut, divisés dans le bas, accompagnés, ainsi que leurs divisions, de deux bractées opposées;, linéaires-aiguës, velues. F LEURs nombreuses, très-rapprochées, longues de 3 à 4 lignes, d'une odeur agréable qui rappelle celle du lilas, portées par un pédicelle velu. Calice petit, quinquépartite, hérissé $N^{\circ} \mathrm{I}$. 
de poils roux; à divisions lancéolées-linéaires, aiguës. Conolle hypogyne, hypocratériforme, quinquéfide, pubescente à sa surface extérieure, laineuse à l'entrée du tube, blanchâtre ou verdâtre; à divisions sémi-lancéolées-linéaires, étalées. Cinq antuères, sessiles, insérées au sommet du tube entre les divisions de la corolle, courtes, elliptiques-linéaires; un peu obtuses, glabres, biloculaires, s'ouvrant longitudinalement, ayant la face tournée vers le centre de la fleur, et sortant à peine du tube de la corolle. Point de Nectaire. Sty te souvent chargé de quelques poils à son sommet ou vers le milieu de sa longueur. Stigmate en tête un peu bilobée. Ovaine ovoïde, glabre, biloculaire, polysperme: ovules nombreux, attachés dans chaque loge à des placentas épais qui couṿrent presque toute la cloison; la plupart avortent bientôt, et ceux qui ont été fécondés repoussant la cloison et les placentas contre le paroi du péricarpe, semblent alors pariétaux. BAIE globuleuse, de 7 à 8 lignes de diamètre, glabre, jaune, luisante, renfermant, sous une écorce coriace, une à quatre semences plongées dans une pulpe douceâtre, d'un goût assez agréable. Semence orbiculaire, discoïde, déprimée, d'environ 6 à 7 lignes de diamètre : ombilic placé vers le milieu d'une des faces de la semence. Périsperme très-grand, corné. Embryon droit, placé dans le bord du périsperme, parallèle au plan de l'ombilic : radicule très-obtuse, en massue, aboutissant presque à l'extérieur de la semence : cotylédons ovales-aigus, minces, planes, à cinq nervures, tournés vers le centre du périsperme.

Localités. Cet arbre croît en général dans les pâturages parsemés d'arbres tortueux et rabougris (tabuleros cobertos). On le trouve dans toute la partie orientale de la province de Minas-Geraes (le certao ou désert), le district de Minas-Novas et celui des Diamans, les déserts de Goyaz, etc.

Usages. De toutes les plantes médicinales du Brésil, le Strychnos pseudoquina, ou Quina do campo est peut-être celle dont l'usage est le plus répandu, et dont les propriétés sont le mieux constatées. A l'exception de la baie qui a une saveur douceâtre, et que les enfans man- 
gent avec plaisir, toutes les parties de la plante sont d'un goût extrêmeiment amer et un peu astringent; mais c'est principalement dans l'écorce que résident ces qualités, et c'est d'elle aussi que les habitans du pays font usage. Ils s'en servent à peu près dans toutes les maladies où les médecins d'Europe administrent le quinquina, et principalement dans les fièvres intermittentes si communes tous les ans sur les bords du Rio-de-S.-Francisco, et des rivières appelées Rio-do-Sono, daPrata, Abaïtè, etc. Tantôt ils emploient l'écorce du pseudoquina en décoction, et tantôt ils la prennent en poudre assez généralement à la dose d'un demi-oitara à un oitava $(0,00$ I 789 à 0,003578 kil.) Un des médecins les plus éclairés du Brésil, qui avait fait des expériences sur le Strychnos pseudoquina comparativement avec le quinquina du Pérou, m'a assuré qu'il avait trouvé l'écorce de la plante de Minas au moins égale pour les propriétés à celle des véritables Cinchona de l'Amérique espagnole; et les essais qui ont été tentés à Paris et dans les environs, tendent à confirmer cette assertion. Si les habitans de la côte, et surtout de Rio-de-Janeiro, qui font un usage si fréquent du quinquina des boutiques, voulaient y substituer l'écorce du pseudoquina, plante commune dans l'intérieur de leur propre pays, ils n'en obtiendraient pas des résultats moins satisfaisans, et ils s'affranchiraient d'un tribut onéreux. D'un autre côté, si ce médicament était adopté en Europe, il pourrait s'y vendre à des prix moins élevés que le quinquina du Pérou, et en même temps il deviendrait pour le Brésil une nouvelle branche de commerce. - M. Vauquelin a fait l'analyse de l'écorce du pseudoquina, et il a trouvé qu' elle contenait principalement, $\mathrm{I}^{\circ}$ une matière amère qui forme la plus grande partie de ses principes solubles, et qui, suivant notre illustre chimiste, paraît être celle en qui résident les propriétés fébrifuges $; 2^{\circ}$ une substance résineuse particulière très-soluble dans l'alcool à $36^{\circ}$, et peu soluble dans l'alcool absolu; $3^{\circ}$ une matière gommeuse colorée et unie à un principe animalisé qui modifie ses propriétés physiques; $4^{\circ}$ un acide particulier qui, comme l'infusion de galle, précipite le sulfate de fer et la colle forte, mais avec des moditications qui ne permettent pas de le regarder comme de l'acide galli- 
que. - Ce qui peut paraître assez singulier, c'est qu'on n'ait découvert, dans la plante qui nous occupe, ni brucine, ni quinine, et surtout aucun atome du principe dangereux que M. Pelletier a trouvé dans les semences des Strychnos nux-vomica (noix-vomique) et ignatia (fève de saint.Ignace). M. Segalas médecin et habile expérimentateur, a aussi constaté que le principe amer du Strychnos pseudoquina, quand il est injecté dans les veines des animaux, produit des effets différens de ceux déterminés par la strychnine. Il a également constaté par des expériences que ce même principe amer est d'une activité beaucoup plus faible que l'extrait alcoolique de noix-vomique, et surtout que la brucine et la strychnine, et, quoiqu'il devienne vénéneux pris en certaine quantité, comme beaucoup d'autres substances usitées en médecine, il peut être administré sans la moindre crainte aux doses auxquelles on l'emploie ordinairement et même à des doses plus fortes. Ainsi quand l'usage qu'une grande partie des Brasiliens fait depuis tant d'années de l'écorce du pseudoquina, n'aurait pas démontré qu'elle est bien loin d'avoir quelque inconvénient pour la santé, on pourrait être, à cet égard, entièrement rassuré par les expériences que je viens de citer. On sait, au reste, que.tous les Strychnos n'ont pas des propriétés dangereuses, et qu'il en est, tels que le Tettan Kotta (S.potatorum), qui soint tout-à-fait innnocens. On sait aussi que les diverses parties des plantes ne contiennent pas toutes les mêmes principes; la pulpe des fruits du Strychnos nux-vomica se mange sans inconvénient; j’ä moi-même mangé plus d'une fois celle des baies du Strychnos pseıdoquina, et il n'est par conséquent pas très-extraordinaire qu'on ne retrouve point dans l'écorce de cette dernière plante ce qu'on a observé dans la graine des $S$. nux-vomica et ignatia.

Observations botaniques. Le genre Strychnos se distingue par un calice quinquépartite; une corolle monopétale infondibuliforme; des étamines au nombre de cinq, insérées à l'entrée du tube; un ovaire supérieur biloculaire et polysperme; un stjle unique; un stignate en tête; un fruit succulent revêtu d'une écorce coriace ou crustacée; des semences peltées avec l'ombilic au mulieu de la face; uñ périsperme corné et très-grand; enfin un embryon droit ou flexueux paral- 
lèle au plan de l'ombilic et placé dans le bord de la graine, à cotylédons foliacés, à radicule aboutissant presque à l'extérieur de la semence. Ce genre, dont l'Ignatia L. sup. n'est probablement pas distinct, a été placé parmi les Apocinées par Jussieu, Brown, A. Richard et ious les autres botanistes. M. de Candole propose, il est vrai, d'en faire une famille séparée (Theor. 1, ed. 217 et Prop. med. 208); mais il paraît que lui-même attache peu d'importance à cette idée, car non-seulement il ne donne point le diagnostic de ses Strychnées; mais encore il ajoute en propres termes que ce groupe est mal connu, quant $\grave{a}$ ses caractères botaniques et à la circonscription des genres qui doivent le composer. J'ai étudié le genre Strychnos avec le plus grand soin, et il m'a semblé que les caractères qui paraissent le distinguer du plus grand nombre des Apocinées se nuançaient cependant si bien avec ceux de quelques genres qui appartiennent certainement à cette famille, qu’il se ait impossible de le séparer d'elle. Les propriétés et les principes du Strychnos pseudoquina se retrouvent dans l'A pocinée, appelée par les Brasiliens Paratodo. On observe l'absence d'un suc propre laiteux jusque dans le genre Échites. Si la préfloraison est valvaire dans les Strychnos, elle n'est pas non plus décidément tordue dans l'Alyxia, puisqu'un des deux bords des pétales rentre en dedans à la manière des cloisons; et $M$. de Candole lui - mème a reconnu que la préfloraison n'était pas tordue dans toutes les Apocinées. Le fruit est succulent dans beaucoup de genres qui apparliennent à cette famille. La structure extérieure ef intérieure des graines, très-variable dans les Apocinées, n'y a peut-être pas autant d'importance que d'autres caractères. Mais d'ailleurs des seménces peltées avec un périsperme corné se retrouvent dans le fruit unique et succulent du genre Carissa qui a la préfloraison tordue, et un suc propre laiteux, souvent trèsabondant; et dans le Carissa speciosa N̦. (Handcomia speciosa Bern. Gom Mem. Lis.11I, p. 51) en parliculier, j’ai observé, comme dans le $S$. pseudoquina, des semences déprimées et discoïdes avec l'ombilic placé au milien de leur face, et un embryon droit, parallèle à l'ombilic; à la vérité cet embryon esí axile, tandis que celui des $S$. nux-vomica, potatorum et pseudoquina est rejeté vers le bord du périsperme ; mais cette différence est réellement peu de chose, puisque dans l'Ignatia où l'embryon est plus alongé, il passe par le centre de la graine. Quoi qu'il en soit, l'absence du suc propre laiteux dans les Strychnos, leurs nervures convergentes, et peut-être les propriétés du $S$. pseudoquina achèvent de confirmer les rapports des Apocinées et des Gentianées:

EXPLICATION DE IAA FIGURE.

1. Fleur très-grossie. - 2. Corolle vae à l'intéricur. - 3. Pistil. - 4. Coupe de l'ovaire uniloculaire et polysperme.

$\mathrm{N}^{\circ} \mathrm{I}$. 



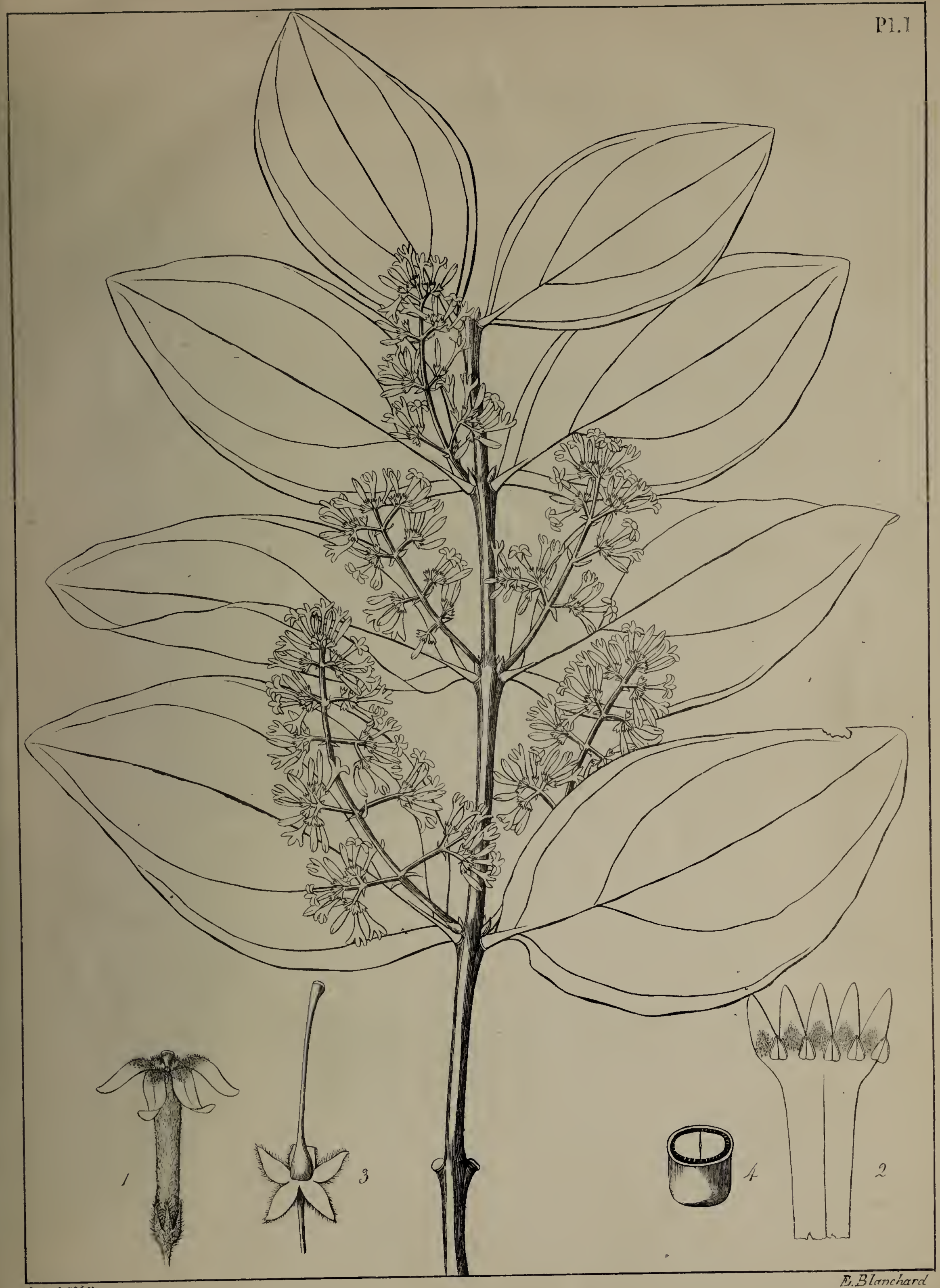

ELPYCHAOS-PSHTDOOUINA 



\title{
$I^{\circ}$ CINCHONA FERRUGINEA.
}

\author{
QUINQUINA COULEUR DE ROUILLE. \\ FAM ILLE DES IRUBIACÉS.
}

C. frutescente, gracili, vix ramoso; foliis oblongo-lanceolatis, subangustis, margine revolutis, superne profunde sulcatis, coriaceis; racemis elongatis, interruptis.

Macrocnemum foliis oblongo-lanceolatis, coriaceis, integerrimis. Vel. in Vand. Lus. et Bras., p. I/4.-Raem. et Schult., vol. v, p. I6.

Cinchona ferruginea. Aug. de S. Hil. App. Voy.p. 8.

Noms vulgaires : Quina da Serra; Quina de Remijo.

Description. Arbrisseau de 4 à 5 pieds, plus rarement davantage; à tige grêle, droite, simple ou peu rameuse, trigone ou tétragone à son sommet, suivant que les feuilles sont ternées ou opposées. A l'exception du bas de la tige et de la surface supérieure des feuilles qui y est glabre ou simplement pubescente, du moins quand elles sont adultes, toutes les parties extérieures de la plante sont chargées de porss couleur de rouille, plus abondans et plus serrés sur les pédoncules, l'axe des grappes, les bractées et le calice. Feuilues opposées ou plus souvent ternées, pétiolées, longues de 5 à 8 pouces, larges d'un pouce et demi à 2 pouces, oblongues-lancéolées, un peu étroites, aiguës aux deux extrémités, quelquefois un peu acuminées au sommet, entières, repliées en dessous en leurs bords, coriaces, relevées inférieurement de nervures très - saillantes, creusées à la surface supérieure d'un sillon longitudinal qui répond à la nervure moyenne, et de sillons latéraux arqués et profonds qui correspondent aux nervures latérales : pétiole court, velu, convexe en dessous, canaliculé en dessus. Strpules placées entre les feuilles, soudées'à la base, longues d'un demi-pouce, élargies, linéaires-lancéolées, aiguës, caduques. Grappes axillaires, plus ou moins longuement péNo II. 
donculées, dressées ou ascendantes, composées de quatre à sept paires écartées dans le bas, de rameaux simples, généralement assez courts, nuls ou presque nuls à l'extrémité de la grappe : pédoncule long, comprimé : rameaux de la panicule comprimés, ascendans, accompagnés de deux bractées opposées, linéaires-aiguës entre lesquelles sont autant de stipules larges à la base, demi-ovales, aiguës. FLeurs sessilles à l'extrémité de la grappe ou de ses rameaux et entremêlées de bractées linéaires-aiguës. CALIcE adhérent, à peu près turbiné, dont le limbe est à cinq dents profondes, aiguës et inégales. Corolle tubuleuse infondibuliforme, longue de 6 à 8 lignes, légèrement courbée, couleur de chair; à limbe quinquépartite, dont les divisions sont linéaires-aiguës, charnues, triangulaires dans leur circonférence, avec l'angle interne obliquement tronqué à sa base. Cinq ÉTAMINEs incluses, glabres, insérées au-dessous du milieu du tube de la corolle, mais à des hauteurs inégales, quoique aboutissant toutes au même niveau : filets aplatis, très-inégaux; deux presque nuls, le troisième ayant environ le cinquième de la longueur de l'anthère, le quatrième un peu plus du tiers, et le cinquième environ les deux tiers : anthères, linéaires, étroites, biloculaires, s'ouvrant longitudinalement. ST y LE inclus, glabre, ayant deux fois la longueur du calice, divisé au sommet en deux branches linéaires-aiguës, épaisses, stigmatiques à la face. Nrctarne épigyne, presque cylindrique entourant la base du style, sans y adhérer. Ovarne biloculaire, à loges polyspermes : ovules nombreux, déprimés, presque orbiculaires, ascendans, embriqués, attachés dans chaque loge à un placenta alongé, charnu, semi-cylindrique, porté par la cloison. CaAsule longue de 6 à ro lignes, ovoïde-elliptique, comprimée, creusée d'un sillon sur le milieu de chaque face, dure, presque ligneuse, divisée en deux loges et dans le sens le plus étroit par les valves rentrantes, s'ouvrant en deux valves par le milieu de la cloison dont chaque moitié présente alors dans son milieu une interruption linéaire (déhiscence loculicide). Semences nombreuses, embriquées; peltées, très-aplaties, déprimées, munies d'un large bord membraneux, ayant avec ce bord la longueur d'environ trois lignes et une 
forme ovale-elliptique irrégulière. Ombilic placé un peu au-dessous du milieu de la face de la semence.

Avec cette plante, les habitans du pays en confondent deux autres qui, malgré la différence de forme que présentent leurs feuilles, pourraient être considérées comme des variétés avec d'autant moins d'invraisemblance, que les feuilles des Cinchona sont en général très-sujettes à varier. Ces deux plantes sont:

\section{$2^{\circ}$ CINCHONA VELLOZII.}

QUINQUINA DE VELL OZO.

C.caule frutescente, gracili, vix ramoso; foliis ovatis, utrinque acuminatis, margine revolutis, superne profunde sulcatis, coriaceis ; racemis axillaribus, interruptis.

Macrocnemum foliis ternis, lato-lanceolatis, undatis, integerrimis, coriaceis. Vell. in Vand. Lus. et Bras. I4. - Vell. in Script. Lus., 88. - Rcem. et Schult. vol.v. p. 6.

Cet arbrisseau diffère du précédent par ses feuilles ovales, acuminées aux deux bouts, larges de 3 à 4 pouces; par ses pédoncules ordinairement plus courts; ses bractées moins linéaires; ses fleurs plus longues et plus nombreuses.

\section{$3^{\circ}$ CINGHONA REMIJIANA.}

QUINQUINA DE REMIJO.

C. caule frutescente, gracili, vix ramoso; foliis late ellipticis, obtusis, cuspidatis, in summum petiolum subdecurrentibus, margine revolutis, superne profunde sulcatis, coriaceis; racemis axillaribus, interruptis.

Cette espèce offrè à peu près tous les caractères du C. ferruginea. 
Cependant elle s'en distingue par ses feuilles larges d'environ 3 à 4 pouces, elliptiques, obtuses, un peu décurrentes sur le pétiole et terminées par une pointe courte.

Localités. J'ai trouvé les Cinchona ferruginea, Vellozii et Remijiana entre les $2 \mathrm{I}^{\circ} 4^{5^{\prime}}$ de lat. sud et les $17^{\circ} 50^{\prime}$. Ils croissent à la hauteur de deux à quatre mille pieds au-dessus du niveau de la mer, sur les sommets arides et découverts de cette chaine de montagnes qui s'étend du sud au nord dans la province de Minas, et qui forme la limite des bois vierges et des pays découverts. Ces trois plantes sont un indice à peu près certain de la présence du fer. On les trouve, entre autres, dans le voisinage de $S$. Joao-del-Rey, les alentours de Villa-Rica, la Serra-dos-Piloes près $\boldsymbol{S}$. Miguel-deMato-Dentro, Penha dans le termo de Minas-Novas, etc.

Étymologie. Ces plantes ont été appelées par les habitans du pays Quina da Serra, parce qu'elles croissent dans les montagnes, et Quina de Remijo, parce qu'un chirurgien de ce nom fut le premier qui en indiqua l'usage. J'ai appelé la première des trois espèces $C$. ferruginea, à cause de sa couleur; la seconde $C$.Vellozii en l'honneur de l'abbé Vellozo deVilla-Rica qui l'avait distinguée comme moi, et qui l'a brièvement indiquée dans le Floree Lusitanica et Brasiliensis specimen de Vandelli; et enfin la troisième $C$. Remijiana, afin de conserver le souvenir de celui auquel on est redevable de l'application de ces plantes comme fébrifuges.

Usages. Au milieu de tant de plantes auxquelles les Brasiliens donnent à tort le nom de Quina, les Cinchona ferruginea, Vellozii et Remijiana doivent être distingués comme de véritables quinquina. Leur écorce amère et astringente ressemble singulièrement, pour la sareur, à celles du quinquina de l'Amérique espagnole; je ne doute pas qu'elle n'offrît les mêmes principes, et elle a été employée avec succès comme fébrifuge par les habitans des pays ou on la trouve. Il faut avouer cependant qu'elle ne 'paraît pas produire des résultats tout-à-fait aussi heureux que le quinquina du Pérou et le Strychnos 
pseudoquina. Mais comme on ne rencontre pas cette dernière plante dans les lieux où croissent les trois quinquina dont il s'agit ici; ils peuvent être employés comme d'utiles succédanées.

Oscervations botrniques: On sait que le genre Cinchona se distingue par un caï:e adhérent, 5-denté; une coiolie infondibuliforme à linbe quinqzépartite; cing ctamines inciuses; un ovcile à der:x loges polyspermes; une capsule à de ex ralyes qui souvrent par le milieu des cloisons (déhiscence septicide); des semences emóriquées bordées d'une membrane irrégulière. Les trois espèces décrites plus haut, présentant tous ces caractères, n'appartiennent évidemment point au genre Macrocnenum, comme l'avait cru Vellozo. Ce qui au reste rend très-excusable l'erreur du botaniste brasilien, c'est que, pendant longtemps, les caractères de ce dernier genre ont été tracés d'une manière extrêmement vague, et de nos jours seulement on a reconnu qu'il se distinguait essentiellement du Cinchona par sa déhiscence loculicide. ( $V$. Kunth Nov., grn. III, p. 39S.) Quoi qu'il en soit, on ne saurait nier que les $C$. ferruginea, $V$ ellizï ei Fenijiana ne diffèrent beaucoup par leur aspect des autres Cin... chont, et ils pourraient former, dans ce genre, une section bien caractérisée par l'inflorescence et la structure très-remarquable des feuilles.

\section{EXPLICATION DES FIGURES.}

\section{Cinchona ferruginea.}

I. Fleur très-g̛rossie. - 2. Intérieur de la corolle. - 3. Calice adhérent très-grossi.4. Style et stigmate $i d$. -5 . Coupe longitudinale de l'ovaire très-grossi. a Nectaire épigyne. $b$ Ovules. - 6. Capsule de grandeur naturelle. -7 . Coupe horizontale de la capsule un peu grossie. - 8. Semence grossie. 


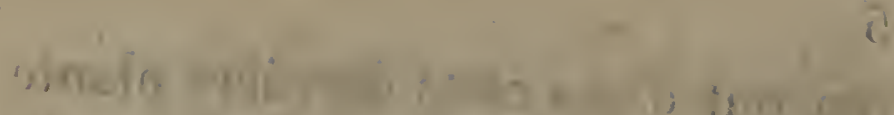

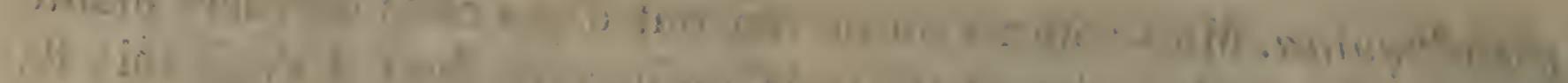

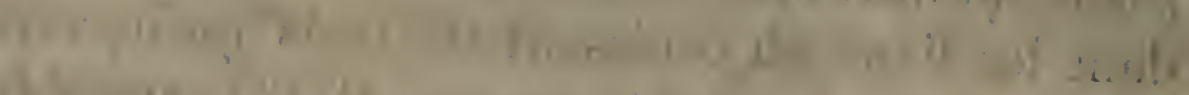

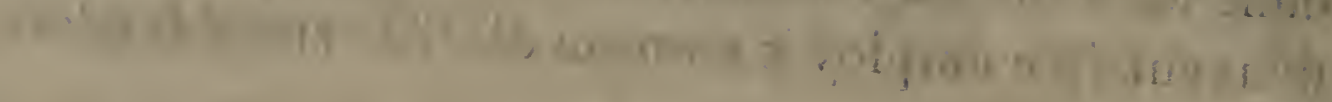

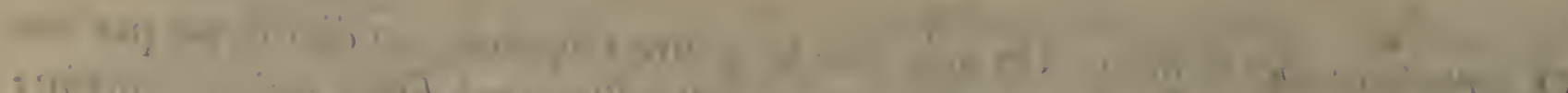

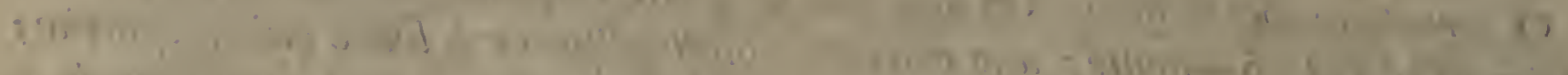

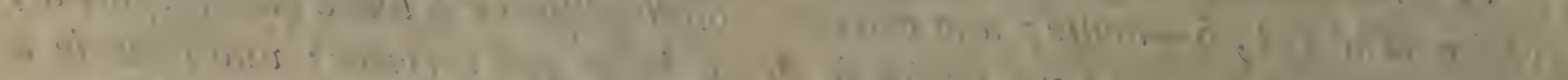

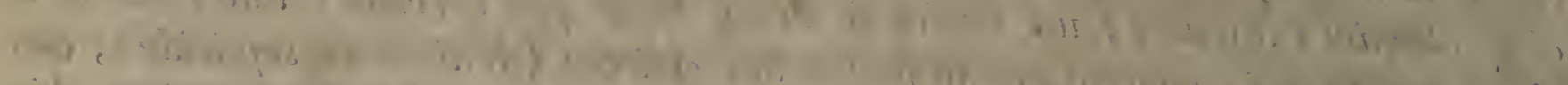

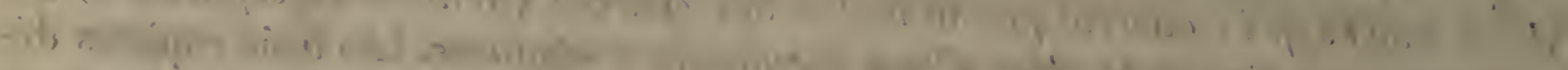

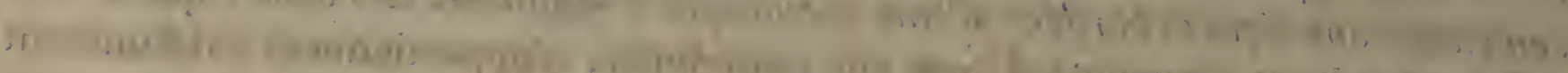



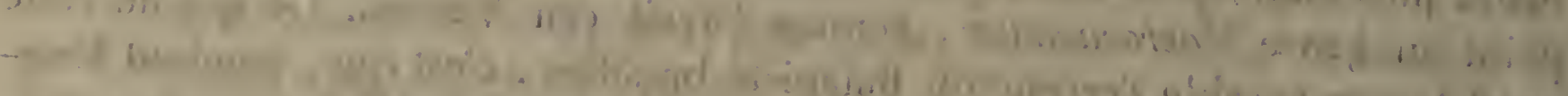

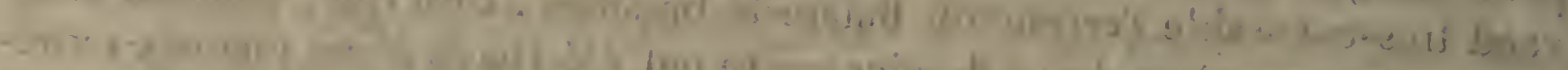

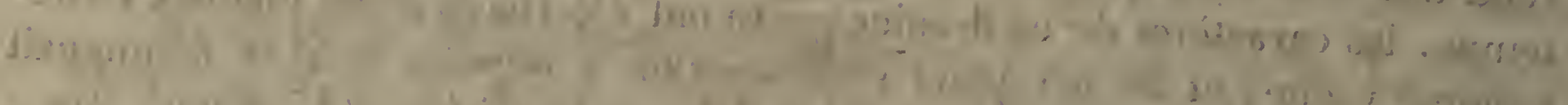

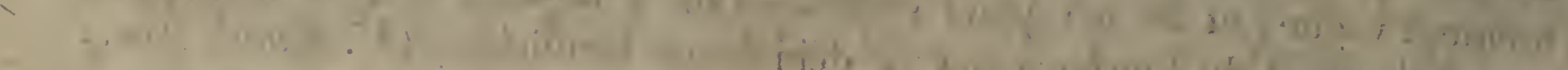

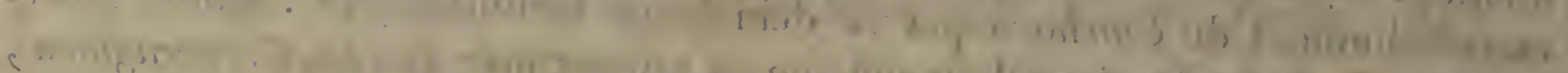

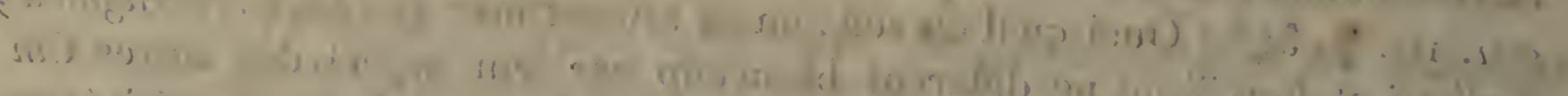

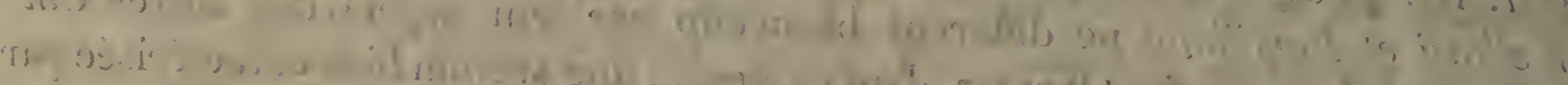

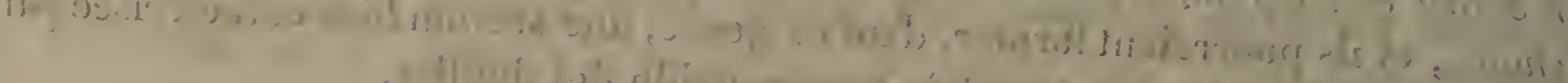

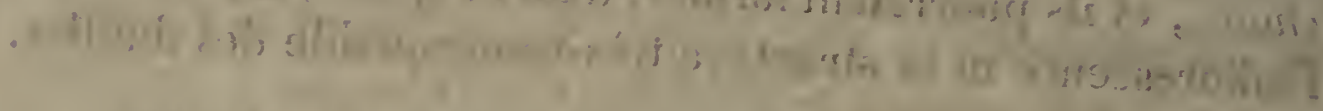

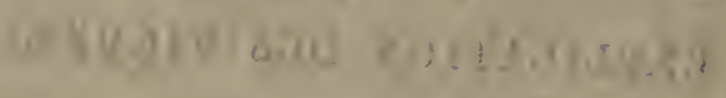

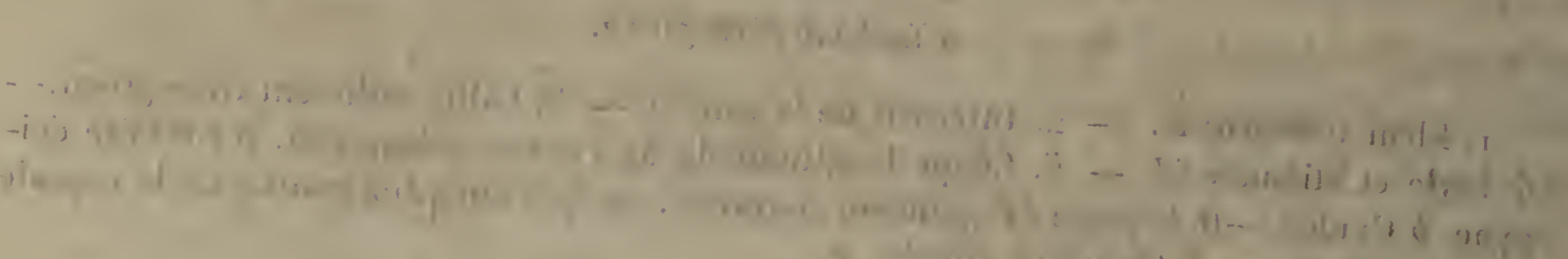







\title{
EXOSTEMA CUSPIDATUM.
}

\author{
EXOSTEMA CUSPIDE.
}

FAMLLE DES RUBACÉS.

E. foliis magnis, lanceolato-ovatis, cuspidatis, nervosis, subtus villosis; paniculá terminali ; limbo calycino obscure quinquedentato, ovario longiore; filamentis medio villosis; stigmate bifido.

Nom vulgaire : Quina do mato.

Description. Tige arborescente, droite, haute de 8 à ıo pieds et peut-être davantage. Fruilles opposées, pétiolées, longues de 9 à I 5 pouces, lancéolées-ovales, aiguës à la base, légèrement obtuses à leur sommet, terminées assez brusquement par une pointe aiguë, un peu ondulées sur leurs bords, pubescentes en dessus, velnes en dessous : nervure moyenne très-velue, saillante en dessus et en dessous : nervures latérales, arquées, ascendantes, également saillantes et velues : veines ne paraissant qu'en dessous et s'étendant d'une nervure à l'autre : pétiole court, velu, anguleux en dessous, canaliculé en dessus. Stipures caduques. Panicule terminale, plus courte que les feuilles, étalée, velue, blanchâtre, portée par un pédoncule triangulaire et velu, long de 2 à 3 pouces : rameaux de la panicule presque horizontaux, comprimés, divisés, accompagnés, ainsi que leurs divisions, de bractées ovales-aiguës, larges à la base, glabres en dessus, velues en dessous. Fleurs sessiles ou presque sessiles, réunies au nombre d'environ trois à six à l'extrémité des subdivisions de la panicule et accompagnées de bractéoles d'une forme semblable à celle des bractées. CaLice turbiné, velu, blanchâtre; son limbe est sensiblement évasé, plus long que la partie adhérente et à cinq dents peu marquées. Conolle tubulée, 5 - fide, longue de 2 à 4 lignes, blanche, dont le tube est sensiblement plus étroit que le limbe du calice, pubescent par intervalles et garni à son entrée de poils nom$\mathrm{N} \cdot$ III. 
breux et serrés; dont les divisions sont oblongues, très-obtuses, réfléchies dans leur moitié supérieure et plus longues que le tube. Cinq Étamines s'élevant hors de la corolle, alternes avec ses divisions, insérées un peu au-dessus de la moitié du tube : filets barbus au milieu de leur face : anthères linéaires, glabres, bifides à leur base, attachées par le dos un peu au-dessus de cette même base, biloculaires et s'ouvrant longitudinalement. STrue glabre, divisé jusqu' au tiers ou environ en deux branches linéaires-lancéolées, obtuses, épaisses, stigmatiques à la face. Nectarre épigyne déprimé, entourant la base du style sans y adhérer. Ovaire adhérent, biloculaire, polysperme: ovules extrêmement nombreux, attachés dans chaque loge à un placenta proéminent, mais point embriqués. Je n'ai pas vu le fruit.

Localités. Cette plante croît dans les bois vierges du Brésil méridional.

Avec l'espèce précédente, on en confond très-aisément une autre qui cependant en est fort distincte et que nous allons décrire ici. $\mathrm{Ne}$ pouvant la figurer tout entière, nous donnons cependant le dessin de la fleur et du fruit.

\section{EXOSTEMA AUSTRALE.}

\section{EXOSTEMA AUSTRAL.}

E. foliis magnis, ovatis, nervosis, inferne subvillosis; paniculâ terminali, sessili, profunde tripartitá ; limbo calycino ovario multo breviore,' quinquelobo; staminibus glaberrimis; stigmate indiviso.

Description. Trge arborescente. Feurldes ressemblant beaucoup à celles de l'Exostema cuspidatum, opposées, pétiolées, longues de I 2 à 15 pouces, larges de 7 à 8 , ovales, aiguës à la base et un peu décurrentes sur le pétiole, obtuses au sommet ou à peine aiguës, 
très-légèrement sinuées et un peu caleuses sur les bords, à peine pubescentes en dessus, un peu velues inférieurement, munies d'une nervure moyenne velue, saillante en dessus et en dessous; de nervures latérales presque horizontales également saillantes et velues, et enfin de veines qui ne paraissent qu'en dessous et s'étendent d'une nervure à l'autre : pétiole fort court, velu, convexe en dessous, canaliculé en dessus. Stripules persistantes, ovales-triangulaires, trèsaiguës, velues en dehors sur le milieu. Panicule terminale, sessile, longue d'environ 7 pouces à un pied, velue, divisée dès la base en trois branches dont les deux intermédiaires plus courtes : rameaux de la panicule opposés, comprimés, divisés et subdivisés en ramules également comprimés, rarement alternes; les divisions principales de la panicule sont accompagnées de bractées linéaires-subulées, velues en dehors, entre lesquelles se trouvent des stipules triangulaires également velues à l'extérieur. FuEurs longues d'environ 3 lignes, portées par des pédicelles très-courts et glomerulées à l'extrémité des dernières divisions de la panicule. Calice turbiné, velu; à limbe beaucoup plus court que la partie adhérente, plus étroit qu'elle et quinquélobé. Corolde quinquéfide, dont le tube est plus court que les divisions qui sont ovales, très-obtuses, courbées en dedans, un peu pubescentes à leur base. Étamines au nombre de cinq, parfaitement glabres, plus longues que la corolle, insérées au sommet $\mathrm{du}$ tube et entre ses divisions : anthères elliptiques, courtes, ayant la face tournée vers le centre de la fleur. Strue velu. StiGma te indivis et en tête. Nectaire épigyne, très-déprimé. Ovatre biloculaire, polysperme : ovules très-nombreux, attachés dans chaque loge à des placentas charnus, proéminens. Capsule turbinée-ovoïde, terminée par le limbe persistant du calice, velue, biloculaire, polysperme, s'ouvrant en deux valves qui, lors de la déhiscence, partagent dans son épaisseur, la cloison dont chaque moitié offre alors une interruption auparavant remplie par les placentas. Semences trèspetites, semblables à de la sciure de bois, comprimées, de forme très-variable, munies d'un bord membraneux, étroit et presque entier. 
Localités. Cette plante croît dans les bois vierges du Brésil méridional : on la trouve jusque dans les environs de $S$. Paul.

Usages. Dans plusieurs parties du Brésil, on se vante de posséder les Quinquina du Pérou; mais le plus souvent on a donné le nom de Quina à des plantes qui n'appartiennent point aux vrais Cinchona. Celles dont je viens de donner la description sont de ce nombre. A la vérité elles se rapportent à un genre très-voisin, l'Exostema, qui fournit les écorces vulgairement connues sous les noms de Quinquina Piton, Quinquina des Antilles, etc.; mais quoique ces écorces soient fébrifuges, l'on n'y a trouvé ni quinine, ni cinchonine, et leurs propriétés sont beaucoup moins actives que celles des véritables Quinquina. L'écorce des Exostema cupidatum et australe peut également être employće dans les fièvres intermittentes à défaut de médicamens plus eflicaces; cependant beaucoup plus aqueuse, moins astringente et même moins amère que celles des. Cinchona ferruginea, Vellozï et Remijiana, elle paraît leur être fort inférieure en qualité, et elle confirme par conséquent ce qui avait été observé dans les autres espèces congénères* ${ }^{*}$.

Olservations botaniques. Le genre Exostema n'est qu'un démembrement des Cinchona, et, quoiqu'il ait été formé de nos jours, les auteurs ont déjà beaucoup varié sur ses caractères. Voici ceux qu'ils lui ont le plus généralement attribués : une corolle glabre à tube fort long; des étamines se montrant en dehors, qui, suivant les uns, sont insérées au bas du tube, et, suivanit les autres, le sont à son sommet; un stigmate èn tête; des semences peu nombreuses, munies d'un bord entier. Mais, $1^{\circ}$ la corolle est glabre dans beaucoup de véritables Cinchona; d'un autre côté, elle est soyeuse dans l'E. Péruvianum (Kunth Nov. Gen. vol. III), et elle a le tube pubescent par intervalles dans l'E. cuspidatum; $2^{\circ}$ le tube est assez court dans cette dernière plante et l'E. aus-

* On trouve dans les Mémoires de l'Académie de Lisbonne (vol. III, ${ }^{\mathrm{e}}$ part., pag. 96), une analyse chimique très-soignée d'une écorce enroyée de Rio-de-Janeiro sous le non de Quina; mais cette analyse est presque sans utilité, parce qu'on n'y a pas joint la description de l'arbre qui avait fourni l'écorce analysée et qu'on ne peut dire avec une entière certitude à quelle espèce il appartenait. Cela seul prouverait la nécessité de joindre des descriptions botaniques aux observations que l'on fait sur les principes et les propriétés des plantes. 
trale, beaucoup plus court même que dans une foule de vrais Cinchona, et pourtant il est impossible de ne pas faire entrer ces deux espèces dans le genre Exostema, puisqu'elles ont des étamines sortantes; $3^{\circ}$ les organes mâles sont insérées au sommet du tube dans les E. Peruvianum et australe, au fond du tube dans les espèces indiquées par Roemer et Schultes, enfin un peu au dessous du milieu dans l'E. cuspidatum; ainsi la position des étamines ne fournit point ici de bons caractères; $4^{\circ}$ on n'en peut pas tirer de meilleurs du stigmate ; en effet il est bilobé dans l'E. Pertuianum; on l'indique comme bilamellé dans l'E. Philippinum; ses divisions très-apparentes dans l'E. cuspidatum y ont au moins le cinquième de la longueur du style, et enfin il est entier dans l'Exostema australe si voisin du cuspidatum; $5^{\circ}$ je trouve dañs l'E. australe, comme M. Kunth dans le Peruvianum, des semences à bords fort étroits et presque entiers; mais on n’a pas étudié ce caractère dans toutes les espèces, et ainsi l'on ne peut assurer qu’il soit général. Le seul donc qui sépare clairement les Exostema des Cinchona se trouve dans les étamines qui, chez ces derniers, sont renfermées dans le tube, tandis que celles des Exostema sortent en dehors. Cette différence facile à saisir semble d'abord artificielle ; cependant elle paraît avoir ici une haute importance, puisqu'elle coïncide avec les principes mêmes des plantes quii nous occupent, et que des étamines incluses indiquent, dans les Cinchona, des propriétés plus héroïques, tandis que des étamines sortantes sont, dans les Exostema, l'indice de l'absence de la quinine et de la cinchonine et en même temps celui de vertus moins efficaces.

\section{EXPLICATION DES FIGURES.}

A. Exostema cuspidatum. - - I. Fleur grrossie. -2. Intérieur de la corolle : ses divisions sont tronquées artificiellement pour laisser voir les étamines. - 3. Style et stiggmate. 4. Calice adhérent très-gुrossi. - B.-Exostema australe. - 1. Fleur très- grossie. 2. Capsule de grandeur naturelle. - 3. Capsule très-grossie. - 4. Une des deux valves de la capsule montrant que la déhiscence est loculicide. - 5. Semence grossie munie d'un bord étroit et membraneux, lequel estindiqué dans le dessin par l'intervalle compris entre les deux ligues du contour.

No III. 


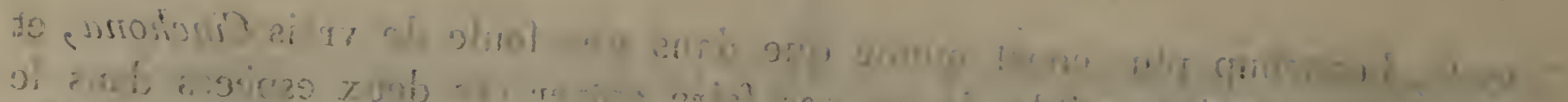

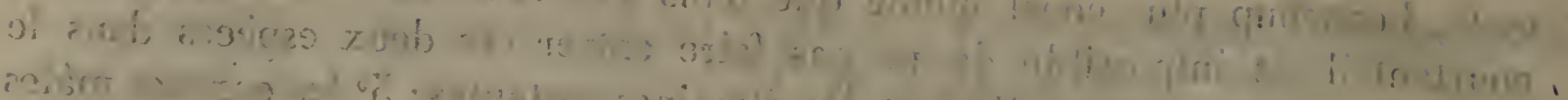

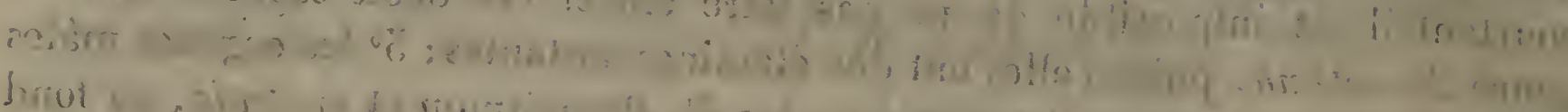

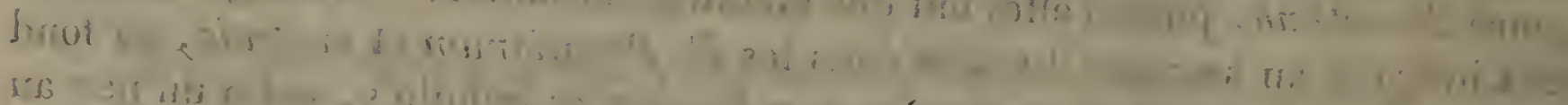

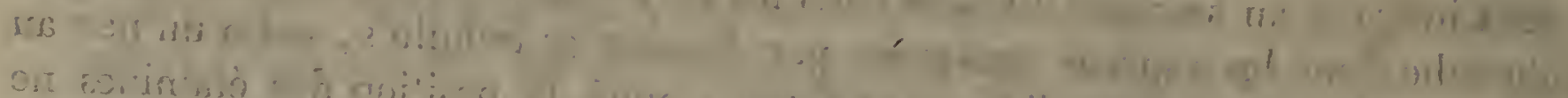

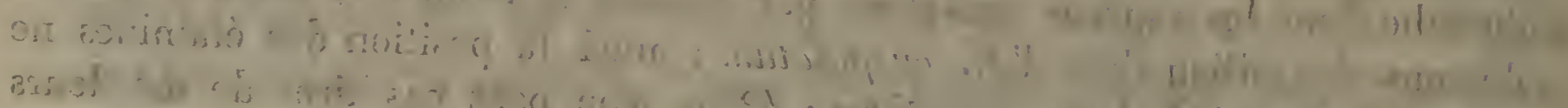

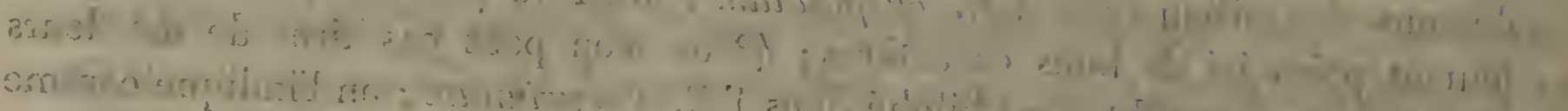

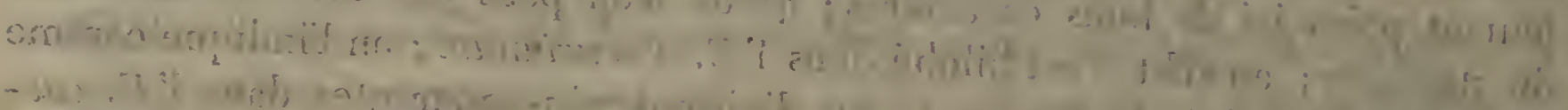

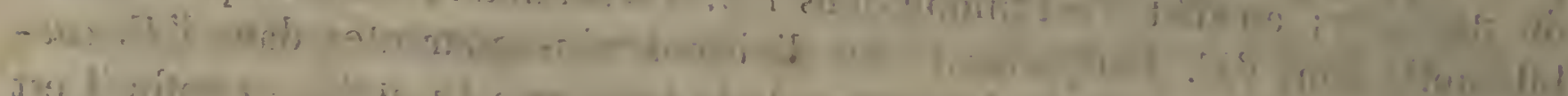

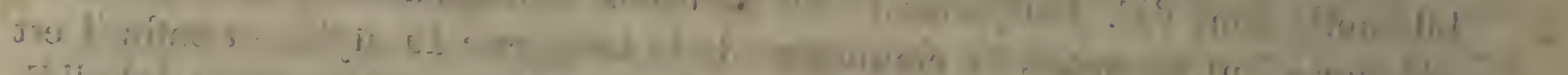

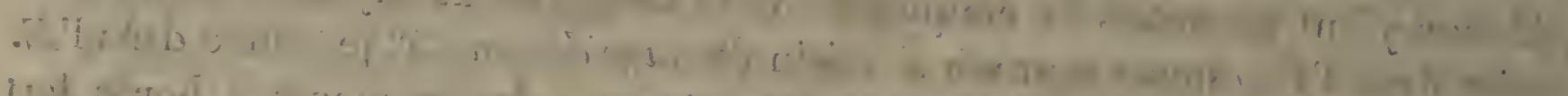

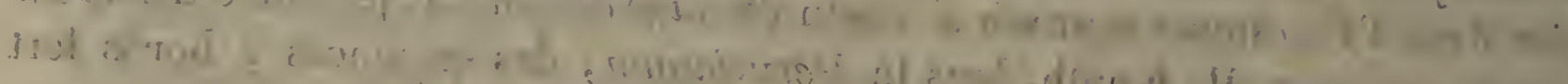

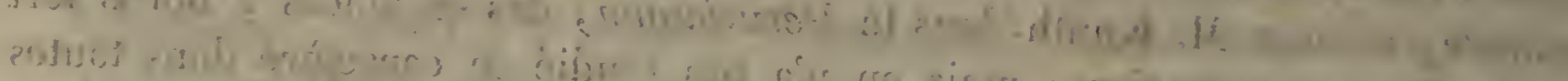
-



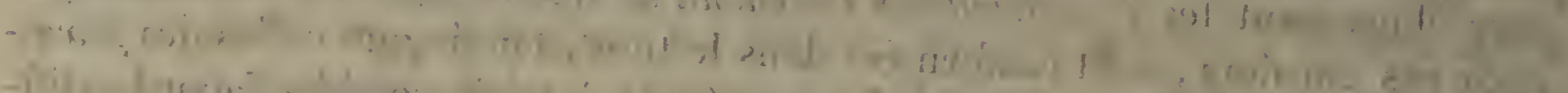

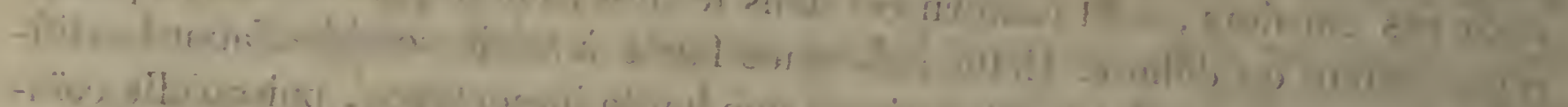

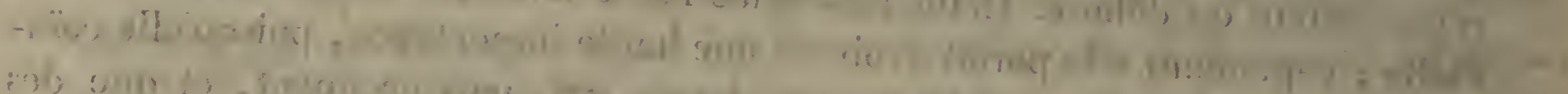

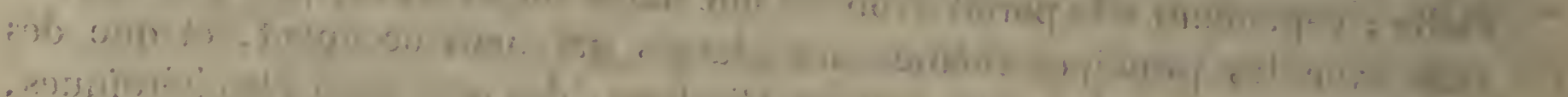

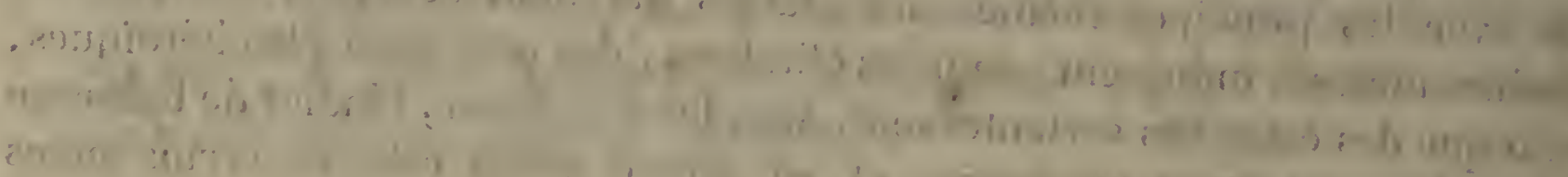

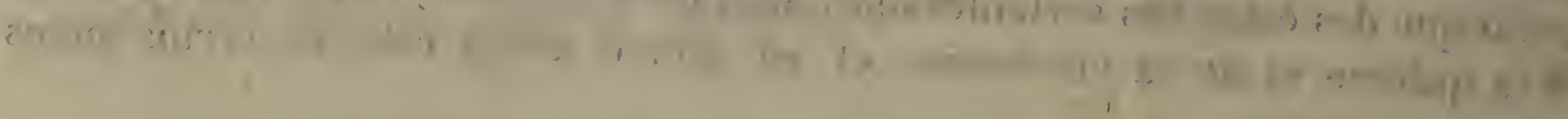



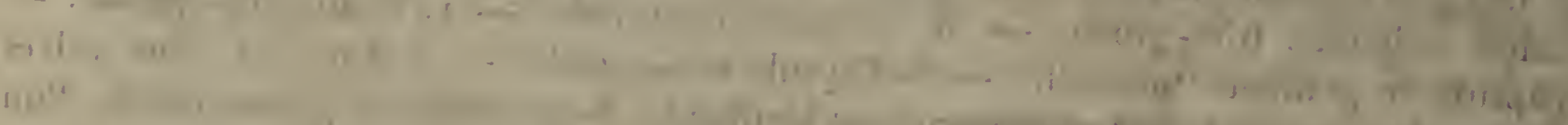



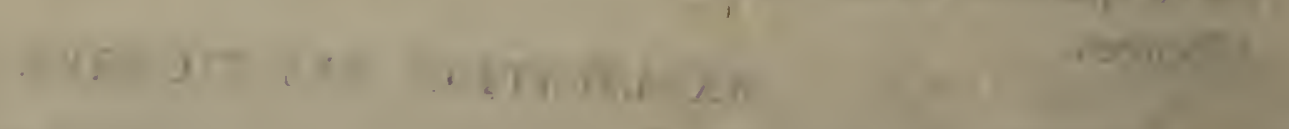




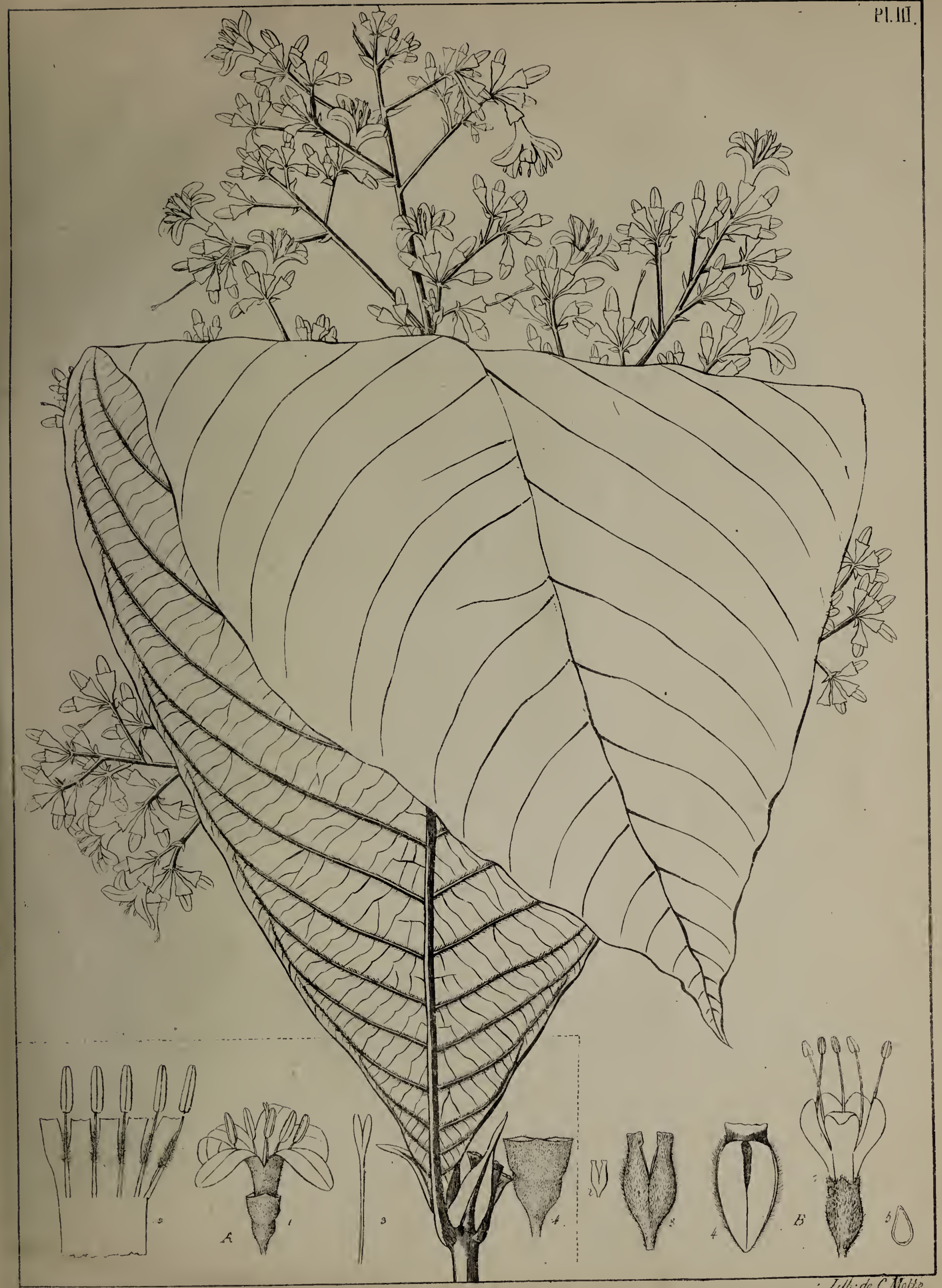

B. EXOSTEMIA AUS'TRALE. A. FXOSTRMAA CUSPIDATUM. 



\section{EVODIA FEBRIFUGA.}

EVODIE FÉBRIFUGE.

FAMILLE DES RUTACÉES.

E. caule arboreo; foliis ternatis; foliolis lanceolato-ellipticis, subacuminatis; paniculâ terminali, pubescente; nectario simplici; ovario muricato.

Noms vulgaires : Tres folhas vermelhas. - Larangeira do mato. - Quina.

Description. Arbre élevé; dont les ramules sont anguleux, rouges, un peu pubescens au somthet. Fevilues opposées ou presque opposées, sans stipule, pétiolées, glabres, trifoliées. Folioles courtement pétiolées, lancéolées-elliptiques, un peu acuminées, très-entières, parsemées de points transparens, longues de 2 à 7 pouces, dont les deux latérales sont plus courtes que l'intermédiaire : quelquefois les deux feuilles les plus voisines de la panicule sont simples. Panicule terminale, pubescente, pédonculée, longue de 4 à 5 pouces, dont les rameaux sont accompagnés de bractéoles semiovales, concaves, ciliées, un peu scarieuses. FLeurs portées par des pédicelles bractéolés. Cialrce petit, 5 - partite, un peu étalé, pubescent, à divisions semi-ovales, obtuses. Pétales au nombre de cinq, hypogynes, égaux, plus longs que le calice, linéaires-ovales, obtus, pubescens en dessous, parsemés de points transparens, un peu plus minces sur les bords. Éramines au nombre de cinq, alternes avec les pétales, hypogynes, glabres : anthères cordiformes, 2 - loculaires, s' ouvrant longitudinalement. Nectarre simple, cupuliforme, à dix côtes, entourant l'ovaire, et l'égalant en hauteur.' $S_{\text {Tyle }}$ très-court, glabre, un peu épais. Strigmate terminal, obtus. Oviıre orbiculaire, déprimé, plane au sommet, purpurin, chargé de pointes, divisé extérieurement en cinq lobes rapprochés et bifides, et intérieurement en cinq loges dispermes : ovules ovales, IV. 
comprimés, attachés à l'angle interne des loges et péritropes. Je n'ai pas vu le fruit.

Locàlités. Cet arbre croît dans les bois élevés de la province des Mines, et en particulier auprès d'Itabira-de-Mato-dentro.

Usages. L'écorce et même le bois de cette plante sont extrêmement amers et astringens, et on les substitue avec beaucoup de succès au quinquina du Pérou, surtout comme fébrifuges. L'efficacité de ce remède doit être d'autant moins révoquée en doute, que ses propriétés se retrouvent au même degré dans unẹ plante de la même famille, le fameux Cusparé, (Galipea febrifuga N. Vulg. : Cortex angusturae); et $l$ Evodia febrifuga peut devenir pour les habitans de la partie orientale de la province des Mines, ce qu'est l'écorce d'angusture pour ceux des bords de l'Orénoque. Je soupçonne que c'est à l'Evodia febrifuga qu'il faut rapporter une écorce très-vantée que quelques Mineurs apportént à Rio-de-Janeiro, sous le nom de Casca de larangeira da terra, et dans laquelle le docteur Bernardino Antonio Gomez dit avoir trouvé de la cinchonine. (V. Mém., Lisb. III, P. 2 I I.)

Observations botaniques. M. de Candole avait déjà pressenti la nécessité de rétablir le genre Evodia de Forster, et l'adoption de ce genre devient indispensable aujourd'hui que M. Kunth a prouvé l'identité générique des Zantoxylum et du Fagara. Le genre Evodia sera caractérisé de la maniere suivante: Calice 4-5 fide on 4-5 parlite. Pélales 4-5 hypogynes, égaux, plus longs que le calice. Étamines en nombre égal à celui des pétales, alternes avec eux, hypogynes : anthères mobiles, biloculaires. Nectaire simple, "cupuliforme ou quatre glandes hypogynes. Style unique, très-court. Stigmate terninal, obtus. Ovaire 4-5 lobé ou 4-5 partite, à loges dispermes: ovules péritropes attachés à l'angle interne des loges. 4-5 coques pour fruits. - Arbres ou arbrisseaux. Feuilles opposées, pétiolées, trifoliées, sans stipules. Fleurs en corymbes axillaires ou en panicules terminales. Le genre Evodia fait partie de la tribu des Rutacées proprement dites.

\section{EXPLICATION DES FIGURES.}

I. Fleur très-grossie. - 2. Pétale détaché : le bord plus mince et plus transparent est indiqué par un double contour. - 3. Intérieur de la fleur $: a$ calice, $b$ pétales; $c$ filets des étamines sans leurs anthères, $d$ nectaire à dix côtes cachant l'oraire, $e$ style, $f$ stigmate. 


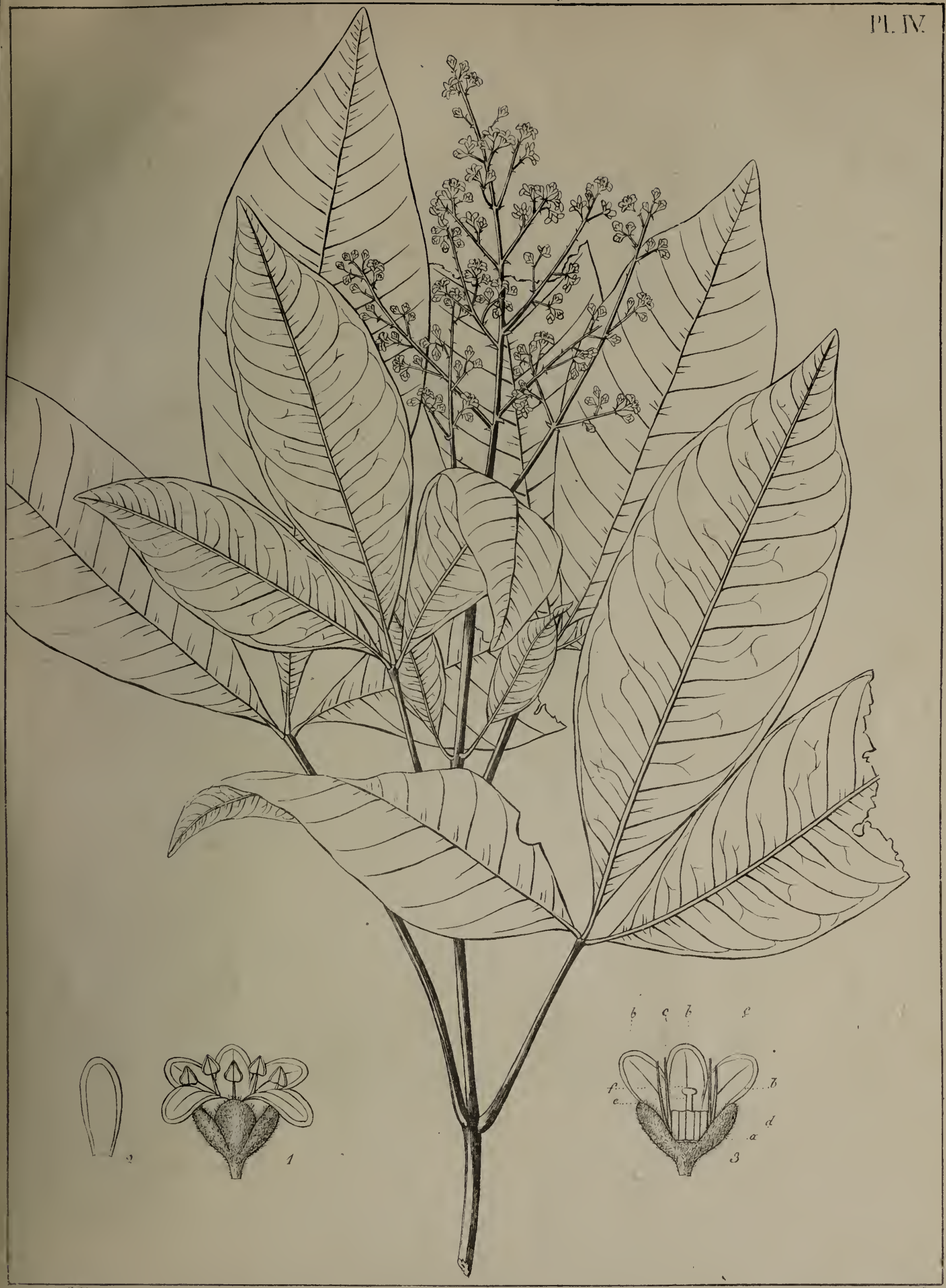

F. Bluentienter 



\title{
SIMARUBA VERSICOLOR.
}

\author{
SIMARUBA BIGARRÉ.
}

S I M A R OUBÉES.

S. foliis pinnatis; foliolis oblongo-ellipticis, obtusissimis, retusis, nervo medio pubescente; paniculá terminali laxa; floribus diøcis decandris.

Nom vulgaire : Paraïba.

Description. Petit arbre rameux, haut de 5 à io pieds. Feutlues sans stipules, alternes, pétiolées, pennées sans impaire, longues de 5 à 12 pouces, portées par un pétiole assez court, glabre et rougeâtre : folioles au nombre de huit à quatorze, alternes, pétiolées, longues d'un demi pouce à trois, oblongues-elliptiques, très-obtuses, échancrées au sommet, vertes et glabres en dessus, blanchâtres à la surface inférieure qui est quelquefois chargée de poils, pourvues d'une nervure moyenne rougeâtre et pubescente : ces folioles diminuent un peu de grandeur de la base au sommet, et la dernière qui, le plus souvent avorte, est alors remplacée par une petite pointe. Panicule terminale, lâche, divisée en cinq à neuf rameaux alternes, écartés, trèslongs, grêles, anguleux, un peu aplatis, glabres, rouges, accompagnées à la base d'une feuille pennée semblable à celle de la tige, mais plus petite; divisions secondaires de la panicule très-courtes, plus ou moins rameuses, le plus souvent solitaires, quelquefois au nombre de deux à trois, munies ainsi que les divisions primaires supérieures, d'une bractée simple, spatulée, rétrécie en pétiole. FLEU RS agglomérées, longues d'environ 3 lignes, portées par un pédicelle trèscourt, à peine pubescent, chargé à la base de très-petites bractées. Mâles. Calice très-petit, en forme de cupule, glabre, un peu épais, à cinq dents profondes et obtuses. Pétales au nombre de cinq, hypogýnes, égaux entre eux, beaucoup plus longs que le calice, étalés ; $\mathrm{N} \circ \mathrm{V}$. 
lancéolés-oblongs, un peu larges à leur base, terminés par deux dents inégales, légèrement épais, glabres, d'un jaune vert avec le bord pourpre, se recouvrant par leurs bords avant la floraison. Étamines io, hypogynes, plus courtes que la corolle : filets glabres, subulés, chargés d'une écaille un peu épaisse, spatulée, très-obtuse, ciliée au sommet : anthères elliptiques, 2 - loculaires, 2 - fides à la base, attachées au dos immédiatement au-dessùs de la fente, et s'ourrant longitudinalement du côté de la face. Givophore cylindrique, plane au sommet, pubescent, à dix côtes. Ovaire entièrement arorté. Je n'ai pas vu les fleurs femelles.

Localités. Cette plante croît assez abondamment dans les pâturages de la province de Minas-Geraes, voisins du Rio-de-S.-Francisco (certao). Elle fleurit au moịs d'août.

Usages. Le $S$. versicolor a l'écorce et les feuilles amères comme le Simaruba amara et toutes les espèces de la même famille, et il doit par conséquent participer à leurs propriétés. Les hábitans du certao considèrent son écorce infusée dans de l'eau-de-vie comme un spécifique contre la morsure des serpens venimeux. Ce qu'il y a de certain, c'est qu'on l'emploie avec le plus grand succès pour guérir la maladie pédiculaire des hommes et súrtout celle des chévaux qui est assez fréquente dans cés contrées. Un fait que je vais rapporter achèvera de prouver la réalité de cette propriété $J^{\prime}$ avais mis quatre échantillons du $S$. versicolor dans une caisse qui contenait un très-grand nombre de plantes de différentes familles; toutes ont été dévorées par un nombre prodigieux de larves de ptinus, et les seuls échantillons du Simaruba sont restés intacts. Peut-être'sera-t-on tenté d'expliquer ce fäit, en supposant que le principe amer est très-concentré dans notre plánte et la partie féculente en petite quantité; mais comment se ferait-il alors que des espècés d'une saveur beaucoup plus amère, telles que le Simaba floribunda et l'Evodia febrifuga qui croissent également dans la province de Minas, aient été rongées, tandis que les insectes ont épargné la plante dont il s'agit? Quoi qu'il en soit, il reste bien démontré que le $S$. versicolor est entièrement contrairè à ces 
animaux; du certao, on pourrait l'envoyer sur la côte et dans les pays de bois vierge ou il ne criôt point, et il remplacerait pour tout le Brésil les anti-vermineux les plus puissans. - On sait aussi que le Simaruba de Cayenne a été employé avec avantage comme vermifuge. Il est à croire, d'après ce qui précède, que notre plante aurait cette propriété à un degré plús éminent encore. Quelques habitans du certao m'ont dit; il est vrai, qu'ils la considéraient commè un poison; mais il est vraisemblable que si elle est dangereuse pour l'homme, ce n'est, comme la plupart des amers, qu'à une trop forte dose ou lorsqu'on en fait une fausse application. Il est évident au reste qu'un simple soupçon de ce genre doit engager à ne faire des essais qu'avec les précautions convenables.

Étymologie. Le nom spécifique que je donne à ma plante n'est autre chose que la traduction de son nom vulgaire Paraiba, qui vient des deux mots indiens para diversité et iba arbre. On l'a appelée ainsi à cause du mélange de couleur produit à la fois par ses feuilles vertes en dessus et blanchâtres en dessous et par le rouge des pétioles, des nervures et des rameaux de la panicule.

Observations botaniques. Le genre Simaruba est très-voisin des genres Quassia et Simaba (Simaba et Aruba. Aubl. et Jus.); cependant on peut les conserver tous les trois, à cause des différences très-sensibles du port aidées de quelques caractères importans tirés de la fructification. Ainsi le Quassia a des pétales rapprochés et connivens et de longues étamines sortantes; les fleurs sont hermaphrodites dans le Simaba dont les fenilles se distinguent aussi de celles des Simaruba par leurs folioles opposées; enfin ce dernier genre est bien caractérisé par des fleurs unisexuelles dont les mâles ont un calice petit à cinq et rarement à quatre ou six divisions, cinq pétales hypogynes ouverts rarement quatre ou six, dix étamines incluses à filamens chargés d'une écaille et un gynophore central sans pistils. Je n'ai vu les fleurs femelles d'aucune espèce; mais je crois pouvoir conclure de la description qu'a donnée Aublet du Simaruba amara que le genre Sintaruba offre, comme toutes les Sinaroubées, (Ex.: Quassia amara, Simaba Guyanensis Aubl., floribunda, suaveolens, triclilioïdes, ferruginea Aug. de S. Hil.) Cinq st)les bientôt sondés en un seul, cinq 


\section{4}

stigmates et enfin cinq ovaires uniloculaires et monospermes où l'ovule est sus-. pendu dans l'angle interne et qui sont placés sur un gynophore (et non gynobase) en forme de colonne. Les Simaroubées sont intermédiaires entre les Ochnacées et les Rutacées; mais beaucoup plus voisines de cette dernière famille, elles ne paraissent même ne devoir en faire qu'une simple tribu *.

\section{EXPLICATION DES FIGURES.}

I Fleur grossie. - 2. Pétale détaché. - 3. Étamine chargée de son écaille. - 4. Pédoncule chargé d'une étamine $a$ et du gynophore à dix côtes $b$.

* Voyez mon Mémoire sur le Gynobase, destiné à faire partie de l'Histoire des Plantes les plus remarquables du Brésil et du Paraguay. 


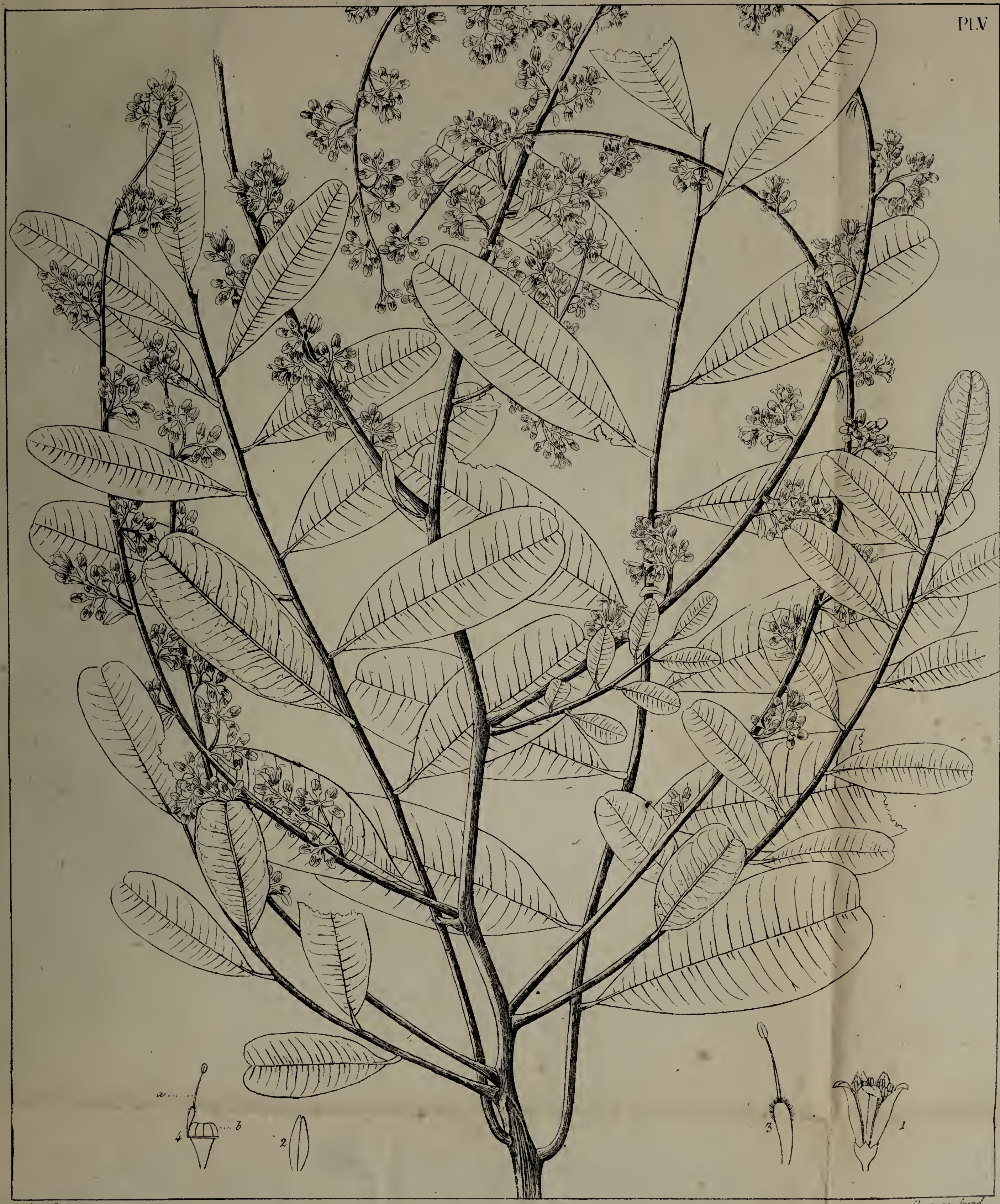





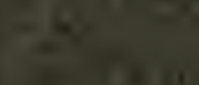

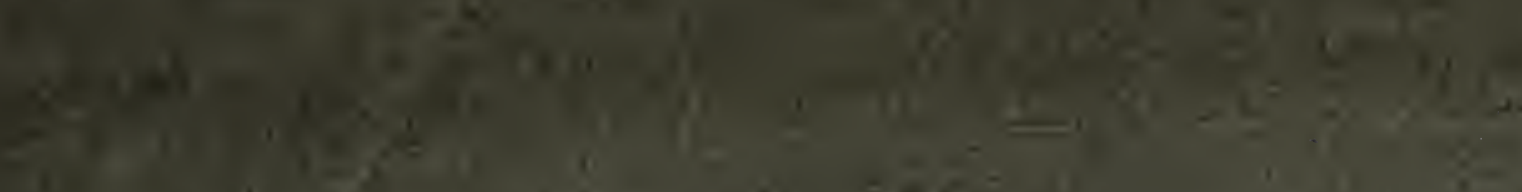

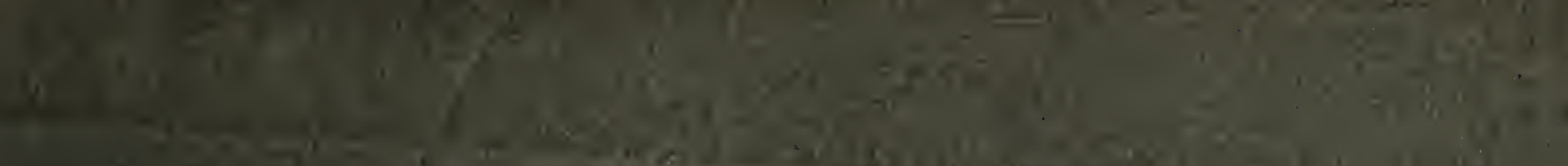

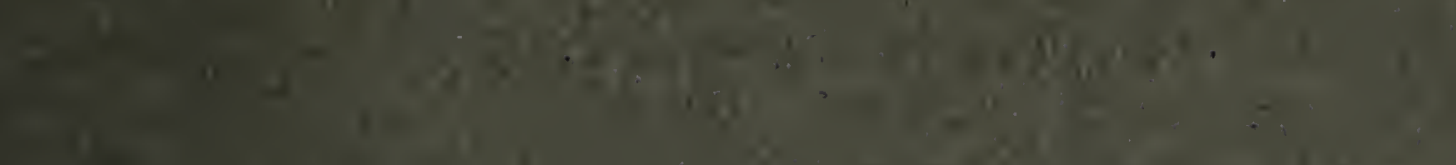

iis

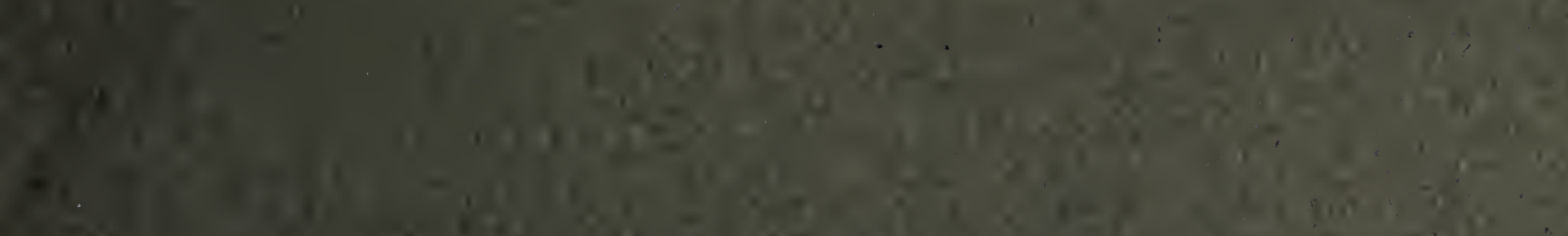

T.8.

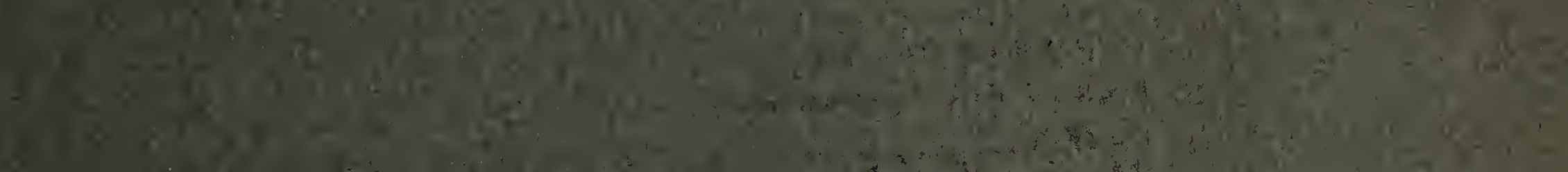

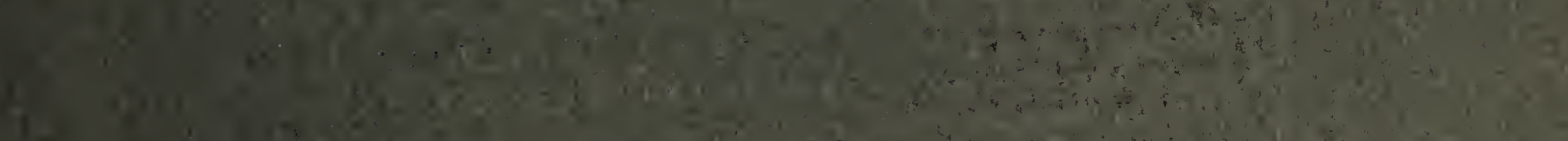

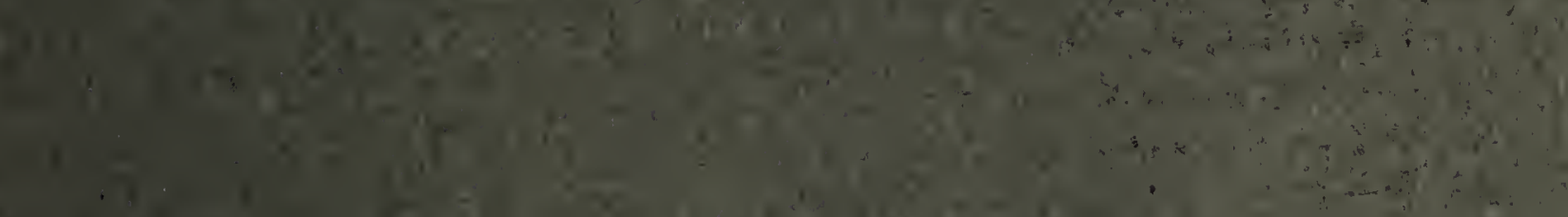

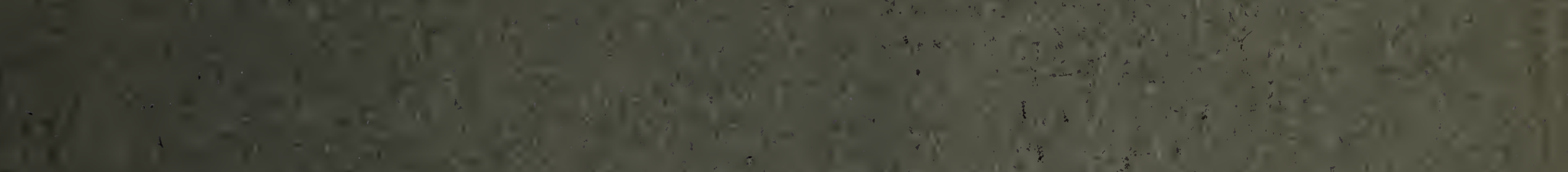

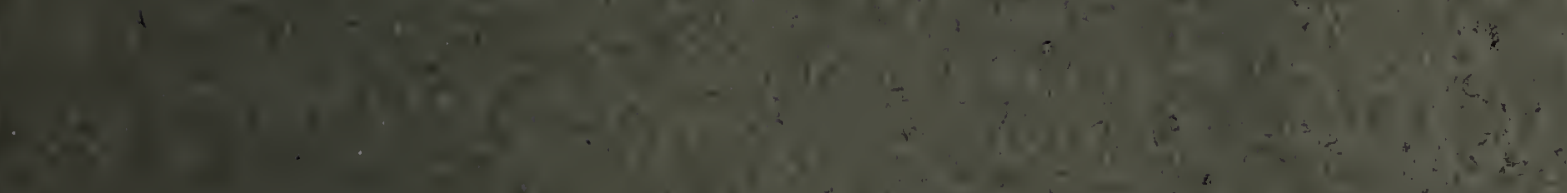
i n.

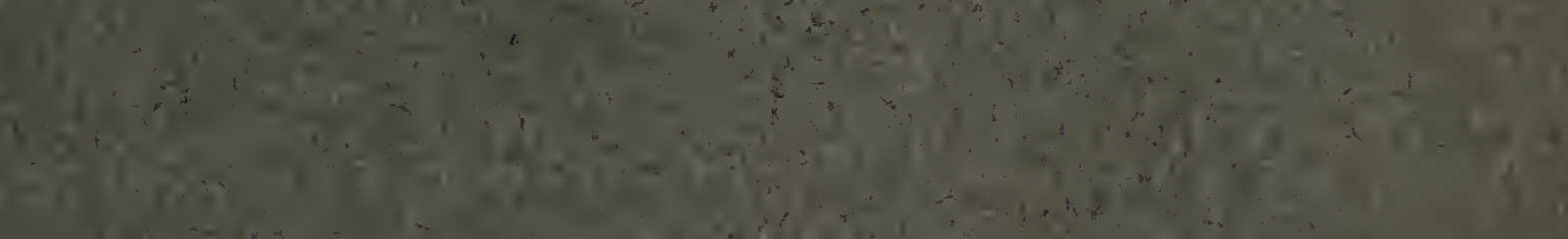



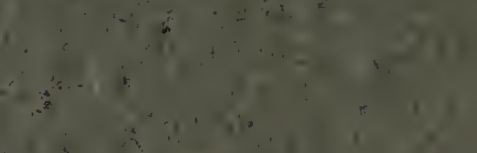

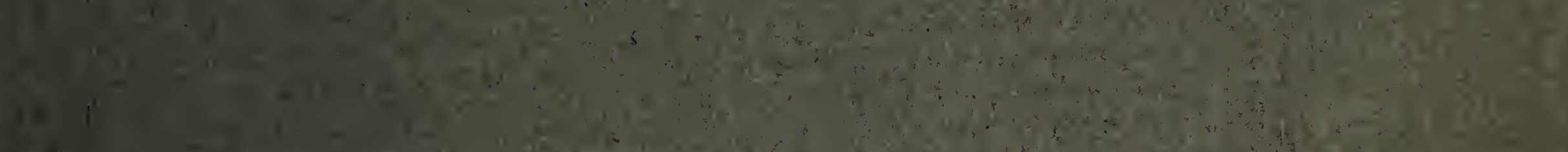
7.

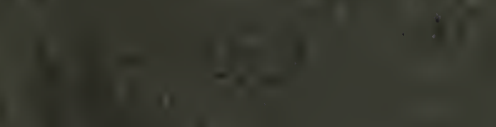

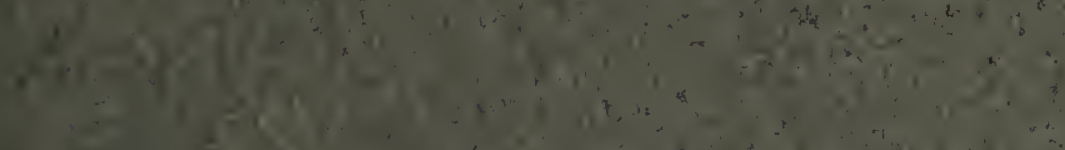

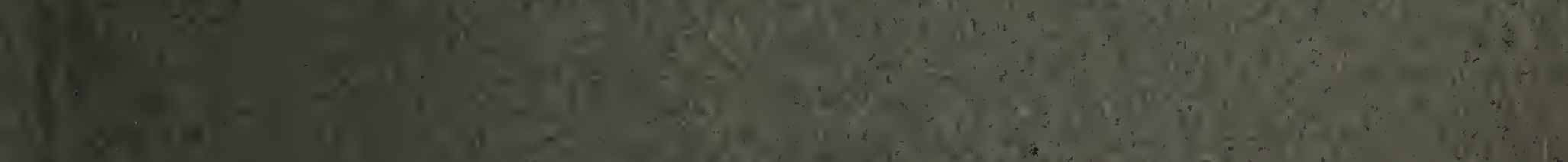



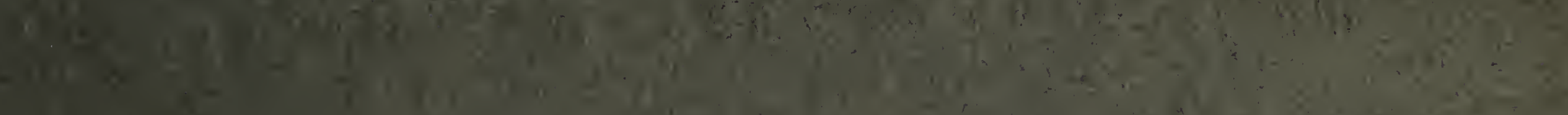

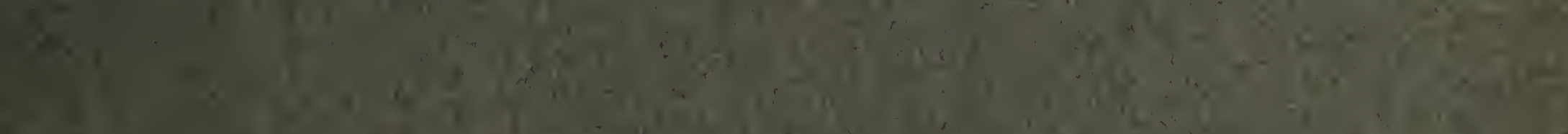




\section{OUVR AGES}

QUI SE TROUVENT CBEZ LE MÉME LIBAAIRE.

Voyage de Policlète, ou Lettres romaines, par $\mathbf{M}$ le baron de Théis, $2^{t}$ éduitor, a an

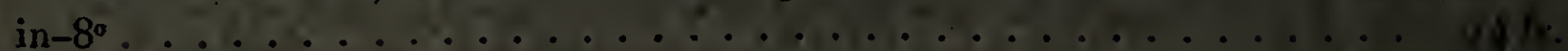

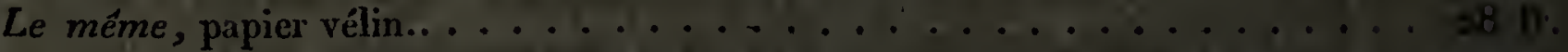

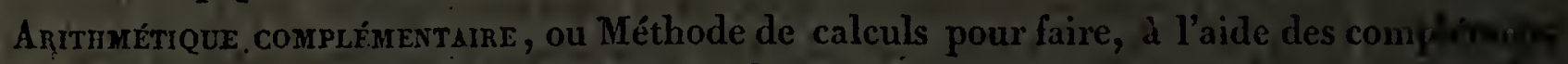
arithmétiques, toutes les opérations sur les nombres entiers, fractionnaires, et ar lo règles qui dépendent des proportions. $\mathrm{vol}$ in $-8^{\circ} \ldots \ldots . . \ldots . . .2$ to. Esprit (de l') Des Irstitctions politiques, par J.-A.-P. Massabiau. 2 vol. in-8 . 126. Art (l') historique, poëme cn quatre cliants, dédié au Roi, par M. le marquis ố

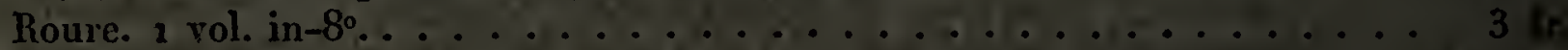
AnNales littératres, ou Choix chronologiques des principaux articles de littéraluve isérés par. M. Dussault dans le Journal des Débats, depuis 1800 jusqu'à 1817 inilusivement; recueillis et publiés par l'auteur des Mémoires historiques sur Louis xvin. 4 gros vol. in-8.......................... 28 te

CALEndraer dE Flore, ou Etude de fleurs d'après nature, par madame Vietorine de Clá

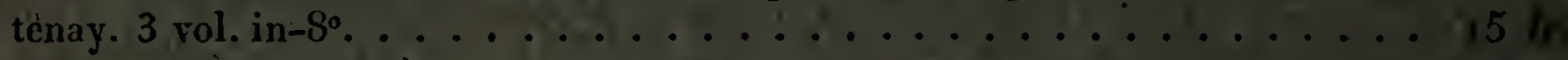

Chevaliers (les) Normands en Italie et en Sicile, et Considérations générales sur I'thitoire de la Chevalerie, etc., par madame Victorine de Chastenay. I vol. in-8 05 ir.

Confessions dE MAdame $* * *$, Principes de morale pour se conduire dans le monile. 2 rul

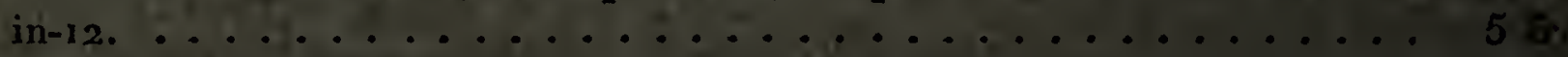

Confiseur (le) moderne, ou l'Art du confiseur et du distillateur, et en outre les propile généraux de quelques arts qui s'y rapportent, particulièrement ceux du pirfü-ure du limonadier; ouvrage enrichi de plusieurs recettes nouvelles et mis a la port af $^{2}$ tout amateur, par J.-J. Machet, confiseur et distillateur. In- $8^{\circ}$, caractères p-iilromain et petit-texte $4^{e}$ édition. . . .............6.6. 6 .

Des $\backslash$ Menveilleux efrets de la vis d'Archimède, rapprochés des mystères de la relipinn Expériences qui les démontrent et les expliquent, avec figures en taille-doure, pir M. l'abbé Moussaud, brochure in $-8^{\circ}$. .............. 2.

Discours et Dissertations tittérarres sur différens sujets, par M. l'abbé Moussiun.

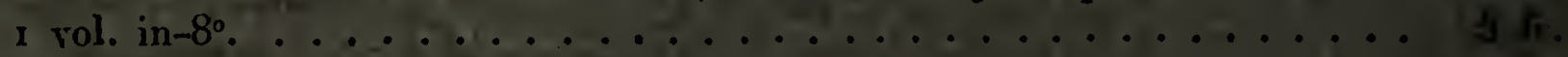

Documens pour servir a L'IFistorre de Frayce en 1820 , par M. Kératry, in-8 $8^{\circ}, 4^{\circ}$ ól

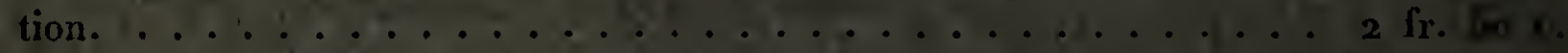




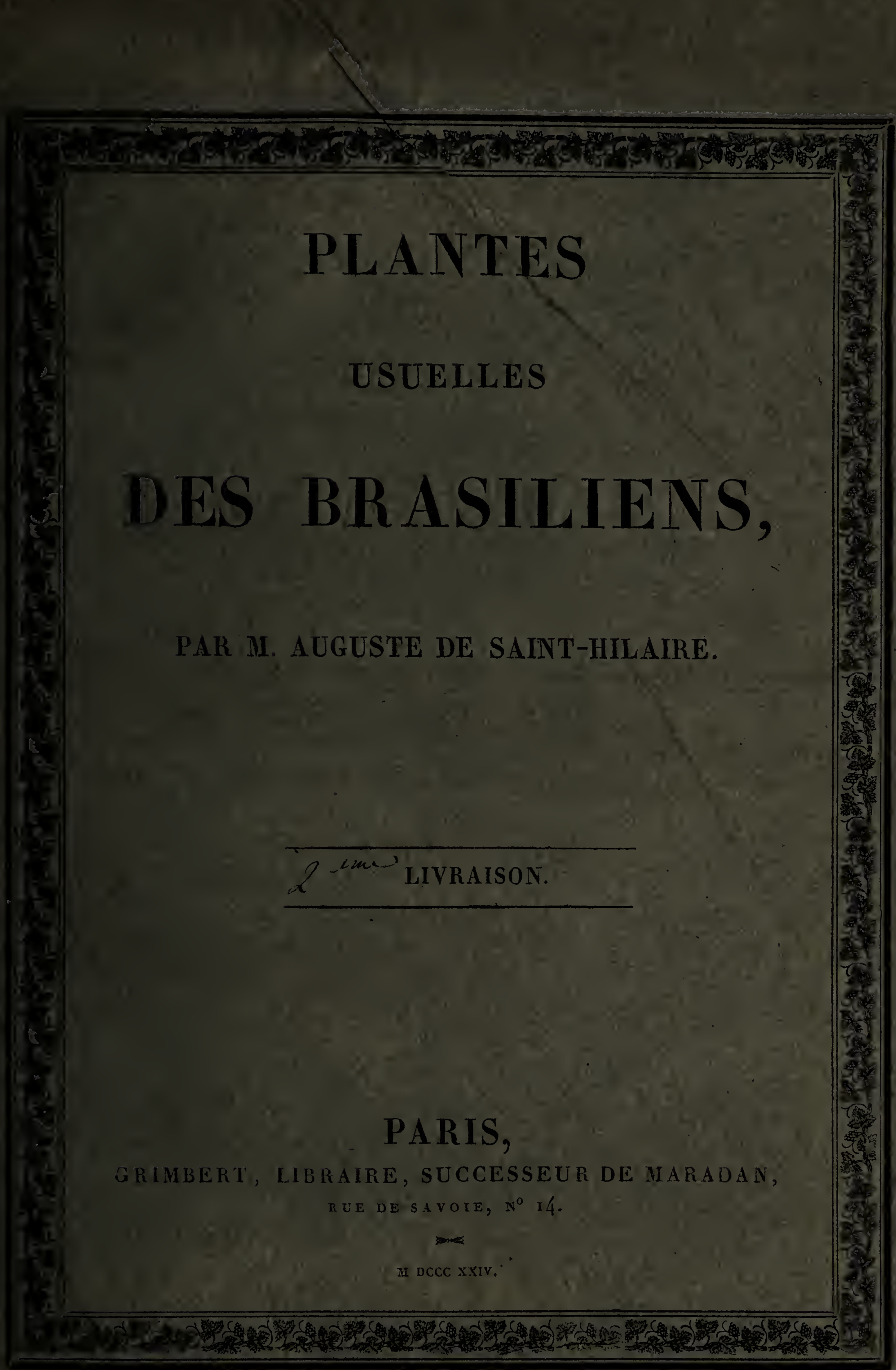

PARIS. IMIPRIMLRIE DE CASIMIR, PRE DE LAA VIEILLE-MONYAIE, $\mathbb{N}^{\circ} 12$. 


$$
\text { I. }
$$

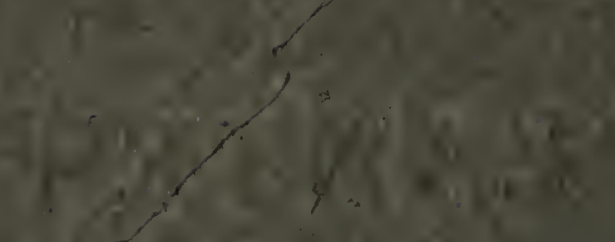

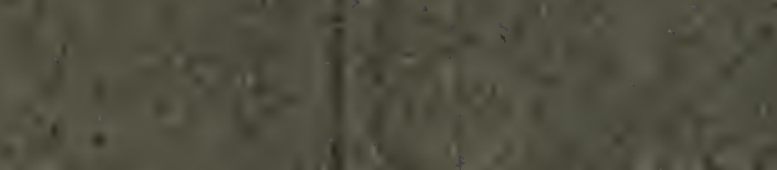

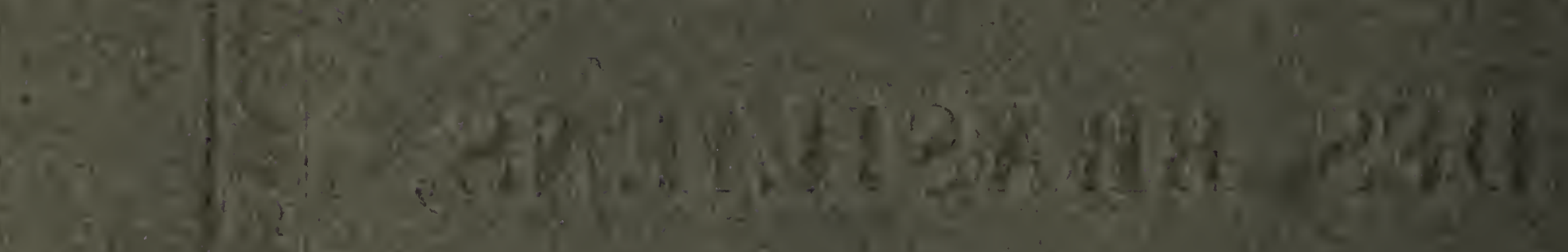

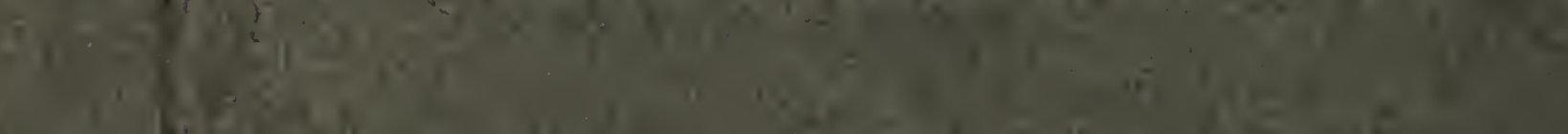

(1)


$1+11$

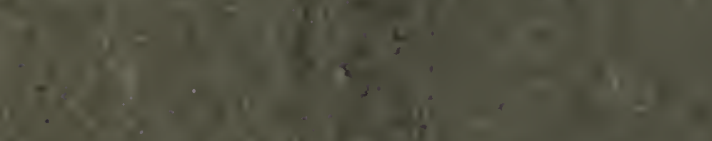



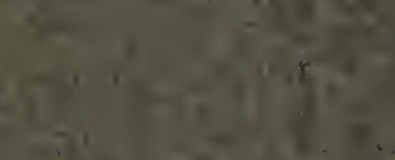

resting

ising

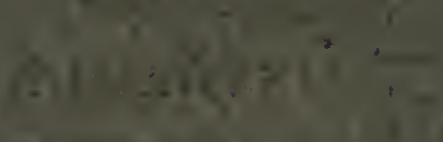

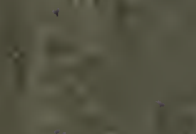

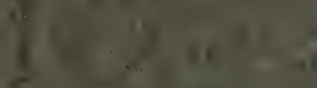

6. 3 a

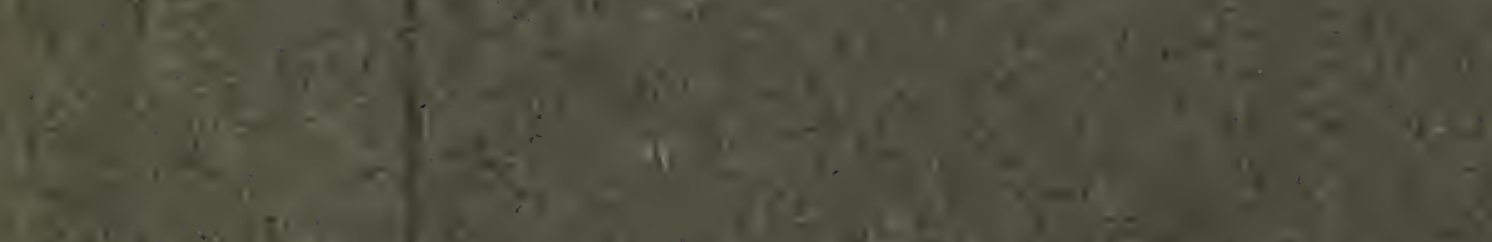

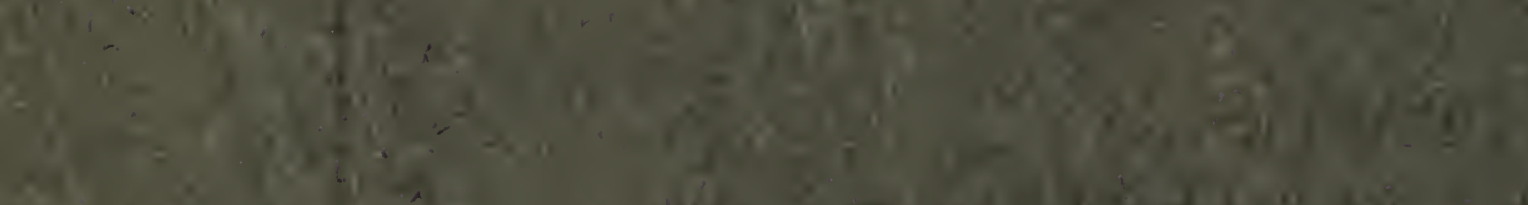

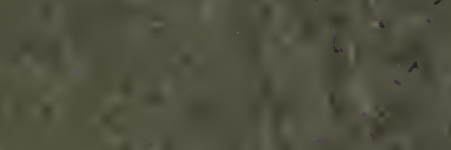

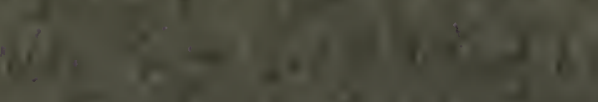



$\int_{1}+193$

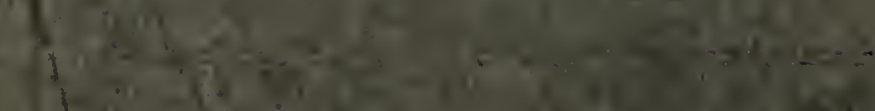

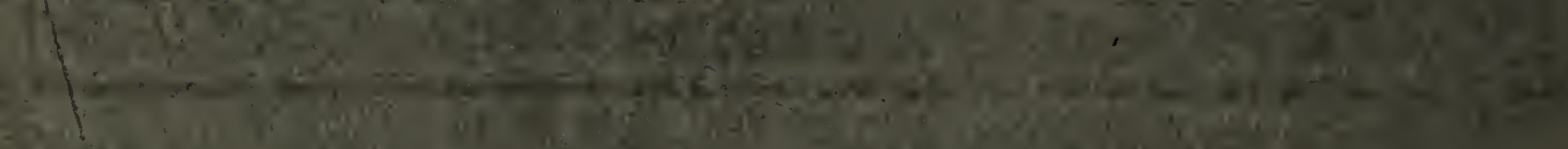




\section{CEPHAELIS IPECACUANHA.}

\section{CEPHAELIS IPECACUANHA.}

\section{FAMILLE DES RUBIACEES.}

C. caule simplici, scepiùs erecto; foliis lanceolato-ovatis, acutis, basi acuminatis, integerrimis, suprà scabriusculis, subtius subpubescentibus; capitulo terminali pedunculato, solitario; pedunculo pubescente; involucro 4-polyphyllo.

Cephaelis Ipecacuanha. Rich. Hist. Ip. p. 2 I, $t$. I. - Kunth Nov. gen. III , p. $376 .-$ Rom. et Schult. Syst. v, p. 2 1 o.-Mart, Reis. $\mathrm{r}$, p. 364.

\section{Ipecacuanha officinalis. Arud. Disc. p. 44.}

Cephaelis emetica. Pers. Syn. I, p. 203, (excl. syn. Lin. et wild.)

Callicocca Ipecacuanha. Brot. Act. Lin. Lond. vi, p. I37. -Bern. Ant. Gom.Mem. Ip. 27, tab. 1.-Mer. Dict.Med. xхvі, p. 2.

Ipecacuanha. Marc. Bras. I 7. - Pis. Bras. 23 г.

Noms vulgaires : Poaya; Psiaya do mato; Poaya da botica; (en France) Ipecacuanha.

Description. Une Souche horizontale de la grosseur d'une plume de corbeau, produit des racines inférieurement, et des tiges à la partie supérieure. Racines longues de 2 à 6 pouces, grêles à la base, augmentant ensuite de grosseur, mais atteignant rarement celle d'une plume à écrire, marquées horizontalement d'anneaux assez épais et irréguliers, blanches en dedans, d'un gris noirâtrłà l'extérieur. Tiges droites ou ascendantes, hautes d'un demi pied à un pied et demi, simples, quelquefois un peu contournées, arrondies à la base, obscurément tétragones au sommet, glabres inférieurement, pubescentes aux entrenœuds supérieurs. Feuilles au nombre de 4 à I 2 , opposées, stipulées, portées par un court

$\mathrm{N}^{\circ} \mathrm{VI}$. 
pétiole, longues d'un pouce et demi à trois pouces, larges de $\mathbf{2} 2$ à i 5 lignes, lancéolées-ovales ou simplement obovées; acuminées à la base, un peu aigües au sommet ou terminées par une petite pointe particulière; très-rarement obtuses, parfaitement entières, un peu rudes au toucher à la surface supérieure, légèrement pubescentes en dessous : nervure moyenne proéminente en dessous; les latérales au nombre de 8 à r2, parallèles et arquées. PÉtrole long de 4 à 5 lignes, légèrement pubescent, canaliculé. Struures intermédiaires, longues de 3 à 6 lignes, orbiculaires, ou semiovales, divisées jusqu’à moitié en découpures sétacées. Fueurs en tête, au nombre de 20 environ, sessiles sur un réceptacle commun, accompagnées d'un involucre et portées par un pédoncule terminal, long de 8 à I 2 lignes et pubescent. INvolucre très-variable, composé de 4 à $\mathbf{2} 2$ folioles fort inégales, pubescentes en dehors, presque glabres en dedans, disposées sur un seul ou sur deux rangs dont l'intérieur est ordinairement incomplet : 4 ou 5 des folioles, et toujours les extérieures, sont plus grandes, presque orbiculaires; parmi les autres, il y en a d'ovales retrécies à leur base, de lancéolées, de linéaires - lancéolées, enfin de linéaires sensiblement plus courtes que les extérieures; toutes sont accompagnées à leur base de petites stipules, et les plus grandes portent en outre un rang de glandes qui s'étend d'une stipule à l'autre. Souvent les fleurs sont entremêlées de bractées foliacées, semblables aux folioles intérieures de l’involucre. Calice entièrement adhérent, oblong, pubescent; dont le limbe est cupuliforme, obscurément 5-lobé, un peu lacinié, et comme cilié à son bord. Conolle longue d'environ 3 lignes, infondibuliforme, 5-fide; dont le tube est renflé audessous des divisions et velu intérieurement; dont les divisions sont linéaires-lancéolées, aigües, longues comme la moitié du tube. Étanines au nombre de 5, alternes avec les divisions de la corolle, insérées vers la moitié du tube, glabres : filet grêle, attaché au tiers inférieur de la longueur de l'anthère : anthère étroite, linéaire, 2-loculaire, s'onvrant longitudinalement du côté de l'ovaire. S Srur sortant, 2-fide; à divisions linéaires-lancéolées, stigmatiques à la 
face. Nectaine épigyne, cylindrique, très-visible, percé d'un trou pour le passage du style auquel il n'adhère pas. Ovaire oblong, biloculaire, disperme : ovules oblongs, ascendans, attachés dans chaque loge à la base de la cloison. Le fruit est un drupe à deux noyaux lisses (ex auct.).

Localités. Cette plante croît dans les forêts humides et ombragées des provinces de Fernambouc, Bahia, des Mines, du SaintEsprit, de Rio-de-Janeiro, et s'étend vers le Sud, jusqu’aux environs de Guaratingueta, dans la province de Saint-Paul, environ par le $22 \div$ d. lat. s. Elle est surtout abondante dans les îles du Parahyba, et sur les bords des rivières appelées Rio-Xipotò, et Pomba, d’où il s'en fait des envois considérables à Rio-de-Janeiro.

Histoire abrégée; nomenclature; étymologie. La découverte de l'Ipecacuanha est due aux Brasiliens indigènes. Marcgraff et Pison furent les premiers qui le firent connaître en Europe; et l'expérience confirma bientôt les éloges qu'ils avaient donnés à ce précieux remède. Cependant comme leur description étoit fort incomplète, on se servit, pendant de longues années, de l'Ipecacuanha, sans savoir à quelle plante il fallait le rapporter. Enfin en r8oo, le docteur Antonio Bernardino Gomes en montra en Europe des échantillons chargés de fleurs; Brotero les décrivit, et les figura dans les actes de la Société Linnéenne de Londres, et mit ainsi un terme aux incertitudes des médecins et des naturalistes.

Le professeur de Coîmbre avait appelé la plante du Brésil Callicocca Ipecacuanha; cependant comme le nom de Cephaelis avait été donné, avant celui de Callicocca, au genre auquel appartient l'Ipecacuanha, M. Richard a cru devoir appeler Cephaelis Ipecacuanha l'espèce qui nous occupe. Si l'on voulait s'en tenir strictement à l'antériorité, ce serait le nom de Tapogomea qüil faudrait préférer, puisqu'il avait été proposé par Aublet, avant que Swartz eùt imaginé celui de Cephaelis; mais, comme ce dernier a été adopté dans les ouvrages les plus importans, il est clair que, pour ne pas 
bouleverser la nomenclature, on doit encore faire ici une exception à la règle d'ailleurs si nécessaire de l'antériorité.

Quant au nom d'Ipecacuanha qui s'est introduit parmi les Européens avec les livres de Marcgraff et de Pison, il est inconnu dans toutes les parties du Brésil que j’ai parcourues; je ne l'ai entendu prononcer que par quelques habitans du district de Minas-Novas, sans même pouvoir découvrir à quelle plante ils l'appliquent, et c'est sous le nom de Poaya que l'on connaît généralement, dans le Brésil méridional, non seulement le Cephaelis Ipecacuanha, mais encore toutes les plantes émétiques que l'on y substitue. Le nom d'Ipecacuanha dont on n'a pas, jusque ici, donné l'étymologie exacte (I) vient des mots indiens ipè écorce, caa plante, cua odorante, $n h a$ rayé (Écorce de plante odorante et rayée). Je ne dirai pas tout-à-fait avec autant de certitude quelle est l'origine du mot Poaya; cependant il me paraît très-probable qu'il vient d'ycipò, liane et ayacà panier ( liane à faire des paniers), et qu'il aura été donné d'abord à une espèce grimpante dont la racine est émétique, et queje ferai connaître par la suite. Ce qui tend à prouver l'exactitude de cette étymologie, c'est que les Portugais d'Europe ne désignent encore chez eux l'Ipecacuanha que par le nom de cipò (liane), dont les Brasiliens auront retranché la première syllabe, comme ils auront supprimé la dernière du mot ayacia:

Usages; commerce; culture. Les usages de la plante qui vient d'être décrite sont trop bien connus chez tous les peuples pour que je croie nécessaire d'entrer à ce sujet dans de longs détails. Il n'est personne qui ne sache que l'Ipecacuanha s'emploie comme émétique; que, donné par portions, il favorise la transpiration cutanée; quil est utile dans les catarrhes chroniques et les coqueluches; qu'il exerce une action tonique sur les organes digestifs, et qu' on peut s'en servir avec le plus grand succès pour la guérison des dissenteries. L'Ipecacuanha fait, à Rio-de-Janeiro, l'objet d'un petit com-

(1) Celle qui a été rapportée dans l'ouvrage estimable intitulé Noles on Brazil, est éridemment erronée. 
merce. Suivant le docteur Antonio Bernardino Gomes, il s'en expédia 432 arobes et demie ( $\mathrm{I}$ ) en $\mathrm{I} 79^{5}, 80$ arobes en $179^{6}$, et $3 \mathrm{I}_{4}$ en 1797 . Comme les négocians qui reçoivent, de l'intérieur, la racine du Cephaelis Ipecacuanha, savent parfaitement la distinguer, ce qui est extrêmement facile, ils l'achètent sans mélange, et c'est le seul Ipecacuanha qui s'expédie actuellement de la capitale du Brésil pour l'Europe. Il n'est donc pas vrai, comme l'a déjà obscrvé M. Merat, que l'on trouve, dans l'Ipecacuanha qui vient de Riode-Janeiro, des racines de l'Ionidium Ipecacuanha, et il l'est encore moins qu'on y mêle celles de l'Ionidium parviflorum, qui croît dans un pays fort éloigné des cantons où l'on recueille le Cephaelis Ipecacuanha.

Quoique cette dernière espèce ait été détruite dans les environs de Rio-de-Janeiro, et en général dans ceux des grandes villes, elle est encore fort commune dans beaucoup d'endroits; cependant comme on l'arrache sans prévoyance, qu'on n'attend point pour cela la maturité de ses fruits, et que, d'un autre côté, on détruit tous les jours de vastes portions de bois vierges où elle naissait en abondance, il est incontestable qu'elle ne tardera pas à devenir rare, et il serait important que l'on songeât sérieusement à la cultiver. Des essais tentés par plusieurs personnes prouvent qu'elle se reproduit également bien par des semis, et par des boutures. Elle n'exige presque aucun soin, quand on la cultive dans les bois à l'ombre des grands arbres; mais, quand on est obligé de la cultiver dans des lieux découverts, il est nécessaire de lui procurer un ombrage artificiel.

Observations botaniques particulières. Le genre Cephaelis ( Tapogomea Aub. - Callicocca Schreb.) se distingue par des fleurs en tête accompagnées d'un involucre, à 2, 4 ou plusieurs folioles; un calice adhérent dont le limbe fort court est à 5 divisions plus ou moins prononcées; une corolle petite, 5-fide, à peu près infondibuliforme; 5 étamines incluses; un style bifide, dont les divisions sont stigmatiques à la face; un ovaire biloculaire qui renferme dans chacune de ses loges un seul ovule ascendant, attaché à la base de la cloison; un drupe à deux noyaux.

( 1 L'arobe est de 32 lignnes.

$\mathrm{N}^{\circ} \mathrm{VI}$. 
On voit, d'après cette description, que le genre Cephaelis ne differe guère

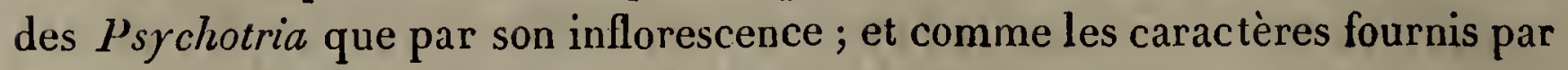
la fleur même sont les plus importans, il est clair que l'on doit, comme l'a pensé M. Kunth, ne point éloigner les Cephaelis des Psychotria, et des Coffea.

L'abbé Vellozo de Villa Rica dit dans ses manuscrits qu'il arrive quelquefois que les étamines du Cephaelis Ipecacuanha sont sortantes : si cela est, comme je n'ai aucun sujet d'en douter, on trouvera dans cette observation une raison de plus pour effectuer la réunion déjà proposée par M. de Jussieu du Carapichea. Aub. au genre Cephaelis.

Les Ipecacuanha connus dans le commerce sous les noms d'I. brun, gris-brun et gris-rouge, n’appartiennent pas même à des variétés botaniques. Ce qui le prouve jusqu'à la dernière évidence, c'est que $M$. Lemaire Isancourt, phar macien très-habile, a trouvé parmi différens pieds de Cephaelis Ipecacuanha que je lui avais remis, des individus chargés tout à la fois de racines qu'il aurait fallu rapporter aux diverses variétés citées plus haut.

Observations botaniques générales. Je dis dans ma description générique que les deux ovules des Cephaelis sont attachés à la base de la cloison et ascendans. Ce n'est pas aux seuls Cephaelis qu'appartient ce caractère. Je me suis assuré par une multitude de dissections qu'il existe dans les Spermacoce, Psychotria, Richardsonia, Coffea, etc., et en général dans toutes les Rubiacées à feuilles opposées, où les loges de l'ovaire sont monospermes, soit que cet ovaire se change en un fruit charnu, soit qu'il devienne un fruit capsuluire. Cette espèce de loi trouve à peine une ou deux exceptions.

\section{EXPLICATION DES FIGURES.}

I. Fleur grossie. - 2. Calice id. a. nectaire. - 3. Fleur ouverte ou l'on voit les étamines. - 4. Portions du style et ses de ux divisions stiginatiques. 


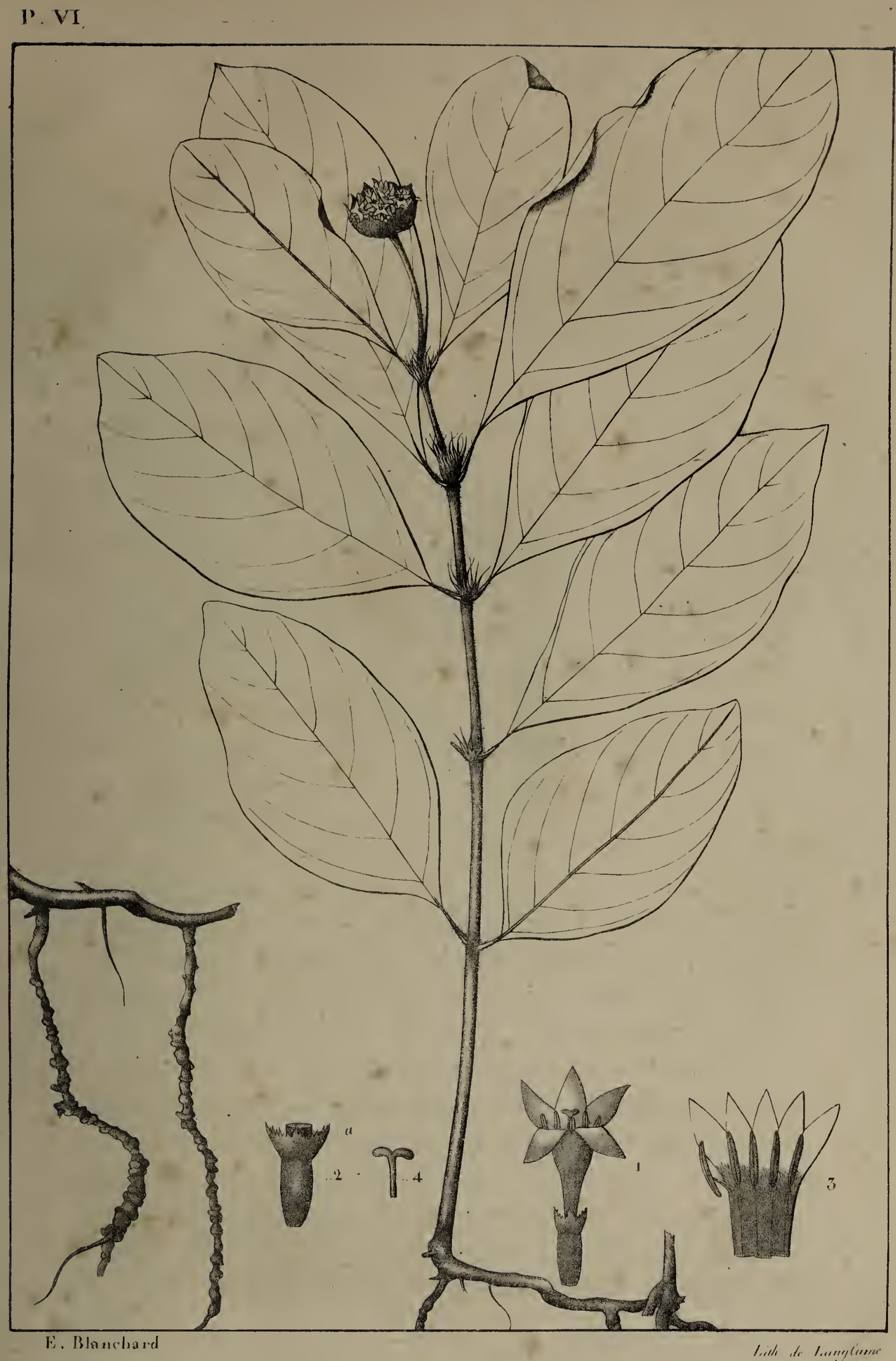

Cephatis Ipecacenth. 



\section{RICHARDSONIA ROSEA.}

RICHARDSONIE ROSE.

FAMILLE DES RUBIACÉES.

R. caulibus apice procipuè molliter hirsutissimis; foliis ovatis vel ovato-ellipticis, acutis, marginibus prcecipuè scabris, per paria distantibus; stipulis ultra medium divisis; corolla laciniis pilosis (floribus roseis).

Nom vulgaire : Poaya do campo.

Description. Racine tortueuse, de la grosseur d'un tuyau de plume, garnie de fibrilles capillaires, blanche au centre, d'un noir violet à l'extérieur, d'une saveur assez analogue à celle du Cephaelis Ipecacuanha. Tiges étalées sur la terre, longues d'un pied à un pied et demi, très-rameuses, quarrées, très-hérissées, surtout au sommet : rameaux étalés, ou ascendans, semblables à la tige : poils de la tige, des rameaux, des pétioles, et des stipules longs, blancs et assez mous. Entrenœuds longs d'environ 2 pouces et demi. Feuilles opposées, pétiolées, longues de 8 à I 5 lignes, larges de 6 à 8 , irrégulièrement ovales ou ovales-elliptiques, un peu décurrentes sur le pétiole, rudes au toucher, principalement sur les bords; les supérieures souvent plus étroites, ovales-lancéolées ou ovales-oblongues : poils des feuilles couchés, courts, subulés, durs : pétiole long de 3 à 6 lignes, assez large, hérissé, cạnaliculé en dessus. Strpules intermédiaires, adhérentes aux pétioles des deux feuilles voisines, arrondies au sommet, hérissées, divisées au-delà de moitié en lanières sétacées, écartées. Frteurs réunies en tête à l'extrémité de la tige et des rameaux, et accompagnées d'un involucre composé de 2 ou 4 folioles sessiles, rudes au toucher; quand il n'y a que deux folioles, elles sont ovales-aiguës, larges à la base; quand il y en a 4 , les deux intérieures sont plus petites, et souvent étroites, oblongues-lancéolées. Outre les têtes de fleurs terminales, il arrive quelquefois qu'à l'entrenœud immédiatement inférieur, il y a aussi $\mathrm{N}^{\circ}$ VII. 
un verticille de fleurs également accompagné d'un involucre à 4 folioles. Calice adhérent, obové-pyramidal, trigone; dont le tube est garni de poilśs courts, couchés, rudes, qui ont quelque chose de la nature des papilles; dont le limbe est 5-7-partite, à divisions semi-ovales-oblongues, aiguës, ciliées, un peu inégales. Совоlle longue d'environ 3 lignes, infondibuliforme, 5-7-fide, rose; dont les divisions sont étalées en étoile, lancéolées-oblongues, aiguës, souvent un peu inégales, hérissées en dehors de poils épars. Étamines au nombre de 5 à 7 , sortantes, glabres, blanches, insérées au sommet du tube de la corolle, et entre les divisions du limbe : filets capillaires : anthères, linéaires, étroites, vacillantes, attachées sur le filet à la moitié de leur dos, biloculaires, et s'ouvrant longitudinalement. STy se sortant, glabre, à 3 divisions fort courtes. Stranates au nombre de 3 ; et en tête. Nectaire épigyne, annulaire, court, entourant la base du style sans y adhérer. Ovaire adhérent, 3 loculaires, à loges monospermes : ovules ascendans, attachés dans l'angle interne des loges, sans placenta particulier. Fruit capsulaire, se séparant, par le milieu des cloisons, en trois coques indéhiscentes, en cœur renversé, applaties, convexes au côté extérieur qui est garni de poils couchés, concaves à la face interne qui est relevée d'une côte à son milieu. Semence adhérente à la coque, ayant à peu près la même forme qu'elle, applatie, orbiculaire-cordiforme, peltée, peu arquée. TÉgument propre membraneux, roussâtre. Ombilic placé au-dessous du milieu de la face de la semence. Périsperme grand, corné-charnu. Embryon placé dans l'axe du périsperme dont il occupe les deux tiers inférieurs, un peu arqué, parallèle au plan de l'ombilic, et suivant la courbure de la semence : cotyledons planes, orbiculaires, beaucoup plus courts que la radicule : radicule cylindrique, un peu aiguë, aboutissant presque au bord inférieur de la semence.

Localités. Cette plante est commune dans les parties assez élevées et découvertes des Comarcas de $\boldsymbol{S}$. Joao-del-Rey et Villa-Rica, surtout sur le bord des chemins, et dans les lieux fréquentés. 
Usages. Cette plante est employée avec un très-grand succès par. les cultivateurs des environs de Joao-del-Rey, pour remplacer le Cephaelis lpecacuanha, qui ne croît point dans leur pays. Nonseulement ses propriétés sont les mêmes que celles du véritable Ipecacuanha, mais encore on en obtient des résultats semblables à des doses moins considérables. A présent que le Cephaelis Ipecacuanha devient moins abondant, les Brasiliens pourraient essayer d'envoyer en Europe les racines du Richardsonia rosea, dont on ne tarderait pas sans doute à reconnaitre les avantages. Cette plante serait aussi beaucoup plus facile à cultiver que le Cephaelis; car elle multiplie avec une extrême facilité; elle n'a pas besoin d'ombrage, et s'accommode très-bien des terrains battus et peu fertiles.

Observations botaniques. Le genre Richardsoris se caractérise principalement par son calice adhérent, dont le limbe est à 5-7 divisions profondes; sa corolle infondibuliforme, dont le tube, toujour's nu, est fort évasé au sommet, dont les divisions au nombre de 5 à 7 sont étalées en étoiles; par ses étamines au nombre de 5 à 7 , sortantes, et insérées entre les divisions de la corolle; son style 3-fide; ses trois stigmates en tête; son ovaire inférieur en pyramide renversée, 3-loculaire, à loges monospermes; ses ovules ascendans; ses fruits capsulaires qui se séparent en 3 coques indéhiscentes; une graine peltée; un grand périsperme charnu-corné; un embryon un peu arqué comme la sentence, placé dans l'axe du périsperne, et parallèle au plan de l'ombilic; enfin une radicule inférieure. - Ce genre est extrèmement voisin du Spermacoce, et ne s'en distingue réellement que par le nombre des parties.

\section{EXPLICATION DE LA FIGURE.}

1. Corolle grossie. 


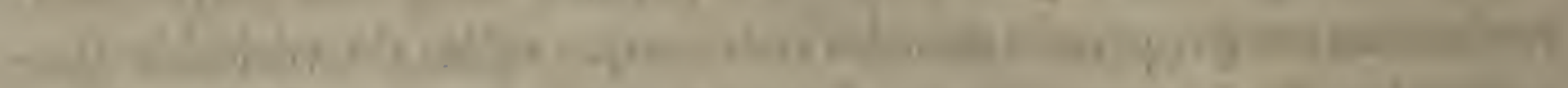

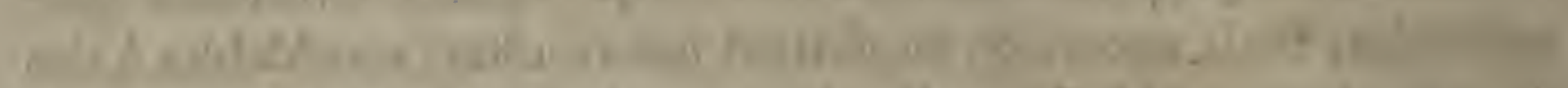

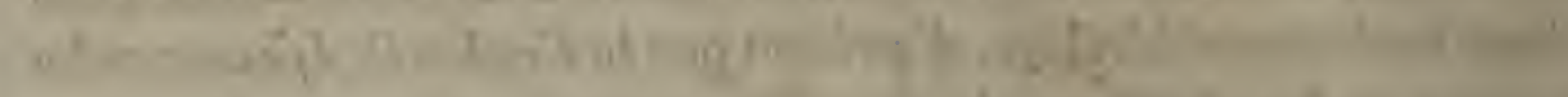

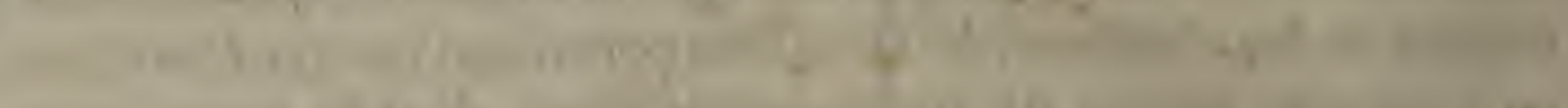

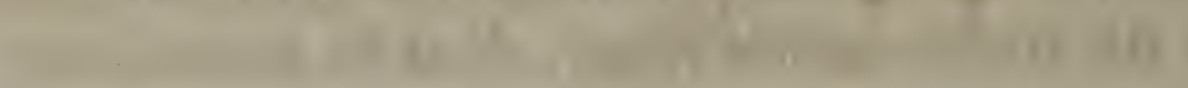

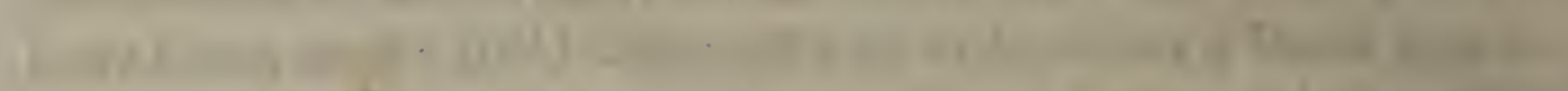

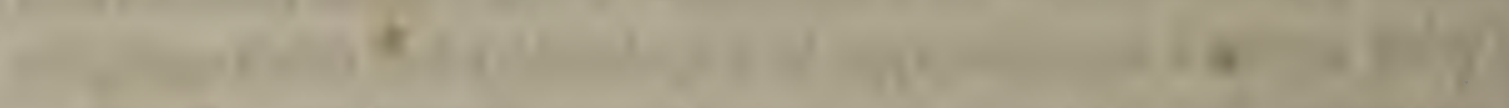

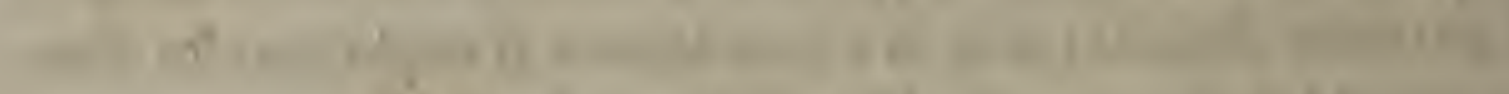

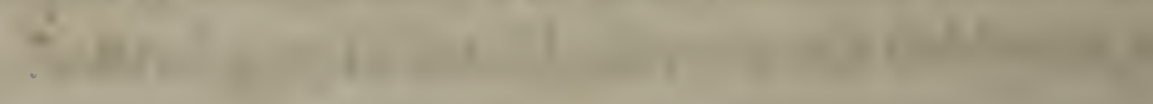
1 1
1

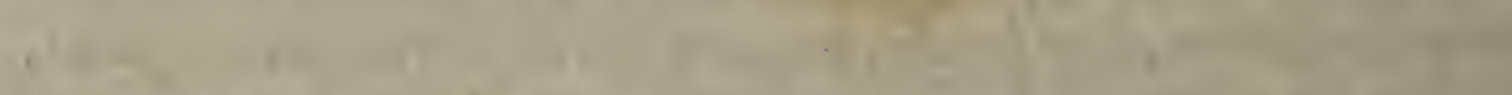

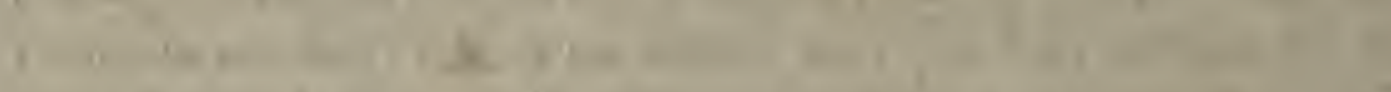

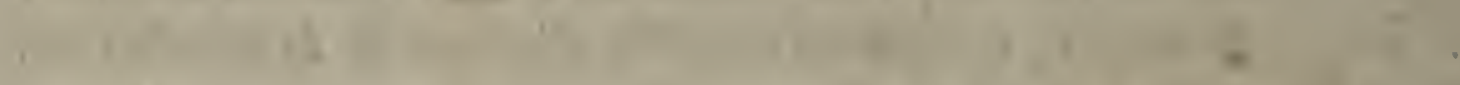

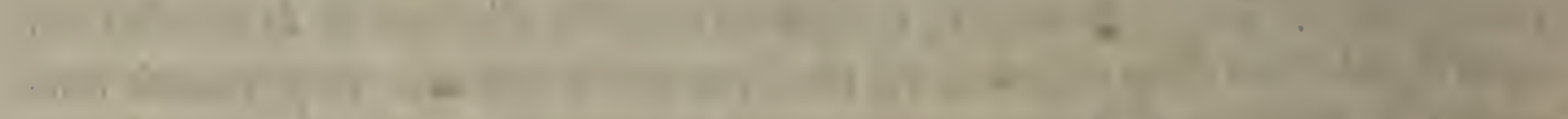
.+ th

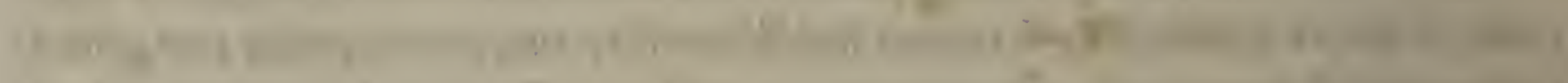

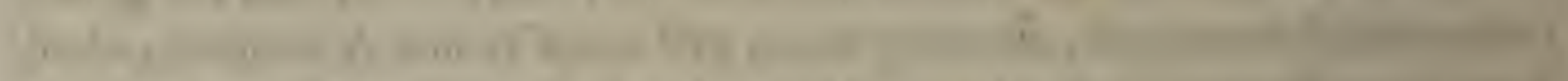

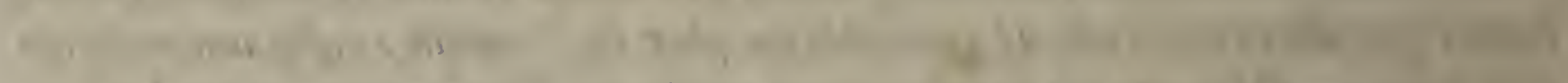

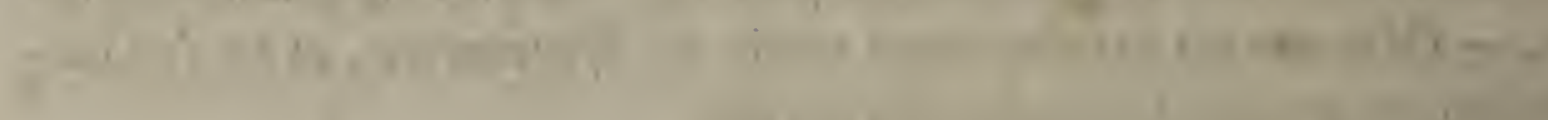

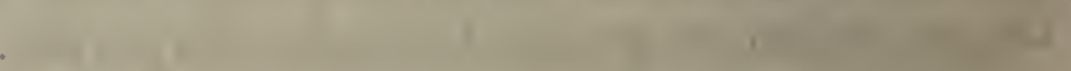

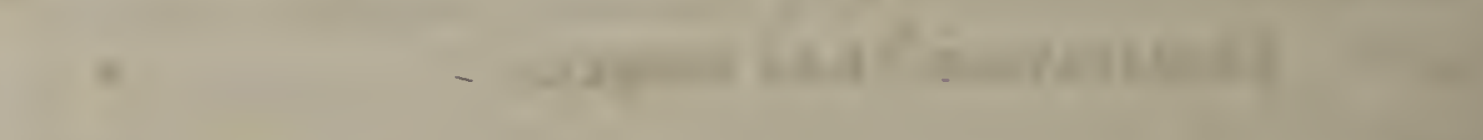

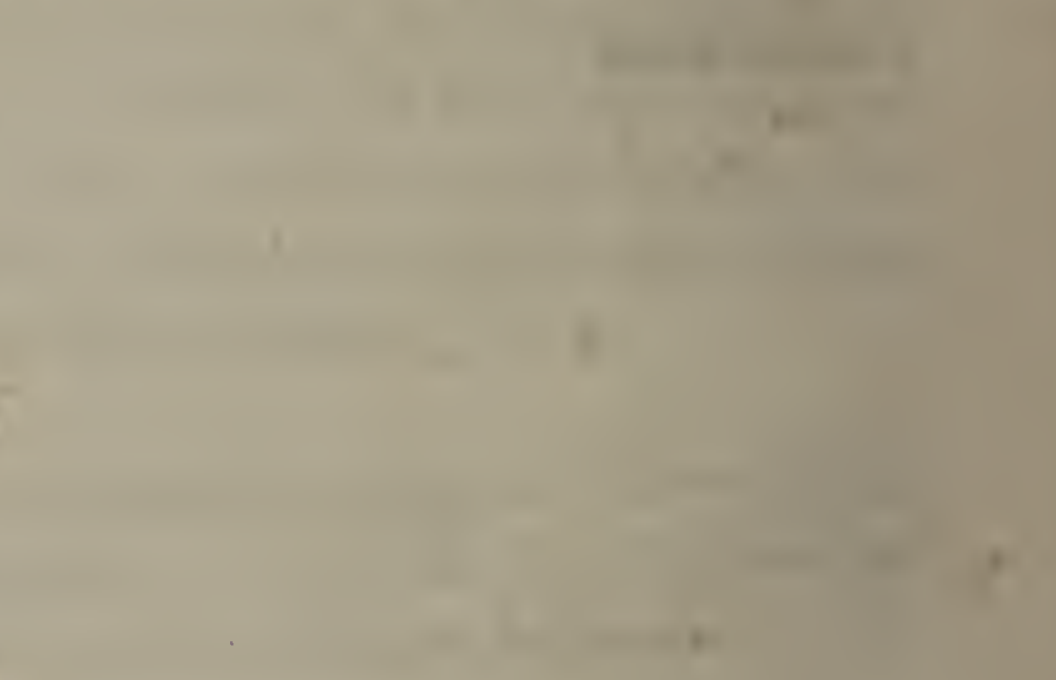




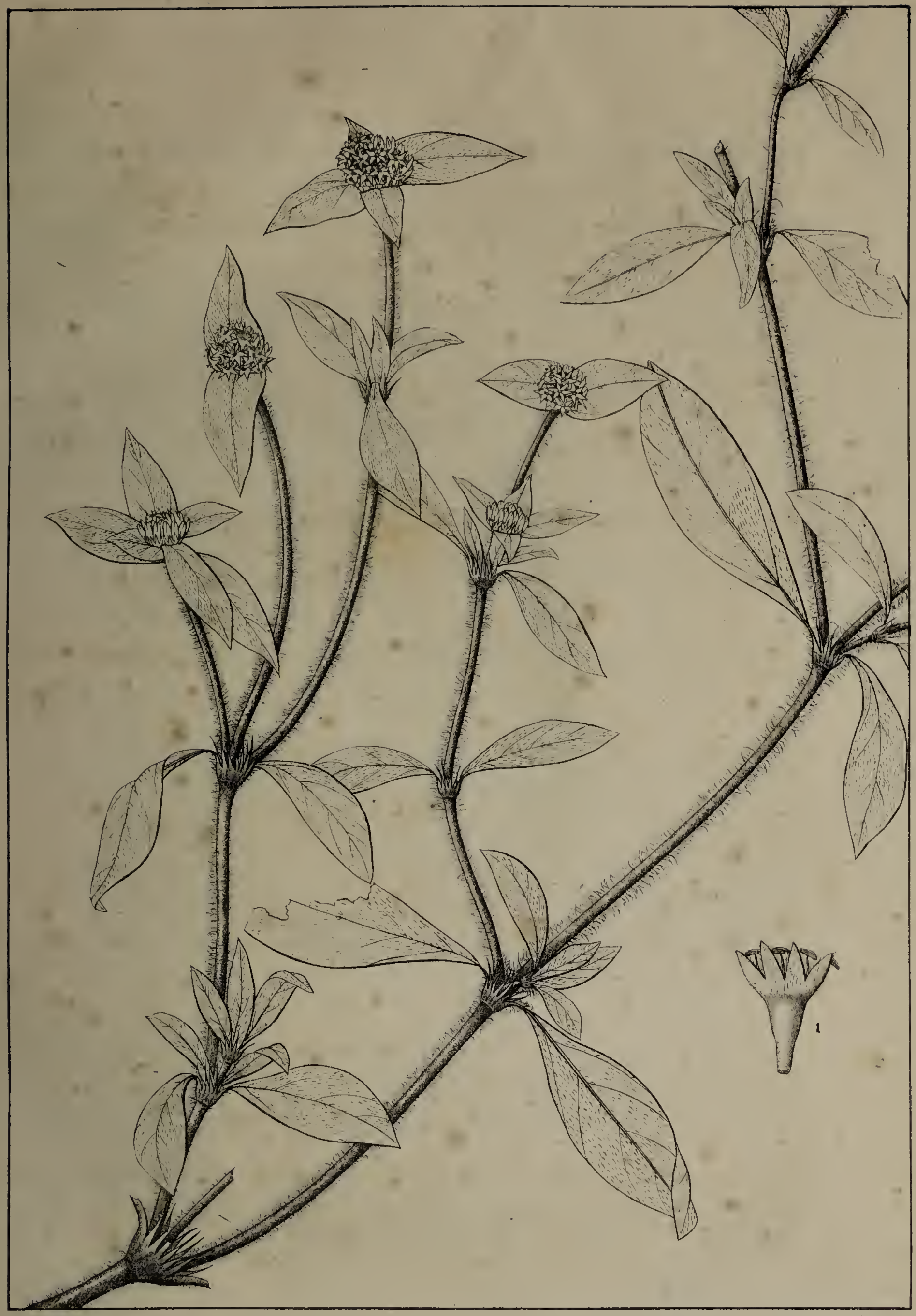

E Blanchard

RICHARTSONIA ROSEA. 



\section{RICHARDSONIA SCABRA.}

\section{RICHARDSONIE RUDE AU TOUCHER.}

FAMILLE DES RUBIACEES.

R. caulibus pilosis; foliis ovatis ovatove-lanceolatis, rariüs oblongis, acutiusculis, marginibus prcecipuè scabris; stipulis usquè ad medium non divisis; corolla laciniis apice pilosis (floribuss albis ).

Richardsonia (I) scabra Lin. Sp. 470. - Goert. I, pag. I 2.3 , tab. xxy.

R. pilosa Ruiz et Pav. II , p. 5o. - Kunth. Nov. Gen. II, p. 35o, tab. cclxxix, (ex fide herb. Humb.).

R. Scabra et pilosa, Pers. Syn. I, p. 392.

Spermacoce hexandra, Rich. Hist. nat. Ip., p. I 3 et 3 I.

Richardsonia Brasiliensis, Bern. Ant. Gom. Mem. Ip.p. 3 I , tab. II. - Vir. Journ. comp. p. 344.

Ipecacuanha amilacé ou blanc, Mer. Dict. med. xxvi, p. ı 3 .

Nom vulgaire : Poaya do campo.

Description. Racine tantôt presque horizontale, et tantôt à peu près verticale, longue de $\mathrm{I}$ à 7 pouces, généralement un peu moins grosse qu'une plume à écrire, simple ou rameuse, souvent recourbée, tantôt sans anneaux, tantôt marquée de rugosités annulaires transversales et généralement plus larges que celles du Céphaelis Ipecacuanha : sa couleur d'abord blanche devient cendrée par la dessication; sa saveur est un peu douceâtre, et ne rappelle point celle du Cephaelis. Tigrs assez nombreuses, longues de 5 à 8 pouces environ, étalées sur la terre, rameuses, quarrécs, hérissées de poils blancs, assez courts, un peu rudes, écartés ct rares dans le bas, nombreux et serrés dans le haut : rameaux sem-

(1) Linné et beaucoup d'autres, après lui, avaient écrit Richardia par contraction; mais cette suppression et le rétablissement d'une syllabe dans un nom ont si peu d'importance, que je crois qu'on peut établir la synonymie, comme si cette légère différence n’avait jamais eu lieu.

$\mathrm{N}^{\circ}$ VIII. 
blables à la tige. Entrenceuds de i à 2 pouces. Feullues opposées, pétiolées, longues d'environ 8 à ir lignes, larges de 3 à 7 lignes, ovales ou ovales-lancéolées, plus rarement oblongues, décurrentes sur le pétiole, à peine aiguës, entières, un peu charnues, d'un verd gai, rudes au toucher surtout sur les bords : poils des feuilles couchés, courts, șubulés, durs, pressés et nombreux dans les jeunes feúilles, écartés et rares dans les anciennes, ceux des bords de la feuille plus longs : pétiole ayant environ 2 à 3 lignes de longueur, et chargé de poils semblables à ceux de la tige. Strpules intermédiaires, adhérentes aux pétioles des 2 feuilles voisines, arrondies au sommet, velues, membraneuses, divisées jusqu'à moins de la moitié en lanières sétacées et écartées. FLEUns réunies en tête à l'extrémité des tiges et des rameaux, et accompagnées d'un involucre composé de 2 à 6 folioles ordinairement sessiles, et rudes au toucher; quand il n'y a que deux folioles, elles sont ordinairement ovales, aiguës', larges à la base; quand il y en a 4 ou 6 , le plus souvent 2 ou 4 d'entre elles sont plus étroites, oblongues-lancéolées; un peu pétiolées; toutes sont quelquefois semblables aux dernières qui viennent d'être décrites. Outre les têtes de fleurs terminales, il existe aussi quelquefois des verticilles de fleurs aux entrenœuds supérieurs. Réceptacle nu. Calice adhérent, obové-pyramidal, 3-tétragone; dont le tube est garni de poils courts, couchés, rudes, qui ont quelque chose de la nature des papilles; dont le limbe est 5-6-partite, à divisions semi-ovales, aiguës, ciliées, un peu inégales. Corolle longue d'environ une ligne et demie, infondibuliforme, 5-6-fide, blanche; dont les divisions sont ovales, aiguës, souvent un peu inégales, hérissées de quelques poils au sommet seulement. Éтмmines au nombre de 5-6, sortantes, glabres, blanches, insérées au sommet du tube de la corolle et entre ses divisions, un peu moins longues que ces dernières : filets eapillaires : anthères étroites, vacillantes, attachées sur le filet à la moitié de leur dos, s'ouvrant longitudinalement. S True sortant, glabre, à trois divisions fort courtes. Stigmates au nombre de 3 et en tête oblongue. Nectaire épigyne, court, annulaire, entourant la base da style 
sans y adhérer. Ovaire adhérent, triloculaire, à loges monospermes : ovules ascendans, attachés dans l'angle interne des loges, sans placenta particulier. Fruit capsulaire, se séparant par le milieu des cloisons en trois coques indéhiscentes, en cceur renversé, convexes à l'extérieur qui est garni de poils ou plutôt de papilles, concaves à la face interne qui est relevée d'une côte à son milieu. Semence à peine adhérente à la coque, absolument conforme à elle, applatie, peltée, un peu arquée. TÉgument propre membraneux. Ombiric placé à la face de la semence, et correspondant au tiers inférieur de l'axe. Périsperme grand, corné-charnu. EMrryor un peu arqué comme la semence, et placé dans l'axe du périsperme dont il occupe les deux tiers : cotylédons planes, orbiculaires-elliptiques, beaucoup plus courts que la radicule : radicule cylindrique, un peu aiguë, aboutissant presque au bord inférieur de la semence.

Localités. Cette plante est très-commune dans la province de Rio-de-Janeiro. On la trouve principalement dans les lieux cultivés, les endroits sabloneux, le bord des chemins, et jusque dans celles des rues de Rio-de-Janeiro, qui sont le moins fréquentées.

Étymologie. Quoiqu' on ne trouve dans la province de Rio-deJaneiro, rien qui ressemble aux paturages naturels que l'on appelle campos, et qui forment une si vaste portion des provinces de SaintPaul, des Mines de Goyaz, etc., on a cependant nommé Poaya do campo la plante que je décris ici, parce qu'elle ne croît point dans les forêts vierges, mais seulement dans les endroits où elles ont été détruites, et dans les espaces de terrain trop sabloneux pour avoir jamais produit de grands arbres.

Usages. Cette plante sans avoir, à beaucoup près, des propriétés aussi héroïques que le Richardsonia rosea, peut cependant, au besoin, remplacer avec succès le Cephaelis Ipecacuanha, et si l'on n'en fait pas un très-grand usage dans la province de Rio-de-Janeiro, où comme je l'ai dit, elle croît en abondance, c'est qu'on n'a généralement aucune peine à s'y procurer le véritable Ipecacuanha. 
Observations botaniques particulières. $1^{\circ}$ La comparaison altentive des descriptions et des échantillons les plus authentiques m’a démontré que les $K i$ chardsonia scabra, L., pilosa, Ruiz et Pav., Kunth, etc., et Brasiliensis Gomes n'élaient qu'une seule et même espèce, et, comme le nom de Linné est le plus ancien, c'est celui que je conserve ici. A la vérité, Linné dit que sa plante a les poils dirigés de haut en bas; mais ce caractère est souvent le résultat de quelque circonstance accidentelle, et, dans le $R$. rosea où les poils sont ordinairement horizontaux, il s'en trouve quelquefois une partie dont la pointe est tournée vers le sol.

$2^{\circ}$ Le $R$. scabra a de très-grands rapports avecle $R$.rosea; mais il s'en distingue parce que ses racines sont blanches, et non d'un noir-violet; parce qu'il est plus petit dans toutes ses parties; qu'il est beaucoup moins hérissé; que sa tige et ses rameaux portent des poils plus durs, et beaucoup moins longs; que ceux des feuilles sont plus nombreux; que celles-ci sont beaucoup moins aiguës, plus charnues, généralement moins grandes, et plus décidément ovales; que les nervures latérales sont plus souvent au nombre de six seulement; que les entrenœuds sont moins longs; que les stipules ne sont pas découpées jusqu'à moitié; que la corolle est trois fois plus petite, et blanche au lieu d'être rose ; enfin que les divisions de cette dernière ne sont chargées de poils qu'au som. met. Les deux plantes en outre croissent dans des localités totalement différentes.

Observations botaniques générales. La plupart des auteurs qui ont décrit l'embryon des Rubiacées, l'ont lait d'une manière vague et souvent peu intelligible. J'ai dit dans la description des $R$. rosea et scabra que l'embryon suirait la courbure de la semence, qu'il était placé dans l'axe du périsperme, et parallèle au plan de l'ombilic, et que sa radicule était inférieure. Mais ce n'est pas seulement dans ces deux plantes qu'existent ces caractères; je me suis convaincu par un nombre prodigieux de dissections qu'ils sont constans dans la plupart des Rubiacées, et s'ils rencontrent quelques exceptions que je signalerai, à mesure que l'occasion s'en présentera, ce n'est, je crois, que dans les espèces polyspermes. M. Richard avait parfaitement reconnu que l'embryon des Rubiacées suit la direction de la graine; mais on sent que celle-ci étant aplatie, et l'ombilic à la face, il est géométriquement impossible que la radicule arrive à l'ombilic, comme l'avait pensé l'illustre auteur de l'Analyse du fruit.

\section{EXPLICATION DES FIGURES.}

I Calice grossi. - 2 Corolle id. -3 Corolle ouverte pour montrer l'insertion des étamines. - 4 Portion du style grossie. - 5 Coque id. vue du côté du dos. - 6 La même, vue du côté de la face. - 7 Semence grossie. - 8 La même id. coupée longitudinalcment pour montrer la place de l'embryon. - 9 Embryon id. tirédu périsperme. 


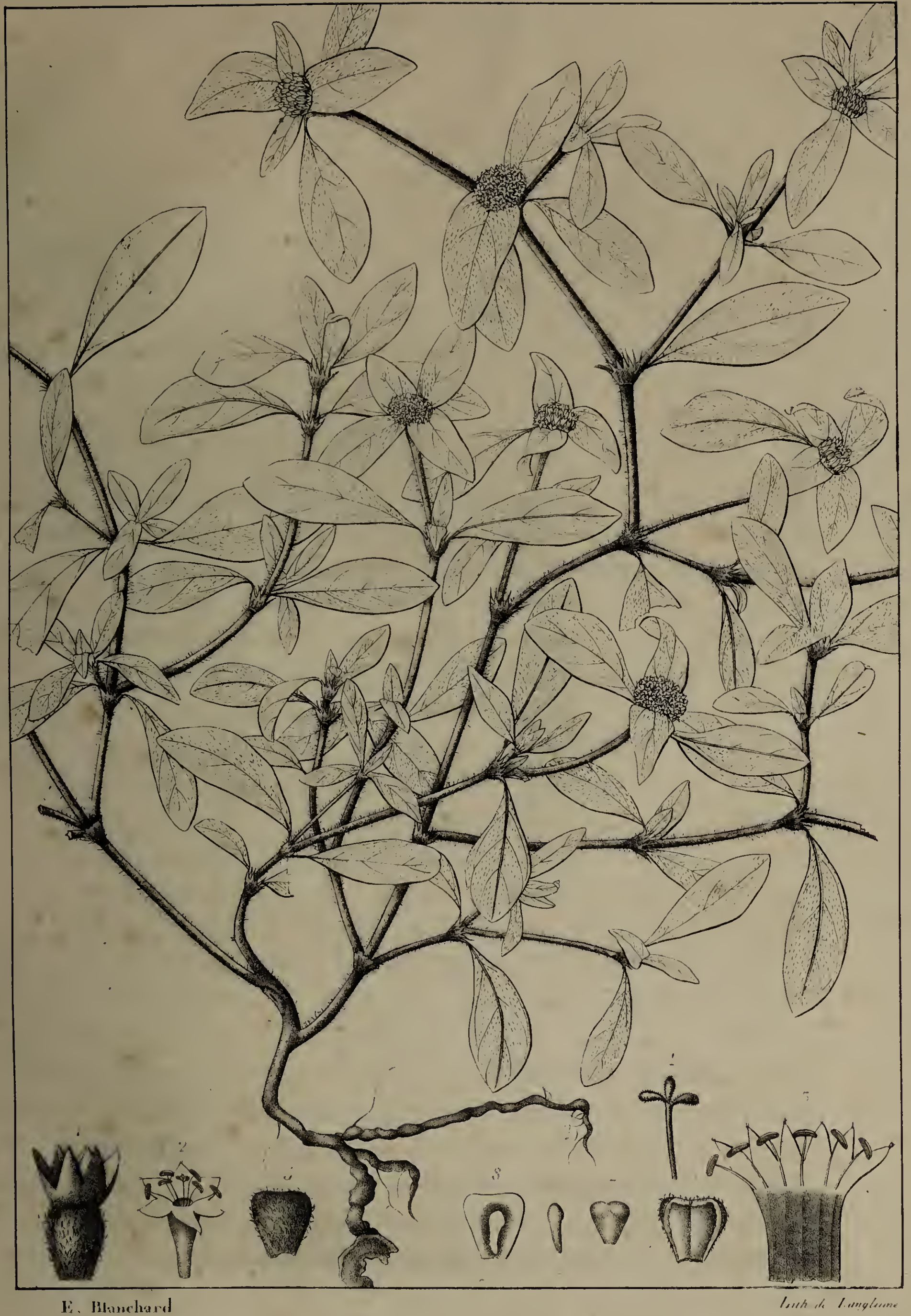

RICHARDSONIA SCABRA. 



\section{IONIDIUM POAYA.}

IONIDE POAYA.

FAMILLE DES VIOLACEES.

J. hirsutissimum; caule suffruticoso, sapiùs simplici; foliis alternis, subsessilibus, ovatis, basi subcordatis, acutiusculis, obsoletè dentatis; stipulis lincaribus, integerrimis, vix manifestis, laciniis calycinis integris; petalo inferiore maximo, latè obcordato ; filamentis extus apice barbatis; antherarum processu membranaceo minimo,

\section{Nom vulgaire : Poaya do campo.}

Description. Sous-arbrisseau hérissé, dans toutes ses parties, de poils longs, simples et d'un vert jaunâtre, Racine blanche. Tiges longues d'un demi pied à un pied et demi, simples ou rameuses, anguleuses, striées, à peine ligneuses. Feurlues alternes, souvent assez rapprochées, sessiles ou à peine pétiolées, longues de 6 à I 2 lignes, larges de 3 à $\eta$ lignes, ovales, un peu aiguës, échancrées en cœur à leur base, grossièrement dentées, peu étalées : nervure

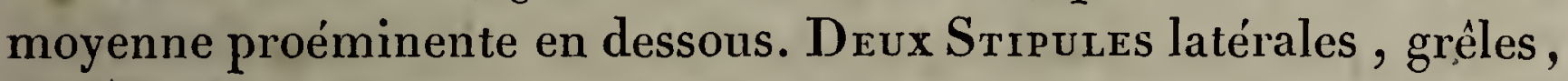
filiformes, cachées au milieu des poils qui les entourent. PÉdoncules axillaires au sommet des tiges, tantôt plus courts et tantôt plus longs que les feuilles, articulés au-dessous du sommet, nus ou chargés de deux bractées alternes, linéaires, très-étroites. CALIce 5-partite, inégal, à divisions lancéolées-linéaires, étroites, acuminées, à une seule nervure; trois des divisions courbées en faux, et deux presque droites. Pétales au nombre de 5 , très-inégaux : deux supérieurs rapprochés, oblongs-linéaires, obtus, un peu recourbés au sommet, à une seule neryure hérissée de poils : deux pétales latéraux presque deux fois aussi grands que le calice, un peu courbés en faux, onguiculés, velus en dehors; à onglet plus long que la lame, linéaire-oblong, un peu rétréci de la base au sommet, muni inférieurement d'une oreillette, chargé de 5 nervures; à lame obovée quelquefois simplement obtuse; quelquefois obtuse et échancrée en $\mathbf{N}^{\circ}$ IX. 
cœur, réfléchie : pétale inférieur très-grand, onguiculé, velu en dehors; à onglet canaliculé, plus large à la base, un peu plus long que la lame; à lame large d'environ i I lignes, transversalement elliptique, échancrée en cœur, arrondie sur les côtés. ÉTamines au nombre de 5 , hypogynes, un peu inégales : filet un peu plus long que l'anthère, étroit, aplati : anthère aplatie, orbiculaire-elliptique, dont la face est tournée du côté de l'ovaire, et dont les loges s'ouvrent longitudinalement; chaque anthère se termine par une membrane fort petite, beaucoup plus étroite qu'elle, un peu tronquée et denticulée; dans les deux étamines inférieures qui sont un peu plus courtes, le filament est épaissi à son sommet. STr LE courbé en $s$, épais, glabre, tronqué horizontalement au sommet. Sticmate terminal, petit, en mamelon. Ovarre ovoïde, très-velu, r-loculaire, 8-9-sperme : ovules pariétaux, attachés sur trois lignes, sans placenta particulier. Je n'ai pas vu le fruit.

Localités. Cette plante est commune à l'ouest du Rio-de-S.-Francisco, dans les pâturages naturels (campoś) de la province de Minas-Geraes, et ceux de la partie méridionale de la province de Goyaz, principalement auprès de Paracatì, de Santa-Luzia-deGoyaz, de Meia-ponte, etc. Je l'ai trouvée en fleur depuis le mois d'avril jusqu'au mois d'août.

Usages. Les habitans du pays où croît la plante que je viens de décrire la substituent avec succès au Cephaelis, qui ne se trouve pas chez eux. Tantôt ils emploient la racine de l'Tonidium Poaya sans la mélanger, et tantôtils la mêlent au tartrate de potasse et d'antimoine, comme on fait ailleurs pour l'Ipecacuanha véritable. Mais ce 'n'est pas seulement comme émétique qu' on administre l' Ionidium Poaya; à d'autres doses il devient un évacuant, et $\mathrm{r} 2$ vintems gu Kil. o, o00340 de sa racine purgent un adulte.

Cette plante confirme les propriétés émétiques que l'on a reconnues aux Violacées, et il est à croire qu'en faisant quelques expériences, on retrouvera_ces propriétés à un degré plus ou moins 
éminent dans les nombreuses espèces de cette famille que fournissent les différentes parties du Brésil.

Observations botaniques. Le genre Ionidium Vent. (Hybanthus Jacq.-Pombalia Vand.-Ionidium, Hybanthus, et Pombalia Gin.) présente les caractères suivans: CALICE profondément 5-partite dont les divisions ne sont ni prolongées au-dessous de leur base ni entièrement séparées. PÉTALEs au nombre de cinq, périgynes ou plus rarement hypogynes, très-inégaux; l'inférieur plus grand, onguiculé, sans éperon, à onglet ordinairement plus large et concave à la base, rétréci au sommet. ÉTaMines au nombre de cinq, insérées comme les pétales, et alternes avec eux: filets libres ou soudés, le plus souvent courts, quelquefois nuls : anthères aplaties, membraneuses au sommet, attachées par la base, immobiles, tournées vers le pistil, biloculaires et s'ouvrant longitudinalement: les connectifs ou les filamens des anthères inférieurs le plus souvent bossus ou munis d'un appendice plus ou moins sensible. STYLE courbé, épaissi au sommet, persistant. Stigmate un peu latéral. Ovaine libre, sessile, olygosperme ou polysperme : ovules attachés à trois placentas pariétaux. CA PSOLE entourée du calice, des pétales et des étamines qui persistent, uniloculaire, olygosperme ou polysperme, s'ouvrant en trois valves étalées, plus épaissies sur le dos, portant les semences dans leur milieu. Sемгnces petites, horizontales, ovales-globuleuses, creusées au sommet d'une chalaze orbiculaire et ridée; quelquefois relevées d'un cóté d'une ligne proéminente (raphe) : ombilic un peu latéral, rarement tout-à-fait terminal. 'TÉGUMANT PROPRE double; l'extérieur crustacé, l'intérieur membraneux, adhérent au périsperme. Périsperme charnu. Embryon axile, droịt, ayant presque la mêne longueur que le périsperme : cotylédons planes : radicule aboutissant presque à l'ombilic, le plus souvent obliquement et quelquefois directement.

$N$. B. En décrivant l'Ionidium Ipecacuanha, je dirai quelles sont les raisons qui obligent de réunir les genres Ionidium, Pombalia et Hybanthus. On trouvera aussi des dissertations sur les organes les plus importans des Ionidium, et en général des Violacées dans la $6^{\mathrm{e}}$ livraison de mon Histoire des plantes les plus remarquables du Brésil et du Paraguaj.

\section{EXPLICATION DES FIGURES.}

1. Un des pétales supérieurs vu en dehors. - 2. Un des pétales intermédiaires vu en dedans. - 3. Le grand pétale vu en dedans. - 4. Les étamines. - 5. Calice et pistil. 


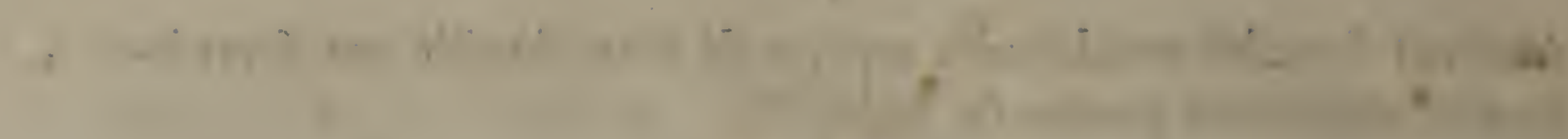

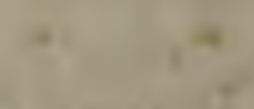

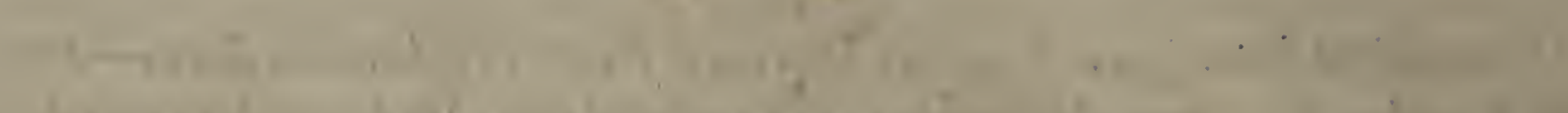

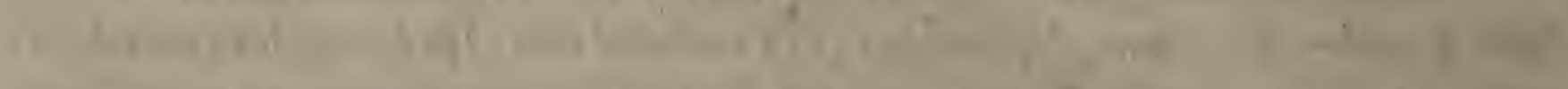

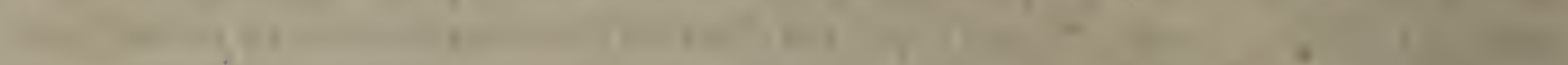

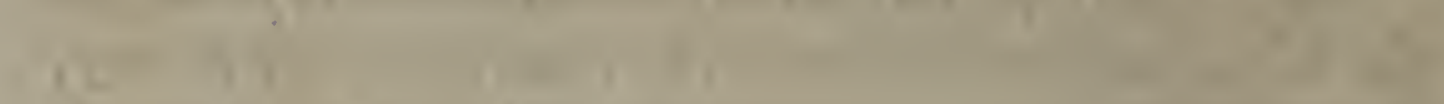

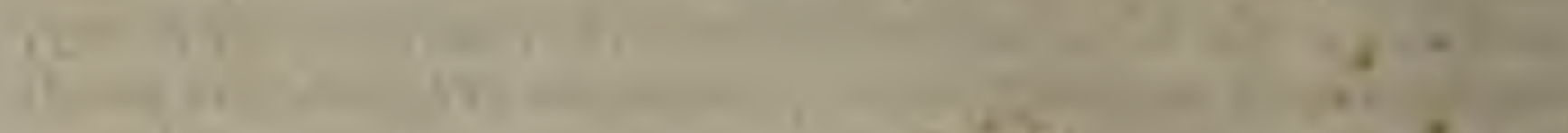

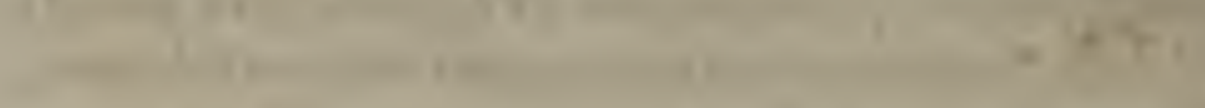

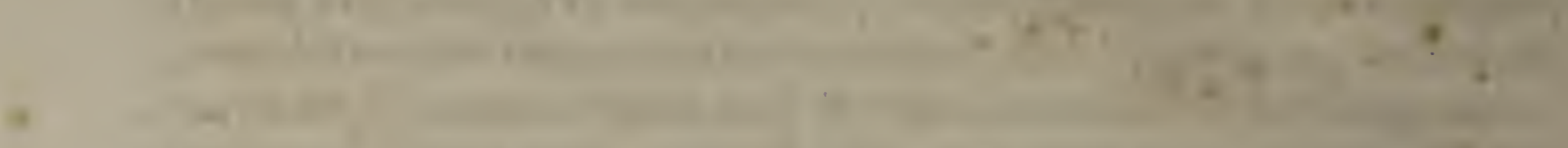

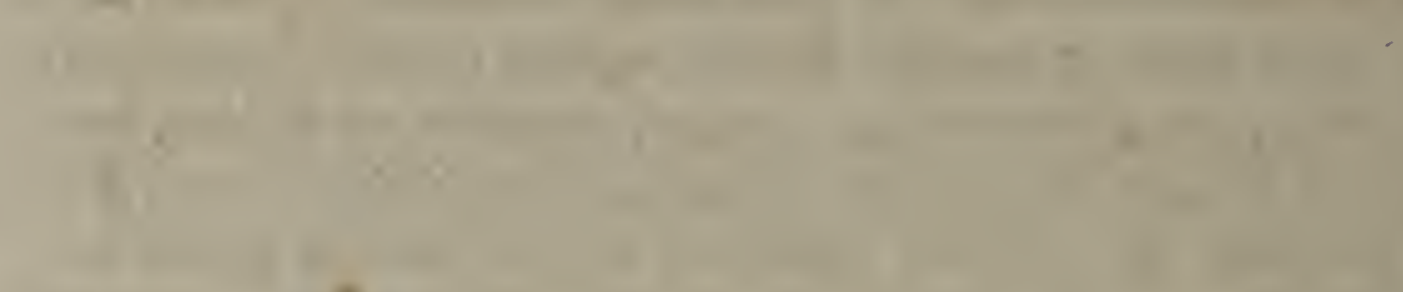

(a)

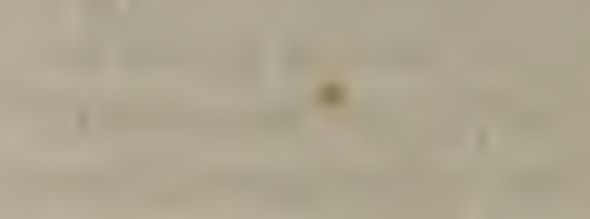

$+$

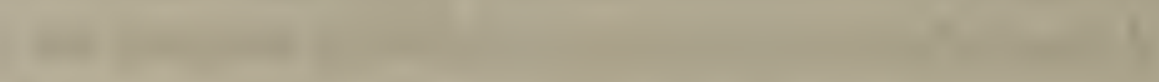

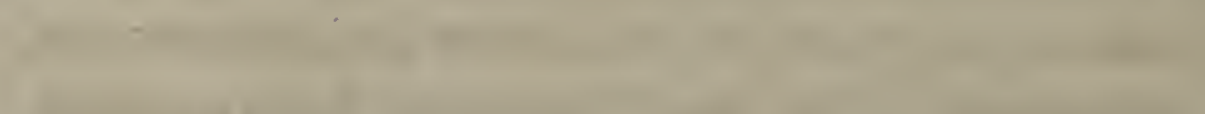

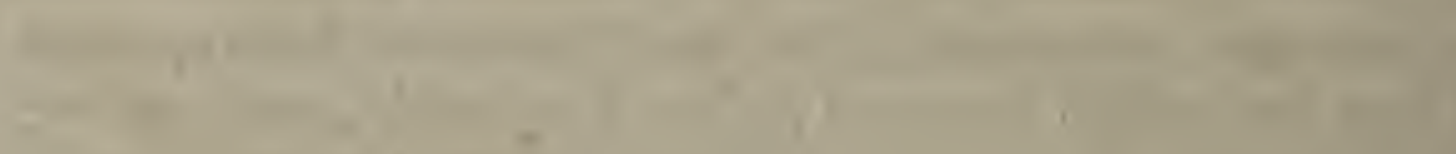

trong

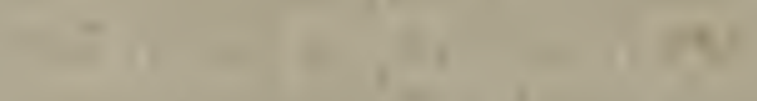

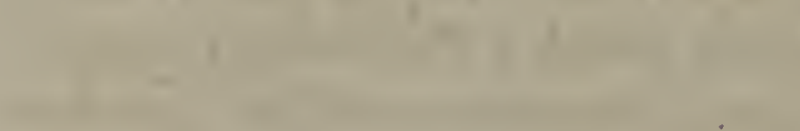

$\left(\frac{10}{2}\right.$

L

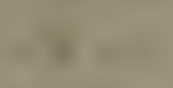



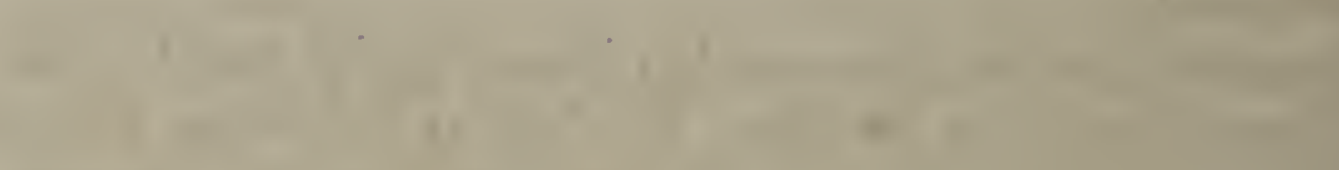

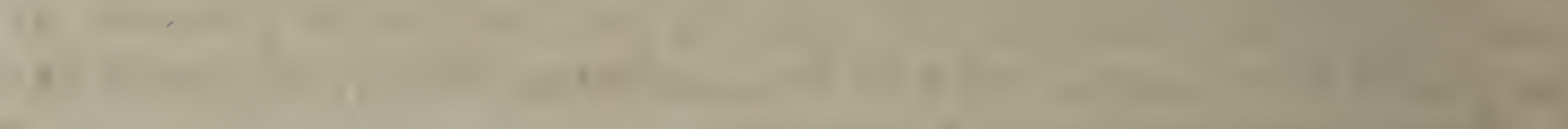
(20)

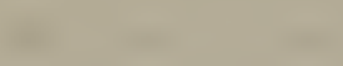

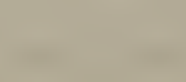

$$
\begin{aligned}
& \text { In }
\end{aligned}
$$



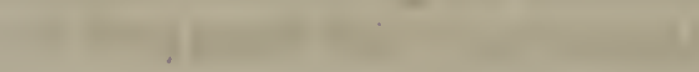

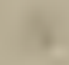


P. IX .

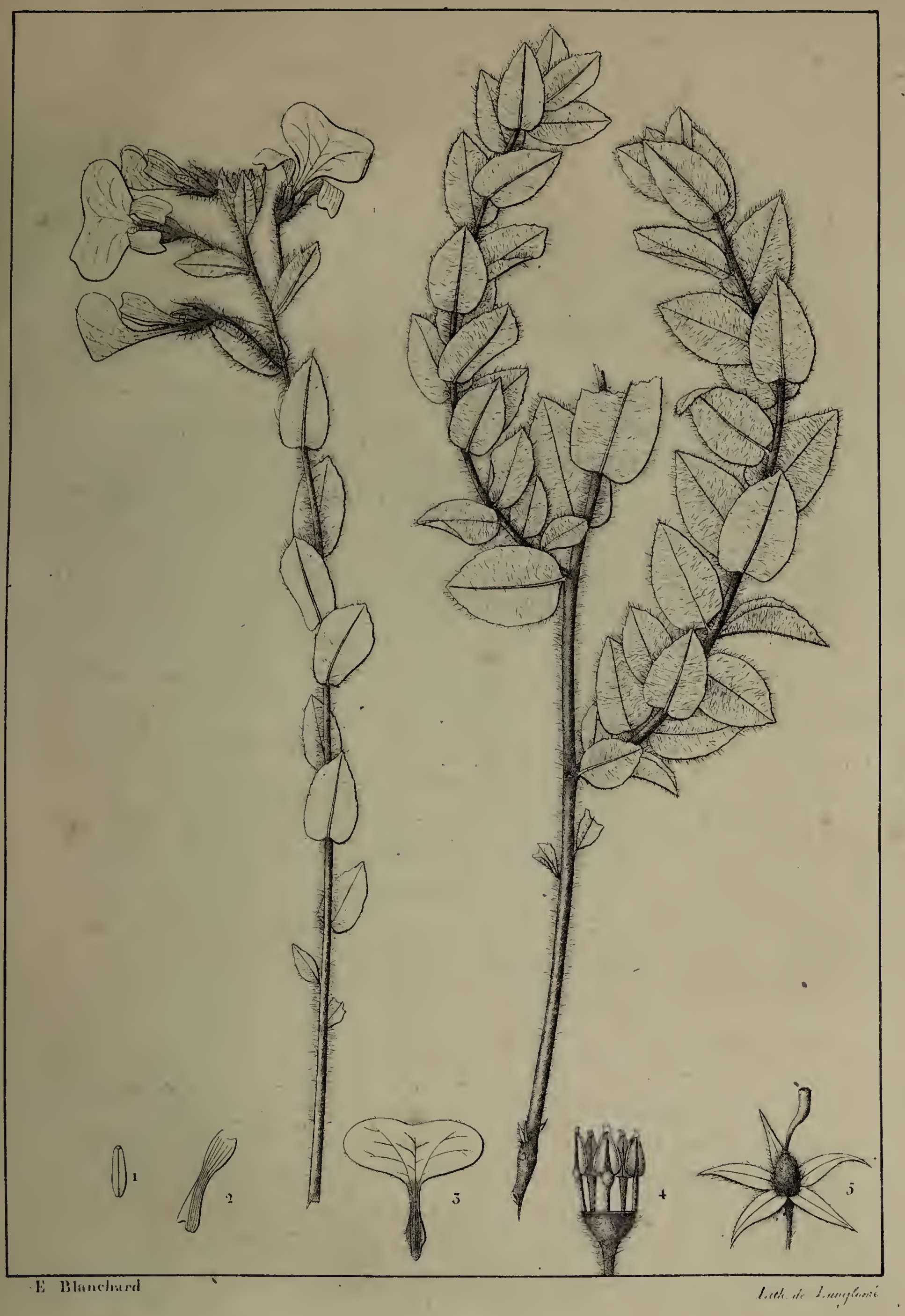

IONIDIUM POAYa. 



\title{
CONOHORIA LOBOLOBO.
}

\author{
CONORI LOBOLOBO.
}

FAMILIE DES VIOLACÉES.

C. foliis alternis et suboppositis, in apice ramulorum confertis, oblongo-lanceolatis, angustis, obsoletè serratis; racemis simplicibus; pedicellis puberulis; squamulis vix manifestis ad basin staminum; ovario villoso; ovulis basi placentarum affixis.

\section{Nom vulgaire : Lobolobo.}

Description. Arbrisseau rameux, dont l'écorce est le plus souvent d'un gris blanchâtre, et dont les rameaux sont quelquefois

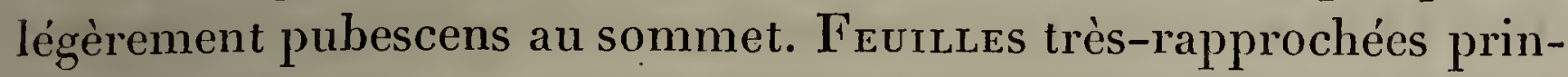
cipalement à l'extrémité des rameaux, opposées et alternes tout à la fois, longues d'un pouce et demi à trois pouces, larges de 6 ì I 2 lignes, oblongues-lancéolées, étroites, aiguës au sommet, un peu aiguës ou plus souvent tronquées à la base, glabres, veinées et bordées de dents qui sont écartées, peu sensibles et noirâtres : pétiole très-court, pubescent, convexe en dessous, canaliculé en dessus. Deux Strpules latérales, scarieuses', fort petites, ovales-lancéolées, aiguës, pubescentes, caduques. FLeurs blanches, longues d'environ deux lignes, pédicellées, réunies en grappes simples, axillaires ou terminales : grappes le plus souvent solitaires quand elles naissent à l'aisselle des feuilles, le plus souvent fasciculées quand elles sont terminales. PÉnoncule de la grappe court, chargé à sa base de petites bractées, ovales-aiguës, le plus souvent embriquées. Axe de la grappe continu avec le pédoncule. PÉdrcelles longs d'environ 2 lignes, le plus souvent tournés dụ même côté, légèrement courbés, articulés un peu au-dessus de la base, accompagnés inférieurement de trois bractées fort petites, scarieuses, ovales-aiguës, couleur de rouille, dont une extérieure est portée sur l'axe même, et les deux autres sur le pédicelle; le plus souvent ces dernières semblent naître au même point que l'extérieur, quelquefois elles sont placées l'une au-dessus de l'autre. Le pédoncule de la grappe, l'axe, les pédicelles, et les bractées sont légèrement pubescens. Calice pro$N^{\circ} \mathrm{X}$. 
fondément 5-partite, un peu charnu; dont les divisions sont ovales, aiguës, très-finement ciliées, blanches, un peu rougeâtres au sommet. Pétales au nombre de 5 , hypogynes, alternes avec les divisions du calice, égaux, dressés, ovales-lancéolés, rapprochés en forme de cloche, acuminés, beaucoup plus longs que le calice, roulés en dehors au sommet. Étamines au nombre de 5, hypogynes, alternes avec les pétales, dressées : filets très-courts, aplatis, à peine soudés entre eux et avec le bas des pétales, chärgés extérieurement d'une écaille très-petite et arrondie : anthères attachées par la base, immobiles, tournées vers le pistil , 2-loculaires, s'ouvrant longitudinalement par les côtés, membraneuses sur les bords et au sommet, d'une couleur fauve, paraissant, avec la membrane terminale, ovales-lancéolées, acuminées : membrane terminale continue avec tout le dos de l'anthère, et égalant ses loges en longueur : loges de l'anthère se terminant antérieurement par deux soies blanches. Strle glabre. Stigmate terminal, obtus. Ovatre ovoïde-globuleux, trilobé, velu, r-loculaire, 3-sperme : ovules péritropes, attachés à la base de trois placentas semi-cylindriques, qui naissent des angles de l'ovaire. Cápsule à trois valves, dont chacune porte une semence dans son miliéu.

Localités. Cette plante est commune dans les bois montueux des environs de Rio-de-Janeiro.

Avec la plante que je viens de décrire, on peut en confondre une autre qui lui ressemble beaucoup, mais qui cependant en est distincte et se caractérise de la manière suivante :

\section{CONOHORIA CASTANEFOLIA.}

\section{CONORI A FEUILLES DE CHATAIGNIER.}

C. foliis alternis et suboppositis, in apice ramulorum confertis, oblongo-lanceolatis, manifestè serratis, mucronulatis; ovario villosissimo; ovulis ex apice placentarum pendulis.

Cette espèce diffère de la précédente par ses feuilles qui ne sont 
point aussi étroites, qui sont évidemment dentées en scie et terminées par une petite pointe particulière. Elle s'en distingue encorè par ses fleurs plus grandes, plus rapprochées, ses pédicelles tout-àfait pubescens, son calice plus charnu, son ovaire ovale et très-velu, enfin par ses ovules suspendus au sommet des placentas. L'odeur de ses fleuirs est agréable. Leurs grappes, comme dans l'espèce précédente, rappellent cèlles du Muguet du mois de mai.

Localités. Cette plante se trouve auprès de Rio-de-Janeiro, et principalement dans les haies qui avoisinent Saint-Christophe.

Usages. On a lieu de s'étonner qu’à l'exception de quelques racines, les habitans du Brésil méridional ne cultivent point de plantes potagères qui appartiennent bien réellement à leur pays. Il est impossible de supposer cependant qu'au milieu d'une quantité si prodigieuse de végétaux, il ne s'en trouve pas un grand nombre qui pussent devenir d'excellens légumes. Mais on ne doit point oublier que si les plantes, qui remplissent les potagers de l'Europe, offrent aujourd'hui des alimens aussi sains qu'agréables, on le doit à des tentatives mille fois répétées, et à un travail opiniâtre; les racines de la carotte sauvage sont dures et extrêmement grêles; on ne pourrait manger, sans de graves inconvéniens, le céleri tel qu'il croît au bord de nos fontaines; enfin nos chous, nos laitues, nos melons, etc., ne sont que le résultat de l'art et de la culture. Il est donc à désirer que les Brasiliens fassent à cet égard des essais que la persévérance rendrait certainement profitables. Je leur indique ici les Conohoria Lobolobo et castanefolia, parce qu'il y a déjà quelques données pour croire qu'en les cultivant, on pourrait finir par en tirer parti. Leurs feuilles crues n'ont qu'un goût herbacé; mais cuites, elles deviennent mucilagineuses, et les nègres de plusieurs cantons des environs de Rio-de-Janeiro les mangent avec leurs alimens. Il faudrait transplanter le Lobolobo dans de bonnes terres, le placer à l'ombre, essayer même quelques moyens pour étioler, ou, comme disent les jardiniers, pour faire blanchir ses feuilles; et il est à présumer que l'on finirait par obtenir un légume agréable. 
Observations botaniques particulières. Le genre Conomoria Kunth, (Conohoria, Passura, Riana et Rinorea Aub. - Alsoïdea Dupetit-Th. - Ceranthera Bauv. - Conohoria, Rinorea, Alsoïdea et Ceranthera Gin.) se caractérise de la manière suivante : Carrice 5-partite, à peine inégal, persis. tant. Pétales au nombre de 5, hypogynes, égaux. Nectaire cupuliforme, entourant les étamines et souvent nul. Éтамines au nombre de 5, alternes avec les pétales, plus courtes qu'eux : filets libres ou soudés en urcéole, le plus souvent fort courts : anthères aplaties, membraneneses au sommet et sur les bords, inmobiles, ayant la face tournée vers l'ovaire, divisées en deux loges et s'ouvrant longitudinalement; les lobes de l'anthière terminés antérieurement par deux soies ou deux petites membranes. Strle persistant. Stigmate termi: nal, oblus. Ovaire supérieur, sessile, 3-lobé, 1-loculaire, 3-9 sperme. Capsura 3-valve, entourée du calice, des pétales et des étamines : valves séminifères dans leur milieu. Semex̣ces presque globuleuses. Tégument propre coriace. Embryor renfermé dans un périsperme charnu : cotylédons planes : radicule tournée vers. le hile (caract. sem. ex Kunth.)

Brown avait déjà reconnu (Congo 21 ) que l'Alsoüdea d'Aubert DupetitThouars, et le Ceranthera de Bauvois étaient identiques, comme anssi le Conohoria et le Passoura d'Aublet. Kunth a été plus loin, et a parfaitement senti que le Riana et le Rinorea ne différaient point du Conohoria, et que celuici devait être également confondu a vec l'Alsoïdea. Mes observations s'accordent parfaitement avec celles de l'auteur savant du Nova Genera, et, comme lui, je réunis tous les genres que je viens de citer. La longueur relative du filament el de l'anthère ne peut servir pour distinguer le Rinorea du Conohoria; car tous les deux offrent également des filets très-courts. A la vérité, quoique Aublet n'ait point parlé d'un nectaire dans son Rinorea, il en existe un dans cette plante, et il n'y en a point dans le Conohoria ulmifolia $(V$. Kunth Nov. Gen.); mais M. Dupetit-Thouars qui a trouvé des Conohoria avec ou sans nectaire, n'a pas cru devoir les séparer, et mon $C$, Lobolobo qui n'est pas. fort éloigné de l'ulmifolia, fait le passage des espèces à nectaire aux espèces qui n'en ont pas, puisque chacun de ses filets porte en dehors une petite écaille distincte, ébauche d'un véritable nectaire. Si les filamens sont libres dans le C. ulmifolia, et soudés dans les Alsoïdea Dup., ils sont également soudés dans mes $C$. Lobolobo et castanefolia, et'il est probable que l'on ne voudra, dans aucun cas, séparer ces plantes de l'ulmifolia. Je conviendrai que dans l'Alsoidea pauciflora Dup.; dont j'ai fait moi-même l'analyse, j'ai trouvé des anthères plus courtes, et des filets plus longs que dans mes Conohoria, et qu'au lieu de finir par deux soies, les lobes de l'anthère se terminent antérieurement par, 
deux membranes; mais l'Alsö̈dea pubescens Dup. que personne, jusqu'à présent, n'a séparé du pauciflora, présente avec un nectaire fort sensible, des anthères presque aussi longues que celles de mes Conohoria, et si nous admettons de semblables caractères pour distinguer des genres, il faudrait, pour ètre conséquent, faire un genre de chaque Ionidium, ou pour mieux dire, renoncer entièrement aux associations génériques. Quant au Piparea que l'on avait cru un instant congénère du Conohoria, N. Kunth pense actuellement, et probablement avec raison, qu'il appartient aux Bixinées, et ce qu'il y a de fort remarquable, c'est que déjà autrefois M. de Jussieu demandait ( Gen. 295) si ce genre ne devait pas être rapproché du Latia.

Observations botaniques générales. J'ai déjà eu l'occasion de faire observer bien des fois qu'aucun caractère, quel qu'il fût, n'avait une importance égale dans tous les groupes. Je vais en donner un nouvel exemple. Rien n'est plus constant, sans doute, que la position des ovules dans les Composées, les Valérianées, les Ombellifères, etc., et par conséquent ce caractère a dans ces familles la plus haute importance : on va voir qu'au contraire il est dans les Violacées sans la moindre valeur. En effet, j’ai rapporté du Brésil trois Conohoria, savoir : C. Lobolobo, castanefolia, et Rinorea (Rinorea Guaganensis Aub): le premier a les ovules attachés au bas des placentas; dans le second ils. sont suspendus à leur sommet; dans le troisième enfin chacun des ovules occupe une place différente, et offre un mode d'adnexion différent, car l'un des trois, inférieur, est ascendant, un autre, intermédiaire, est péritrope, et le supérieur est suspendu.

\section{EXPLICATION DES FIGURES.}

1. Fleur grossie. - 2. Un des pétales $i d$. avec son extrémité roulée. - 3. Un pétale id. déroulé pour montrer sa forme. - 4. Étamine grossie, vue de face. a. Les lobes de l'anthère. - 5. Membrane terminale. - 6. Étamine grossie, vue en dehors. a. Filet chargé d'une écaille. -7 . Calice et pistil. 

P. $\mathrm{x}$.

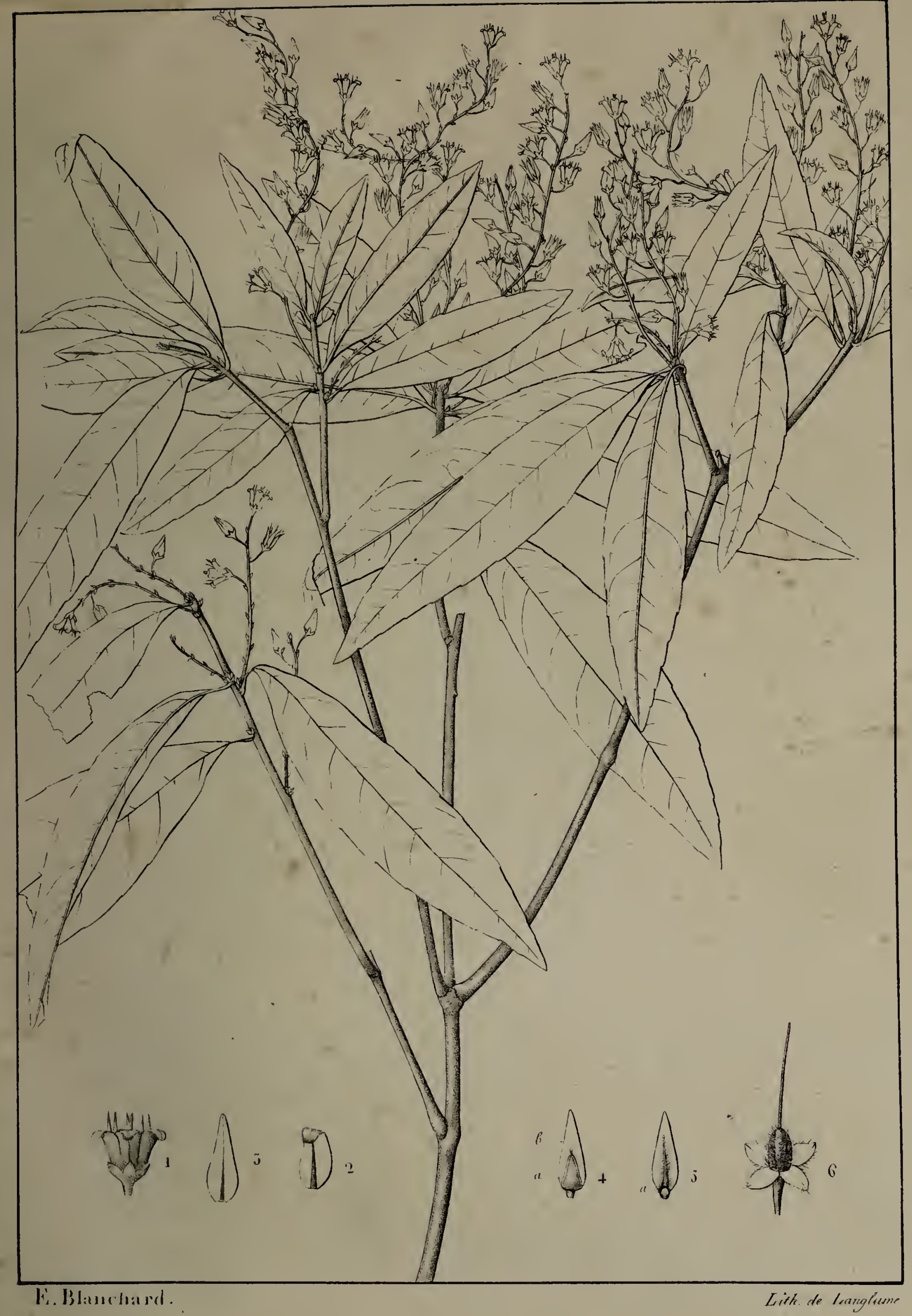

CONOHORIA LOBOLOBO. 



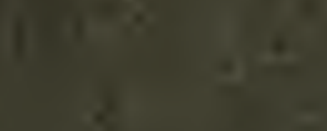

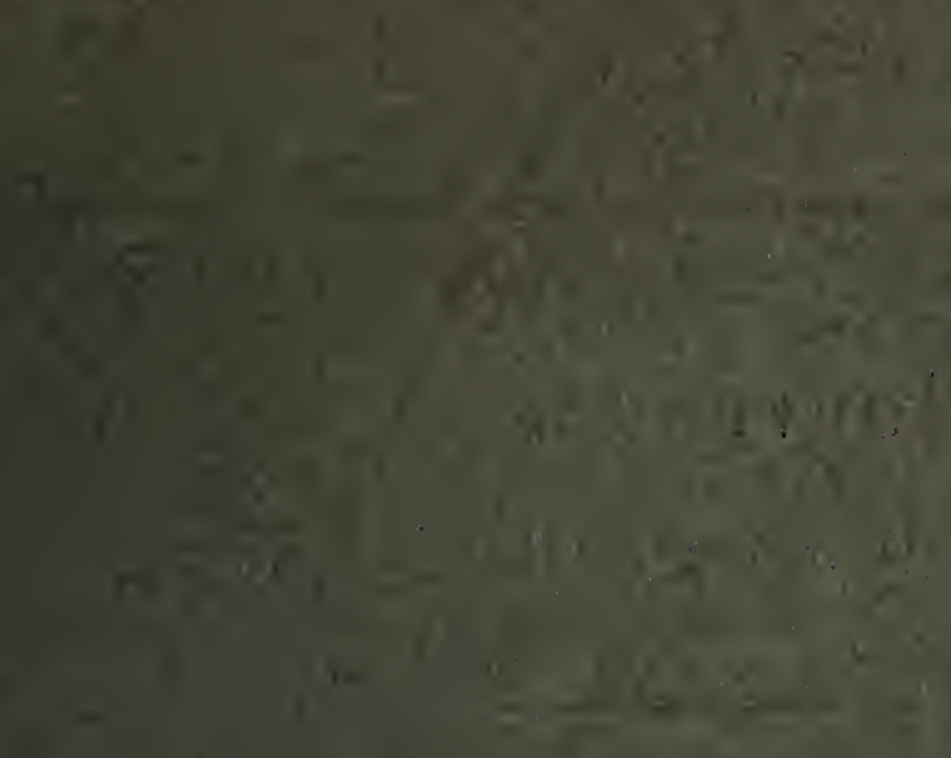

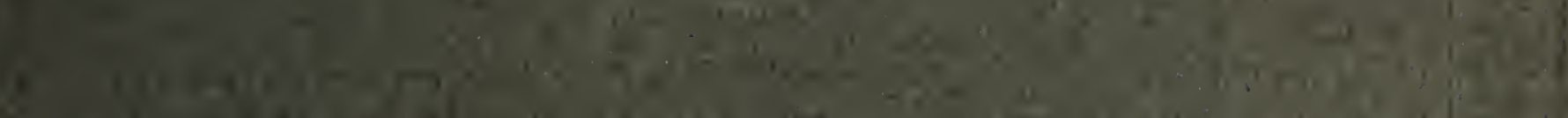

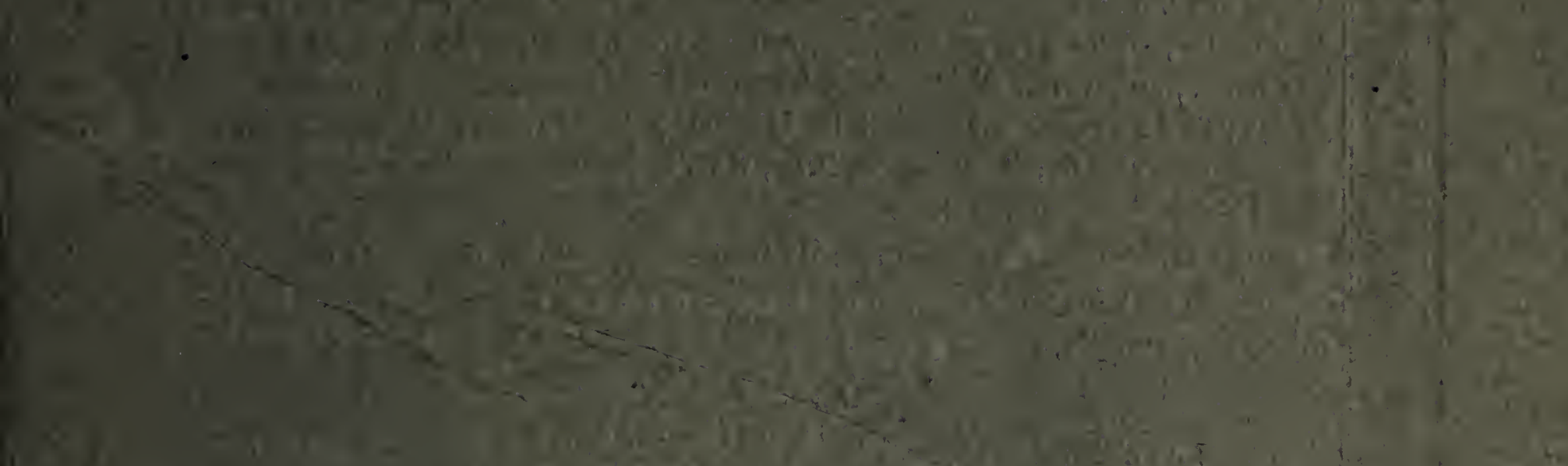

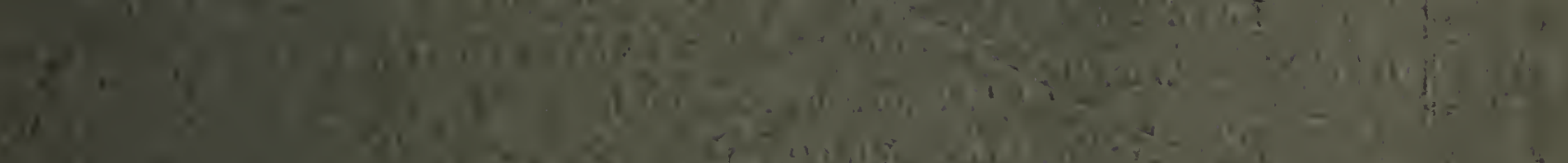

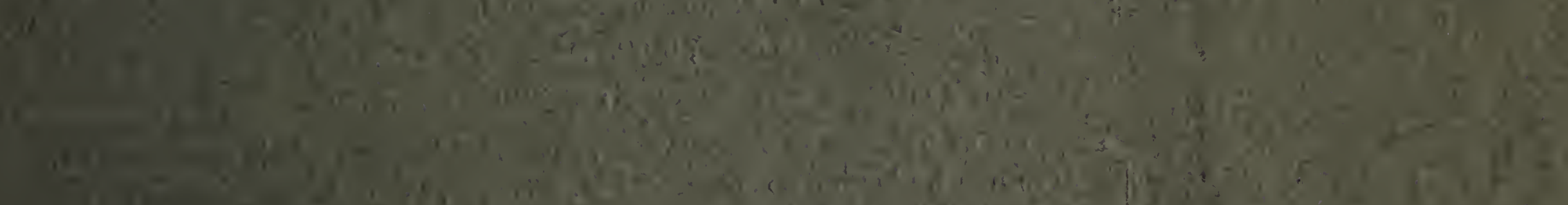

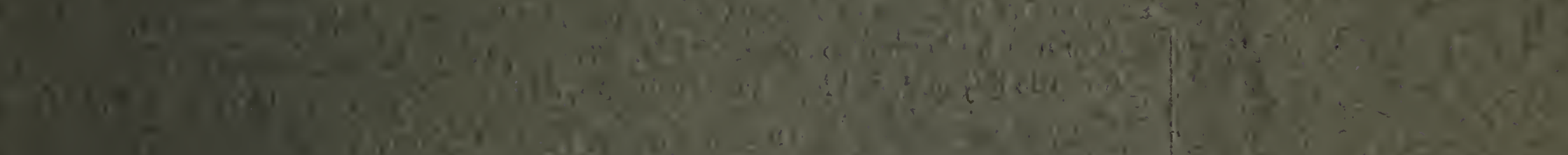



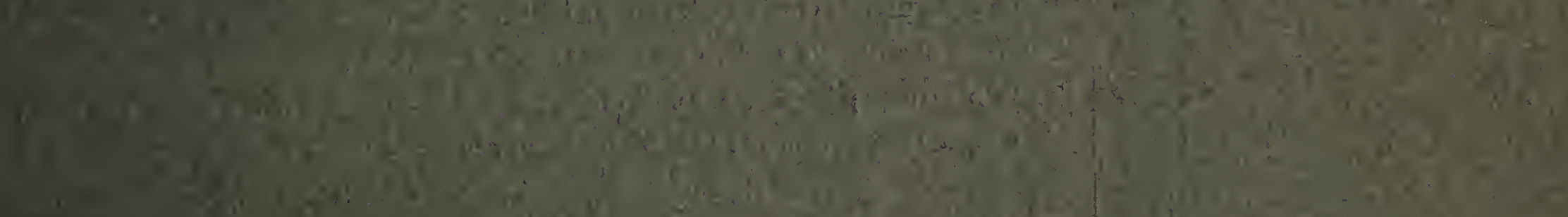

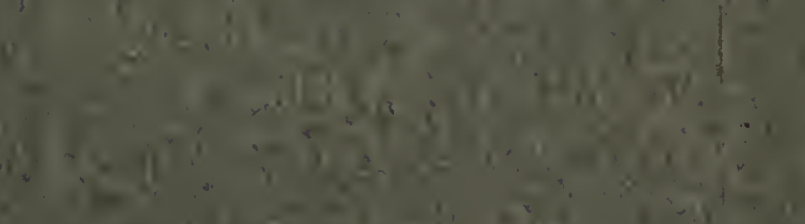

$-1$

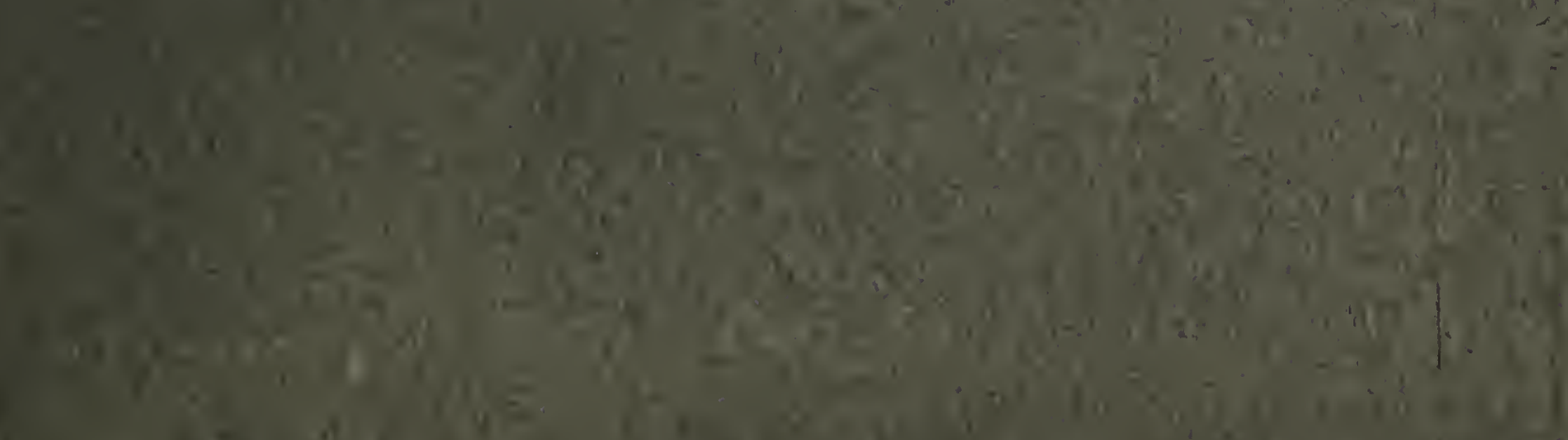

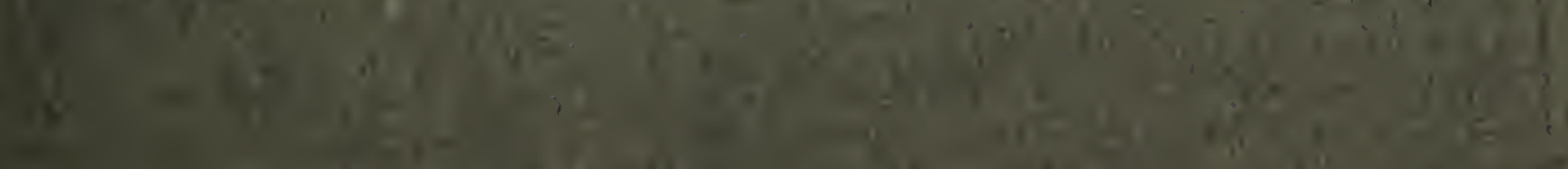




\section{OUVRAGES}

QUI SE TROUVENT CHEZ LE MÉME LIBRAIKE.

$\rightarrow$

\section{Souscription.}

Choix des LetTres édrerantes écrites des Missions étrangères, précédé de Tableaux géogri: phiques, historiques, politiques, religieux et littéraires des pays de missions ; secor de édition, augmentée d'une notice historique sur les Missions étrangères, avec les ectes des rois de France concernant les Missions, de nouvelles Lettres édifiantes et autres morceaux choisis; 8 vol. in- $8^{\circ}$. Prix, 6 fr. le volume pour les souscripteurs.

Le ${ }^{\text {er }}$ vol. est en vente.

Annales littéraires, ou Mélanges de littérature, par M. Dussault; tome $5 \%$, ${ }^{\text {er }}$ vol. de supplément in $-8^{\circ} \ldots \ldots \ldots \ldots \ldots \ldots \ldots$ ofr. L'ouvrage complet. ........................... $35 \mathrm{fr}_{\mathrm{r}}$

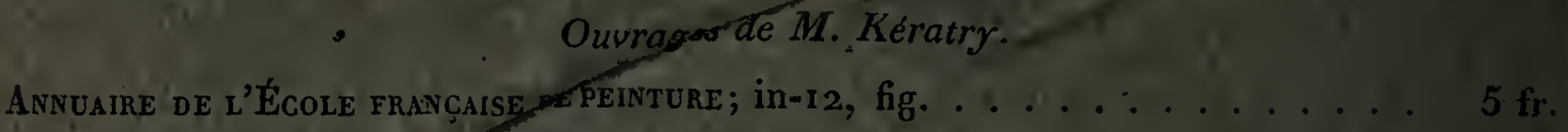

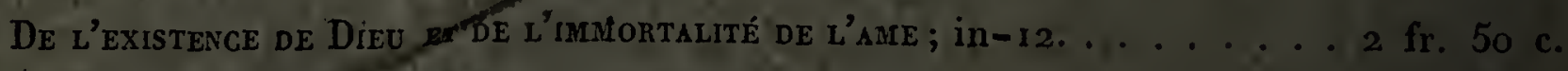

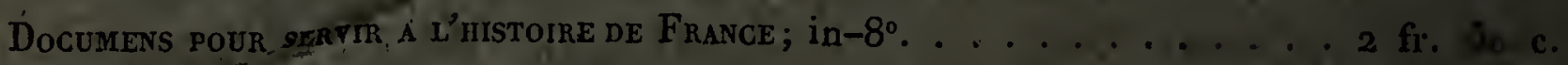

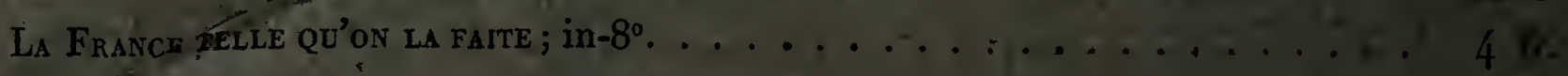

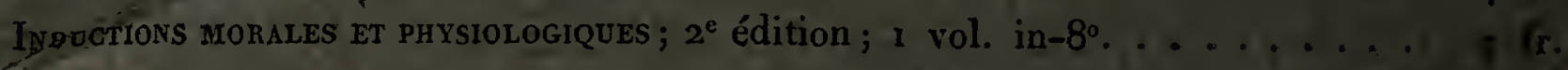
LE GUIDE DE l'artiste ET DE l'AMateur, contenant le Poëme de la peinture de Dufr suroy, avec une traduction nouvelle, par M. Kératry; suivis de Réflexions de cet aucou; de Notes de Reynold, de l'Essai sur la peinture, de Diderot, etc., etc.; x v. in-12 $3 \mathrm{Lr}-; 5 \mathrm{c}$.

\section{Ouvrages de M. l'abbe Moussaud.}

Discours et dissertations littéraires; in- $8^{\circ} \ldots \ldots \ldots \ldots . \ldots \ldots$ fr.

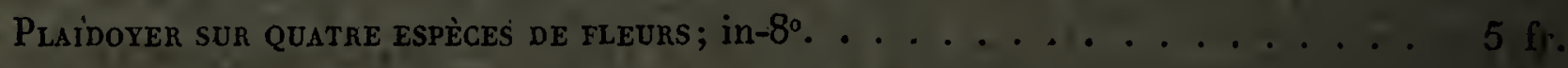

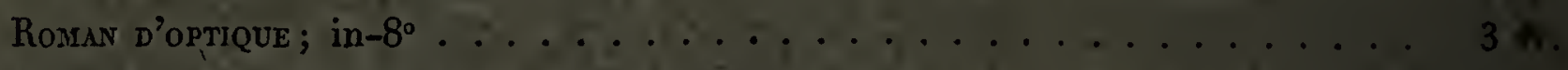

DES MERVEILLEUX EFFETS DE LA VIS D'ARCHIMĖDE; in- $8^{\circ} \ldots \ldots \ldots \ldots . \ldots 2 \mathrm{fr}$.

Ouvrages de madame dé Staël-Holstein.

De r'Allentagne, 3 vol.

Cónsidérations sur la Révolution, 3 vol.

Corinne, 2 vol.

Delphine, 3 vol.

De L'influence des passions sur le bonheur dés individus et des rations, i vol.



RÉFlexions SUR le Sulcide, etc., I vol.

Ensemble 15 vol. in $-8^{\circ} \ldots \ldots \ldots \ldots . \ldots . \ldots . \ldots$. . . . . . . 


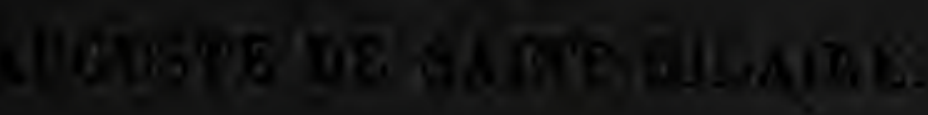

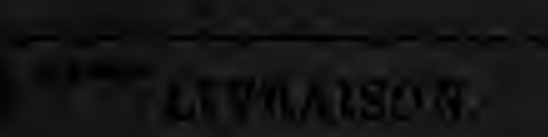

का

\section{PAMS}

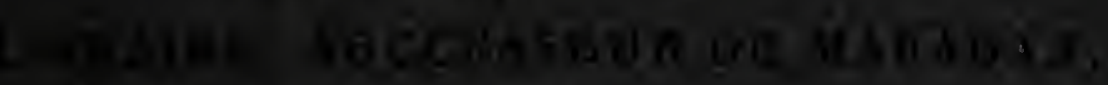

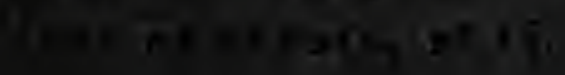




\title{
IONIDIUM IPECACUANHA.
}

\author{
IONIDE IPECACUANHA.
}

VIOL A CÉES.

S. foliis alternis, lanceolato-ovatis, serratis, utrinquè acutis; stipulis acuminatis, membranaceis, medio nervosis; calycinis divisuris semipinnatifidis; petalo inferiore maximo, transversè elliptico.

Ipecacuanha branca. Pis. Mat. Bras, тот.

Calceolaria caulesimplici, hirsuto; foliis axillaribus. Lœfl. It . I 84.

Viola grandiflora veronicæ folio villoso. Bar. Aquin. I 3 .

Viola Calceolaria et Ipecacuanha. Lin. Sp. I327, et Mant. 484.

Viola Itoubon. Aub. Guy. vol. I I, p. 8o8, t. 3 г 8 .

Ionidium Ipecacuanha et Calceolaria. Vent. Malm. p. 28 et 27.

Pombalia Ipecacuanha. Vandel. Fasc. $7, t$. I.

Ionidium Itubu. Kunth Nov. Gen. vol. V, t. 496.

Pombalia Itubu. Gin. in Dec. Prod. vol. I, p. 307 .

Noms vulgaires : Poaya, Poaya da praia, Poaya branca.'

Description. Plante extrêmement variable. Racrne atteignant environ la grosseur d'une plume ou davantage, plus ou moins tortueuse, très-légèrement striée ou ridée, blanche en dedans, d'un blanc grisâtre en dehors, garnie surtout à son extrémité de fibrilles nombreuses et assez grosses : saveur fade et désagréable. Tiges ordinairement nombreuses, longues de 6 à 24 pouces, ascendantes ou étalées en rosette, ligneuses, menues, tantôt chargées de poils épars, tantôt velues ou fort velues surtout au sommet. FEuilles alternes, courtement pétiolées, longues de 7 à I 2 lignes, larges $\mathrm{N}^{\circ} \mathrm{XI}$. 
de 3 à 6 , ovales-lancéolées, plus rarement oblongues ou ovalesoblongues, aiguës aux deux bouts, dentées en scie, quelquefois presque glabres surtout dans le bas de la tige, plus souvent chargées de poils simplement épars, souvent aussi velues ou trèsvelues, principalement les supérieures : pétiole à peine long d'une ligne, plus ou moins velu, canaliculé en dessus, convexe en dessous. Stripules latérales, tantôt ovales-lancéolées, tantôt oblongues ou quelquefois linéaires-oblongues, acuminées, membraneuses, pourvues d'une nervure moyenne, chargées de quelques poils, principalement sur les bords et la nervure. Fueurs solitaires à l'aisselle des feuilles, tantôt sessiles ou presque sessiles, tantôt portées par un pédoncule velu qui atteint jusqu’à 4 lignes, et est chargé de deux bractées, de forme variable, à peu près semblables aux stipules : quand la fleur est sessile, les bractées existent encore, et se confondent alors avec les stipules. Calice 5-partite, mollement hérissé : divisions du calice inégales, oblongues-lancéolées, acuminées, semipinnatifides; à lanières écartées, plus épaisses à leur sommet qui est tronqué. Pétales au nombre de 5, évidemment hypogynes : deux supériemrs à peu près égaux au calice, linéaires, obtus, un peu en faux, uninervés, minces, un peu barlus au sommet : deux intermédiaires un peu plus longs que le calice, oblongs-linéaires ou ovales-oblongs, à peine spatulés, tronqués ou très-obtus, chargés de 4 nervures, réfléchis à leur sommet qui est velu : l'inférieur très-grand, onguiculé, ascendant, ayant à peu près un pouce, trois fois plus long que le calice, velu en dehors; à onglet canaliculé, retréci au sommet, plus large à la base qui est concave; à lame longue d'environ 6 lignes, large de 4 , transversalement elliptique, arrondie sur les côtés, munie d'une petite pointe terminale, décurrente à sa base sur l'onglet. Éramines au nombre de 5, évidemment hypogynes, à peu près inégales, dressées; deux inférieures à peine plus courtes : filets plus longs que les lobes de l'anthère, plus étroits, aplatis, entièrement glabres dans les étamines supérieures, courbés dans les étamines inférieures, épaissis au-dessus ou au-dessous du milieu dans les mêmes étamines, et 
barbus à leur base : anthères attachées par la base, immobiles, aplaties, linéaires, 2-loculaires, bilobées à leur base, terminées par une membrane presque orbiculaire qui est moitié plus courte que les lobes, un peu échancrée au sommet, et de couleur safranée. STrue épaissi de la base au sommet, ayant la forme d'un $s$, velu à la base, concave à son sommet qui est oblique. Stigmate à la surface de la partie concave du style. Ovarre très-velu, I-loculaire, polysperme. Caapsule entourée du calice des pétales et des étamines qui persistent, ovale, 3-gone, plus épaisse sur les angles, aiguë, mollement velue, I-loculaire, 9-I 2 sperme, s'ouvrant en 3 valves naviculaires qui portent les semences dans leur milieu. Semexces ovoïdes-globuleuses, un peu comprimées, glabres, creusées à leur sommet d'une chalaze orbiculaire, tachetées de noir et de blanc, à peine sillonnées d'un côté. TÉGuMEnt propre double; l'extérieur crustacé; l'intérieur membraneux, très-mince. Onibilic terminal. PériSPERME charnu, jaunâtre. Embryon droit, placé dans l'axe du périsperme, et ayant à peu près sa longueur : cotylédons transversalement elliptiques, 2-lobées au sommet : radicule arrondie dans ses contours, un peu plus lougue que les cutylédons, atteignant l'ombilic.

Var. B indecorum. Feuilles assez généralement plus petites et plus ovales que dans le type. Pétales presque trois fois plus courts que le calice, linéaires, obtus, glabres, très-minces, à peu près semblables entre eux; un inférieur quelquefois un peu plus grand et oblong. Les trois Étanines supérieures stériles, presque égales, filiformes, extrêmement étroites, aplaties, membraneuses, glabres, un peu spatulées : les deux inférieures fertiles; à filets aplatis, étroits, à peu près filiformes, glabres; à anthères très-petites, à peu près elliptiques, terminées par une membrane courte, presque 3-angulaire. Style court, courbé, aplati, glabre. Strgma te obtus.

Localités. Cette plante croît à Cayenne; elle se trouve par intervalle sur toute la côte du Brésil, depuis la rivière des Amazones jusqu'au Cap Frio; mais on ne la revoit plus au midi de ce Cap. 
Usages. Tout le monde sait que les racines de cette plante sont émétiques et peuvent remplacer celles du Cephaelis Ipecacuanha. A Fernambouc on les regarde comme le meilleur remède que l'on puisse employer dans les dysenteries. Enfin quelques habitans de la province de Rio-Grande-do-Norte, assurent que pour guérir radicalement ceux qui sont tourmentés de la goutte, il suffit de leur faire prendre pendant quelques jours une légère décoction de ces mêmes racines. Je ne pourrais citer aucun fait particulier qui vînt à l'appui de cette dernière assertion; mais elle paraît a voir assez d'importance pour mériter l'attention des gens de l'art.

On vend souvent à la ville de S. Salvador-de-Campos les racines de l'Ionidium Ipecacuantia pour remplacer l'Ipecacuanha véritable : quelques habitans du Cap Frio en vendent aussi de petites portions à Rio-de-Janeiro; mais aujourd'hui aucun négociant du Brésil n'en envoie en Europe.

Observations botaniques. $\$ I. De deux genres qui doivent rentrer dans le genre Ionidiun.

$1^{\circ}$ Pombalia. Vandelli qui ne connaissait d'autre Ionidium que l'Ipecacuanha, avait reconnu cette plante pour un genre distinct, et l'avait appelée Pombalia. Ventenat qui écrivit après le professeur de Coimbre, méprisa la loi conservatrice de l'antériorité, et substitua au mot de Pombalia celui d'Ionidium qui, ayant malheureusement passé dans un grand nombre de livres, ne pourrait être rejeté aujourd'hui, sans qu'on bouleversât toute la nomenclature. Frappé sans doute de cetle infraction aux lois adoptées par les botanistes vraiment amis de la science, M. de Gingins a cru que le Pombalia pouvait être conservé, et quill ne serait pas nécessaire pour cela de supprimer l'Tonidium. Cela serait à désirer; mais nous sommes malheureusement forcés de reconnaître qu'il y a identité parfaite, et M. de Gingins l'aurait incontestablement senti, s'il eût eu sous les yeux la suite des espèces brasiliennes. La différence du Pomb̉alia et de l'Ionidium consisterait, d'après M. de Gingins, en ce que le calice du Pombalia serait très-grand, et à bords hérissés de pointes roides (echinatus); en ce que les filamens seraient plus longs que dans l'Ionidium; l'ovaire très-velu, et le pédoncule non articulé. J'ai quatre espèces où le calice est pinnatifide; mais il en est une, l'Ionidium scariosum, dont les divisions sont entières au sommet, el celles des cillices du setigerum ne présentent en tout que 5 à 6 lanières. Si le 
calice des Ionidium villosissimum et Ipecacuanha est assez grand, celui du scariosum ne l'est pas plus que dans l'Tonidium lanatum, et le calice de l'I. setigerum est aussi petit, et même beaucoup plus petit que dans beaucoup d'autres espèces, à divisions calicinales non découpées. Les I. Ipecacuantla et villosissimum ont, il est vrai, la lame de leur pétale inférieur transversalement elliptique ; mais les $I$. scariosum et setigerum offrent, avec un calice semblable ou à peu près semblable, une lame presque orbiculaire; et d'un autre côté, l'I. Poaga, et une foule d'autres qui n'ont pas de découpures à leur calice, ont la lame de leur pétale inférieur transversalement elliptique. Il est incontestable que les étamines ont des filets très-sensibles dans les $I$. Ipecacuanla et villosissimum; mais les anthères sont sessiles dans l' 1 . setigerum. Les $I$. lanatum et Poaya qui ont le calice sans divisions offrent un ovaire velu comme l'Ipecacuanta ; les pédoncules de l'I. setigertum sont articulés comme ceux de beaucoup d'espèces à calice non divisé ; enfin celui qui voudra consulter le port des plantes dont il s'agit, ne pourra jamais se décider à séparer les $I$. Poaya et lanatum, des $I$. Ipecacuanha et villosissimum zas plus que l'I. setigerum des $I$. commune et sylvaticumn.

$2^{\circ}$ Hybanthus. J'aurais désiré conserver le genre Hybanthus de Jaquin, fondé sur l'avortement de deux étamines, l'existence d'une glande, celle d'un pétale inférieur concave à sa base, enfin sur l'inflorescence et le port; mais j'avouerai franchement que je n’ai su quelles espèces rapporter à ce genre; car ses faibles caractères se nuancent dans les Ionidium de l'une à l'autre espèce. Presque toutes celles du Brésil ont le pétale inférieur, concave à la base, et plusieurs des Ionidium de Ventenat présentent le même caractère d'une manière plus prononcée encore. L'avortement de deux ou plusieurs étamines est commune chez les Violacées, comme l'a très-bien observé M. de Gingins; mon savant ami M. Kunth eł moi nous avons trouvé toutes les étamines stériles dans plusieurs Noisettia par conséquent diö̈ques ou polygames, et une simple variété de l'Ionidium Ipecacuanta présente deux anthères avortées. Si l'Hy banthus a une glande dans sa fleur, l'I. glutinosum en a deux, et personne ne le rapporte à l'Hybanthus dont il n'a point l'inflorescence. I'un autre côté l'I. atropurpureum qui se rapproche de ce dernier par l'inflorescence, n'a ni glandes ni étamines stériles. Quant au port, celui de l'Hybantlus lui est certainement particulier; mais si les Viola diffèrent singulièrement des Ionidium pour la physiocomie, ces derniers ne different guère moins entre eux, et, par exemple, 1.es $I$. nanum, lanatum, setige rum et bigibbosum ont bien peu de ressemblance dans le port. Ventenat, Jussieu, Persoon, Poiret, Ræmer et Schultes, n'ont point adopté le genre $\mathbb{N}^{\circ}$ XI. 
Hybanthus, et il est fort vraisemblable que si Jaquin lui-même eût eu d'autres Ionidium à décrire, il les eût rapportés au genre Hybanthus (1).

$\$$ II. Des variétés de l' Ionidium Ipecacuanha:-Comme toutes les plantes qui croissent dans un grand nombre de localités différentes, l'I. Ipecacuanha est sujet à une foule de modifications. Je n'ai indiqué que celles que j’ai remarquées dans les individus que j'ai trouvés au Brésil, et j’ai cru devoir les décrire successivement, en traitant de chaque organe, plutôt que de faire un long catalogue de variétés qui, encore se serait trouvé probablement incomplet. J'ai cependant signalé la variété indecorum, parce qu'elle présente des différences. qui vont jusqu’à contrarier les caractères génériques.

$N$. $B$. Je ne dis rien ici de la synonymie que j'établis ici pour I'T. Ipecacuanha, parce que je l'ai déjà discutée ailleurs. (PI. Rem. Bres. et Par. Introduction, p. XXII.)

\section{EXPLICATION DES FIGURES.}

1. Feuilles de diverses variétés. - 2. Une des divisions du calice. - 3. Le grand pétale vu en dedans. - 4. Pétale intermédiaire vu en dehors. - 5. Pétale supérieur. - 6. Étamines. - 7. Pistil. - 8. Fleur de la variété indecorum.

(1) Toutes les espèces citées ici doivent se trouver décrites dans la cinquième livraison des Plantes. les plus remarquables du Brésil et du Paraguay. 
PI. XI

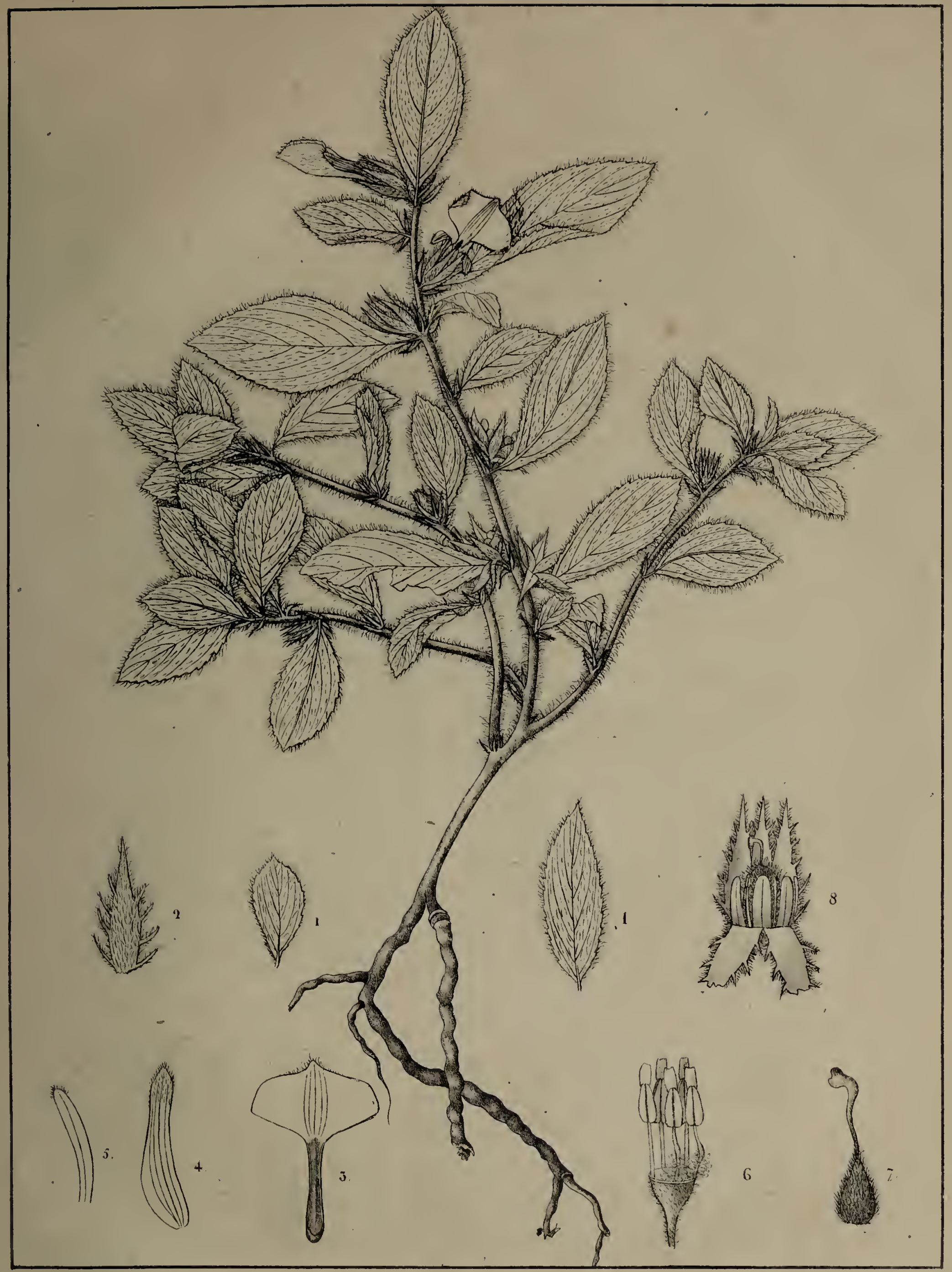

F. Blanchard.

Lich de Lunglum

\section{ONIDIUM IPECACUANHA}





\title{
SPERMACOCE POAYA.
}

\author{
SPERMACOCE POAYA.
}

FAMILLE DES RUBIACÉES.

S. glaberrima; foliis oblongo-ellipticis, basi obtusis, apice acutis ; stipulis setaceo-multifidis; floribus capitatis verticillatisque; staminibus exsertis.

Nom vulgaire : Poaya do campo.

Description. Plante glabre dans toutes ses parties. Racine blanche, un peu plus grosse qu'une plume de corbeau, d'un goût peu agréable qui rappelle celui du véritáble Ipécacuanha ( Cephaelis Ipecacuanha). Tige herbacée, mais dure, ayant de 8 à I 4 pouces, droite ou contournée, simple, quadrangulaire, ordinairement d'un vert jaunâtre. Feuilies opposées, sessiles, longues de ro à 22 lignes, larges de 5 à 9 , oblongues-elliptiques, obtuses à la base, aiguës au sommet, d'un vert jaune ou rouge : nervure moyenne proéminente en dessous : nervures latérales au nombre de 12 et également proéminentes : goût des feuilles d'abord trèsdoux, puis acide. Strpules intermédiaires, divisées au-delà de moitié en lanières sétacées, longues de 3 à 5 lignes. Fueurs disposées en tête terminale, et en même temps verticillées à l'aisselle des feuilles supérieures : tête de fleurs terminale accompagnée de 2 à 6 feuilles, ovales, aiguës, beaucoup plus petites que celles de la tige, mais en même temps fort variables pour la grandeur : bractées fort petites, inégales, linéaires ou laciniées, à peu près membraneuses, placées entre les fleurs. Caxtce adhérent, long d'environ 3 à 4 lignes, turbiné, aplati, 4-fide, couleur de lie de vin; à divisions profondes, oblongues, aiguës, un peu inégales. Conolle infondibuliforme, 4-fide, longue de 3 à 4 lignes, glabre en dehors, d'un bleu céleste; à divisions semi-lancéolées, étalées; chargées à la face de poils aplatis, nues à leur sommet. Éт amines au nombre de 4, sortantes, glabres, insérées au sommet du tube de la corolle et entre ses divisions : fi- 
lets courts : anthères linéaires, assez longues, 2-lobées à la base, bleues, attachées au filet vers le tiers inférieur de leur dos, mobiles, tournées vers l'ovaire, à deux loges qui s'ouvrent longitudinalement. Nectatre épigyne, elliptique; 2-partite. Strue sortant, glabre , 2-fide; à divisions contournées en dehors, stigmatiques à leur face. Ovarne adhérent, à deux loges monospermes : ovules elliptiques, à peu près ascendans, attachés à un placenta linéaire qui s'incruste dans une cavité occupant toute la longueur de lear face. Frutt (observé dans la variété $\beta$.), capsulaire, se séparant en deux coques dont chacune, s'ouvrant au sommet du côté intérieur, forme une sorte de cornet.

Localités. Cette plante est extrêmement commune dans les pâturages naturels et élevés de la province des Mines. Elle fleurit de décembre en avril.

Var. B. pubescens. Cette plante diffère du type principal par ses tiges souvent plus menues, pubescentes au sommet, quelquefois un peu rameuses, quelquefois aussi un peu ailées; par ses feuilles rudes sur les bords, légèrement pubescentes et seulement à 4 nervures, par ses stipules un peu pubescentes, découpées jusqu’à la base en lanières plus longues; enfin par le calice pubescent, à divisions un peu rudes et ciliées.

Localités. Cette variété crô̂t dans des contrées plus méridionales que la précédente. Je l'ai trouvée dans les pâturages naturels près l'habitation de Morongava, province de Saint-Paul, et ceux qui avoisinent la Serra-de-S.-Xavier dans la province des Missions. Elle fleurit de janvier en avril.

$U$ sages. Dans les parties des provinces de Minas-Geraes et de Saint-Paul où croît le Spermacoce Poaya, on substitue avec succès ses racines pilées au véritable Ipécacuanha. Les feuilles sont fort remarquables par leur saveur d'abord très-douce, et ensuite acide; on les emploie en décoction dans les coliques et les autres douleurs internes. 
Observations botaniques. \$I. Caractères génériques des Sperata coce. - Ca fuce adhérent, 4-fide. Conolue infondibuliforme, 4-fide. Ét土мines au nombre de 4, alternes avec les divisions de la corolle, sortantes ou incluses: filets gréles, anthères linéaires ou elliptiques, attachées à peu près par le milieu du dos, mobiles 2-loculaires, s'ouvrant longitudinalement. STy te simple ou 2-fide. STIGanate en tête quand le style est simple, et placé à la face de ses divisions quand il est bifide. Nectarre épigyne, elliptique, déprimé, 2-partite. Ovalne 2-loculaire, ì loges 2-spermes : ovules ascendans ou presque ascendans. Fnurt capsulaire, tantốt se divisant entièrement en deux coques parfaitement closes ou ouvertes au sommet, tantôt se séparant par le milieu de la cloison en deux valves qui restent unies inférieurement. Semences libres ou adliérentes au péricarpe. Tégunent propre membraneux. Pérusperme charnu-corné. Earbryon placé dans le périsperme, parallèle au plan de l'ombilic : radicule inférieure.

\$II. Calice. - Quelques auteurs ont attribué à cette plante un calice 4-partite; mais il est évident qu'ils n’ont voulu parler que du limbe. En général, pour éviter toute équivoque, il ne faudrait jamais dire, comme on l'a fait si souvent, qu'un calice adhérent est 2-3-4 ou 5-partite. En effet ces expressions indiquent que les divisions s'étendent jusqu'à la base, et cela ne saurait avoir lieu lorsque le calice est soudé avec l'ovaire.

$\$$ III. Ovules. - Je montre ailleurs (Plantes les plus remarquables du Brésil et du Paraguay) que dans toutes les Rubiacées à feuilles verticillées, l'ovule présente à sa face une cavité assez profonde; qu'un placenta charnu s'incruste dans cette cavité, qu'ensuite ce placenta s'oblitère, et que de là résulte ce creux qu'on observe à la face des graines des Galium, Rubia, etc. On peut voir par ma description que ce caractère fort singulier se retrouve chez la plante que je fais connaître ici. Il contribue à montrer combien sont intimes les rapports des Rubiacées à feuilles verticillées a vec celles où les feuilles sont simplement opposées, le fruit 2-sperme et capsulaire.

\$ IV. Affinités spécifiques du Spermacoce Poaya. - Cette plante est voisine d'une autre espèce également nouvelle qui croît dans les pâturages naturels du village du district de Minas-Novas, appelé Nossa-Senhora-da-1'enha. Je la caractérise de la manière suivante :

Spenadicoce gentianoides glaberrina; caule suffruticoso, ramoso; foliis oblongis vel ovato-oblongis seu ovatis, basi obtusis, apice acutissimis; stipulis acutis, sphacelato-dentatis; floribus capitatis et scepe simul verticillatis; staminibus exsertis.

\section{EXPLICATION DES FIGURES.}

r. Fleur très-grossie. - 2. Style. 



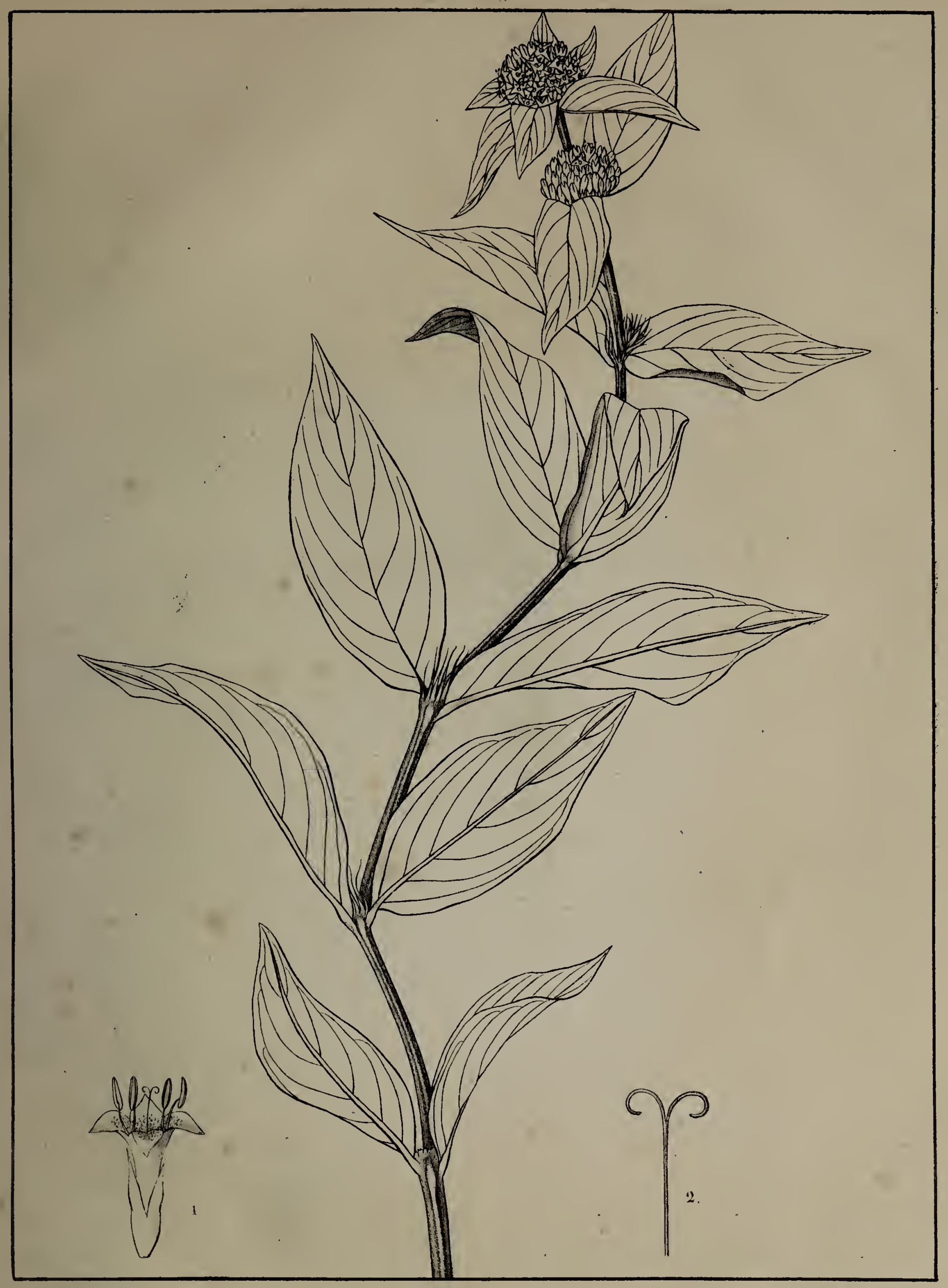

E. Blanchard 



\title{
SPERMACOCE FERRUGINEA.
}

\author{
SPERMACOCE COULEUR DE ROUILLE.
}

\author{
FAMILLE DES RUBIACEES.
}

S. caule pubescente; foliis lanceolatis vel lanceolato-ovatis, lanceolatove-oblongis, lineatis, subpubescentibus; floribus capitatis verticillatisque; involucro 6-8 phyllo; bracteis setaceo-multipartitis ; staninibus exsertis.

Nom vulgaire (au Cap Frio ) : Poaya, Poaya da praia.

Description. Racine à peu près de la grosseur d'une plume de corbeau, d'un brun couleur de rouille, blanche en dedans, garnie de fibrilles capillaires. Tians hautes d'environ ro à I 2 pouces, herbacées, mais dures, naissant ordinairement plusieurs ensemble d'une souche commune, droites, simples ou rameuses, 4-gones, pubescentes ou velues, couleur de rouille. Entre-noruds supérieurs assez longs. Feuilles opposées, à peine pétiolées, lancéolées ou lancéolées-ovales, ou lancéolées-oblongues, aiguës, longues d'environ un pouce, larges de 4 à 5 lignes, parfaitement entières, à peine pubescentes en-dessus, un peu pubescentes en-dessous, acquérant, quand elles sont sèches, une couleur de rouille très-prononcée, relevées inférieurement de nervures saillantes, creusées en-dessus d'autant de stries qui correspondent à ces nervures : les feuilles paraissent presque toujours verticillées, parce qu'il en naît de plus jeunes à leur aisselle. Strf ures intermédiaires, arrondies, pubescentes, divisées jusqu'à moitié en lanières sétacées couleur de rouille. FLeurs très-nombreuses, disposées en têle terminale, et en même temps verticillées à l'aisselle des fleurs supérieures : feuilles florales au nombre de 6 à 8 , formant une collerette au-dessous des têtes terminales, fort inégales entre elles, ovales ou oblongues, d'ailleurs semblables aux feuilles inférieures, mais plus petites: des collerettes semblables existent le plus souvent à la base des verticilles de fleurs. Bractéss placées entre les fleurs, divisées jusqu’à la base en 
lanières sétacées et roussàtres. CALICE adhérent, oblong, étroit, 4-fide; dont le tube est glabre ou pubescent au sommet; dont les divisions sont linéaires-oblongues, aiguës, ciliées, souvent mêlées de rouge et de vert, quelquefois violettes. Conolue longue d'envi-ron 3 lignes, infondibuliforme, 4-fide, arquée, parfaitement glabre en dedans, blanche, rose ou violette; à divisions semi-lancéolées, aiguës, chargées de quelques poils au sommet. ÉtAMines au nombre de 4 , insérées entre les divisions de la corolle, sortantes, glabres: filets capillaires : anthères bleues, linéaires-elliptiques, obtuses, 2-fides à la base, attachées à peu près par le milieu du dos, mobiles, 2-loculaires, s'ouvrant longitudinalement. Strue glabre, indivis. Stigmate terminal, en tête. Carpule ovoïde-elliptique, comprimée, marquée d'un sillon sur les deux faces, couronnée par les divisions du calice, rousse, glabre ou pubescente au sommet, 2-loculaire, 2-sperme, s'ouvrant par le milieu de la cloison en deux valves, 2-fides. Semence libre, ayant environ 3 à 4 lignes, oblongue, un peu plus étroite à une extrémité qu'à l'autre, convexe au dos, creusée à la face d'un sillon longitudinal, semblable à un grain de blé par sa forme, striée transversalement, d'un brun foncé. TÉGUmext propre, membraneux. OMbilic dans le sillon de la graine. P'́risperme charnu-corné. Embryon placé dans le périsperme, presque droit, parallèle au sillon de la graine, ou, si l'on aime mieux, au plan de l'ombilic : radicule inférieure, beaucoup plus longue que les cotylédons : cotylédons étroits, lancéolées.

Localités. Cette plante est commune surtout sur le bord des chemins qui traversent les pâturages élevés des provinces des Mines et de Saint-Paul. Elle fleurit presque toute l'année.

Var. B. nana. Cette variété diffère du type, parce qu'elle n'atteint guère que la longueur du doigt. Elle croît dans les sables au Cap Frio.

Usages. Quoique cette espèce ne soit pas rare, c'est seulement au Cap Frio que j'ai vu en faire usage. On l'y substitue comme 
émétique à l'Ionidium Ipecacuanha, et l'on en vante les bons effets. Avec le Spermacoce Poaya et les Richardsonia scabra et rosea, elle confirme la propriété émétique des Rubiacées dispermes.

Observations botaniques. $\$$ I. Fruit des Spermacoce. - Si l'on disait simplement que le fruit des Spermacoce présente tantòt deux coques, et tantôt une capsule 2-valve, on pourrait croire que ces caractères offrent assez de différences pour donner lieu à la formation de deux genres. Mais il faut se rappeler que, dans un fruit à deux coques, la déhiscence s'opère par le milieu des cloisons, ou qu'elle est septicide ; or, dans les Spermacoce simplement capsulaires, c'est également par le milieu des cloisons que se fait la déhiscence; par conséquent il y a déjà ici une ressemblance extrême. Ce n'est cependant pas la seule quel'on observe : quand il existe deux coques distinctes dans les Spermacoce, elles s'ouvrent souvent à la partie supérieure de leuŕ face; et il est clair qu'il n'y a qu'une nuance de ce dernier genre de fruit à celui où deux valves, se séparant par le milieu de la cloison, restent pourtant unies tout-à-fait à leur base.

\$II. Affinités spécifiques du Spermacoce ferruginea. Cette espèce ne doit pas être éloignée du $S$. verticillata; mais elle s'en distingue par unè foule de caraclères importans.

\section{EXPLICATION DES FIGURES.}

1. Fleur très-grossie. - 2. Style. - 3. Capsule s'ouvrant en deux valves. - 4. Une des deux valves détachée. -5 . Semence vue du côté de la face. -6 . $I d$. vue du côté du dos. - 7. Coupe longitudinale de la semence pour montrer la position de l'embryon. 



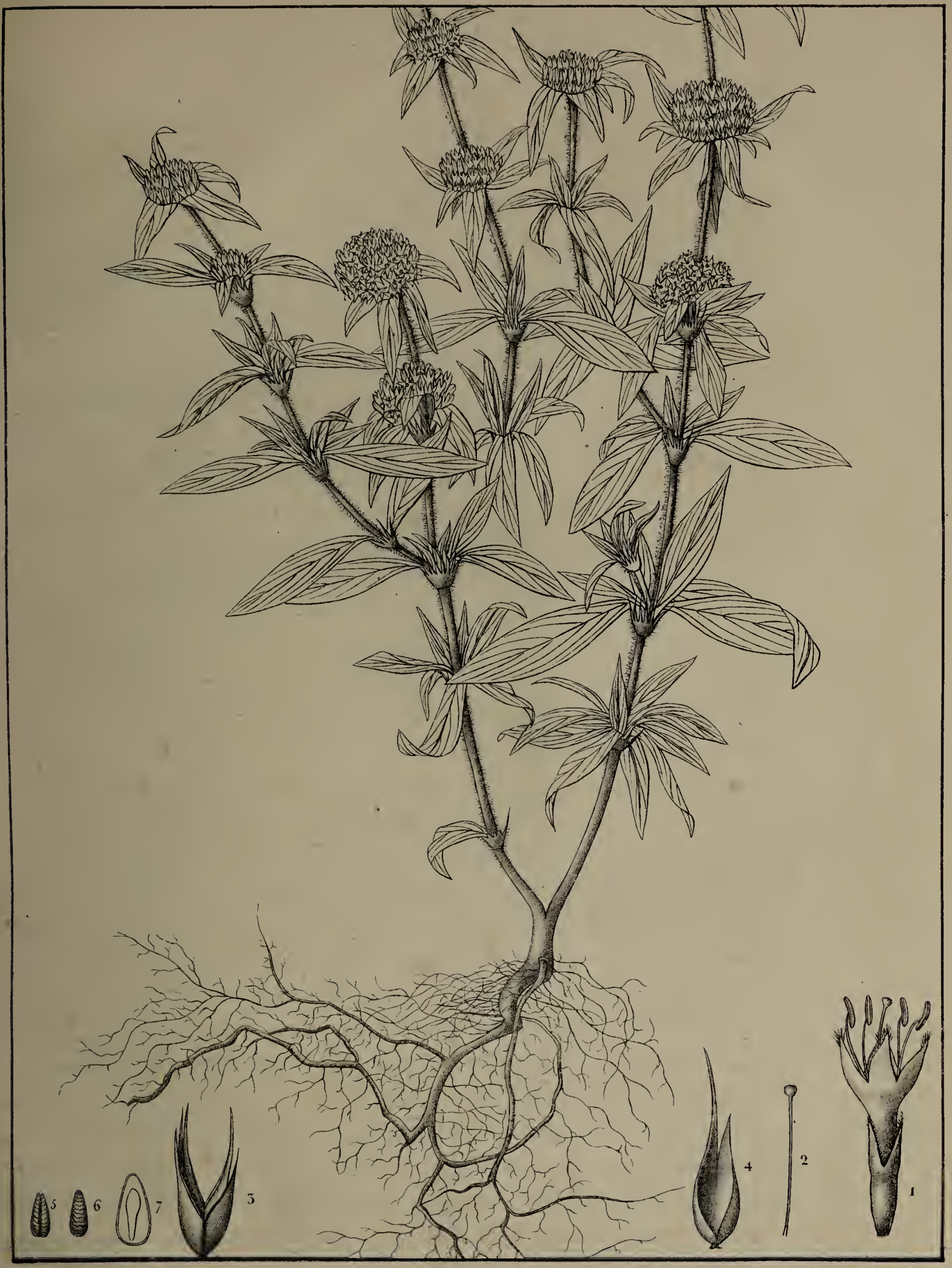

F. Ilanchard

Lish do Tanglumé

SPERMACOCE FERRUGINFA. 



\title{
CALYPTRANTHES AROMATICA.
}

\author{
CALYPTRANTHE AROMATIQUE.
}

FAMILLE DES MYRTEES.

C. frutescens, glaberrima; foliis connatis, magnis, oblongoellipticis; paniculis terminalibus axillaribusve, geminis.

Portugais. Craveiro da terra.

Description. Arbrisseau de 8 à 9 pieds, droit, peu rameux, glabre dans toutes ses parties : rameaux ordinairement dichotomes. Feuilues connées, longues de 12 à 18 pouces, larges de 4 à 6 , oblongues-elliptiques, arrondies à la base, un peu aiguës au sommet, parfaitement entières : nervure moyenne, proéminente endessous : nervures latérales assez nombreuses, parallèles, également proéminentes, et ałsoutissant toutes à une autre nervure longitudinale qui, à peu de distance de la feuille, en suit les contours, en décrivant de légères sinuosités. Panicules de fleurs axillaires ou terminales, placées deux à deux, longues de 5 à 6 pouces, et pédonculées ; quand ces panicules sont axillaires, elles naissent l'une à droite et l'autre à gauche d'un rameau intermédiaire, et comme cette disposition se répète à l'aisselle de chacune des deux feuilles connées, on voit partir à peu près du même point deux rameaux et quatre panicules. P'́doncule long d'un à 4 pouces, roussâtre; axe de la panicule continu avec le pédoncule, et, comme lui, aplati et roussâtre : rameaux de la panicule opposés ou alternes, très-ouverts et se portant brusquement en différens sens. Freurs sessiles sur les rameaux de la panicule, solitaires ou réunies en petits paquets de 2 à 6 . Boutons blanchâtres, de la grosseur d'une groseille, globuleux-turbinés, terminés par une petite pointe. Calice parfaitement entier, fermé et indivis avant la floraison, se déchirant alors horizontalement au-dessus des étamines, et formant ainsi à sa partie $\mathrm{N}^{\circ} \mathrm{XIV}$. 
supérieure un opercule orbiculaire, acuminé, un peu concave, qui se déjette d'un côté, se renverse et reste adhérent par un point à la partie inférieure du calice comme le couvercle d'une boîte à charnière. Pétales au nombre de deux ou trois, petits, ovales-oblongs, obtus, onguiculés, glabres, verdâtres, marqués de points transparens, tombant lorsque le calice s'ouvre, ou restant attachés à l'opercule. Étamines extrêmement nombreuses, insérées sur le calice au-dessous de l'opercule, et parfaitement glabres : filets grêles, flexueux : anthères petites, arrondies, attachées par le dos, biloculaires, s'ouvrant longitudinalement. ST $_{\text {TyE subulé, glabre. }} \mathrm{S}_{\mathrm{TIG}-}$ mate terminal obtus. Ovatre court, adhérent au fond du calice, à 3 loges dispermes : ovules attachés dans l'angle interne et ascendans. Je n'ai pas vu le fruit.

Localités. On trouve cette plante dans les bois vierges de la province de Rio-de-Janeiro, particulièrement au bord de la rivière d'Hytu, près l'habitation de Bemfica ou Joze Gonzalo, située à dix lieues de Rio-de-Janeiro, sur le chemin des Mines, appelé $\mathrm{Ca}$ minho da terra. Les mois de janvier et février sont l'époque de la floraison.

Usages. Jusqu'ici cette plante précieuse avait échappé à l'attention des Brasiliens; maisj'ai cru devoir la leur indiquer parce qu' elle peut donner lieu par la suite à une branche de commerce fort avantageuse. Sans avoir tout-à-fait la même force que le clou de girofle, les boutons et les fleurs du Calyptranthes aromatica en ont cependant le goût et l'odeur, et ces qualités se conservent si bien qu'elles se sont à peine altérées dans les échantillons de mon herbier, qui pourtant ont été passés à la vapeur du soufre. Comme assaisonnement et comme remède, les fleurs de la plante que j'indique ici pourraient donc être utilement substituées à l'épicerie des Moluques; je suis persuadé qu'elles fourniraient une poudre qui ne serait point inférieure à celle que l'on vend sous le nom de poudre de clou de girofle, et il n'est pas douteux, non plus, qu'on n'en obtînt à la distillation une huile essentielle qui ne le céderait guère à celle qu'on 
extrait du clou de girofle lui-même. Quand on voudra cultiver le Calyptranthes aromatica, il sera nécessaire de prendre à peu près les mêmes précautions que pour le giroflier. Comme l'espèce du Brésil croît dans les lieux humides, il faudra en semer les graines dans un terrain frais et d'une bonne qualité, procurer à la plante un ombrage artificiel, ou la cultiver sous des arbres élevés, et l'abriter surtout dans son jeune âge.

Observations botaniques. \$I. Caractères génériques. - Le genre Calyptranthes se distingue de la manière suivante : CALICE adhérent, clos et parfaitement entier avant la floraison, mais qui alors se déchire transversalement au-dessus des étamines pour former un opercule déjeté d'un cóté de la fleur comme le couvercle d'une boîte à charnière. PÉTALEs au nombre de 2 à 3 , fort petits, tombant lors du déchirement du calice, ou restant attachés à l'opercule. ETAMrnes nombreuses, insérées sur le calice : filets grêles: antlières petites, arrondies, attachées par le dos, mobiles, tournées vers l'ovaire, à deux loges qui s'ouvrent longitudinalement. Style unique. Stigmate terminal, simple. Ovatre petit, adhérent, triloculaire, à loges dispermes : ovules ascendans, attacliés dans l'angle interne des loges. BaIE 1-3-loculaire (ex auct).

\$II. Calice. - L’illustre auteur du Genera a demandé (Ann. Mus. vol. XIX, pag. 432) si le calice des Calyptranthes ne serait pas formé par la soudure de deux grandes bractées et d'un calice véritable. Comme la substance calicinale est dans ces plantes parfaitement homogène, et qu'on n'y aperçoit aucu ne trace de suture, il me paraît que la question de M. de Jussieu doit être résolue pas la négative. D'au tres ont demandé encore si l'opercule ne serait point le résultat de la soudure des pétales entre eux (Pers. Syn. II, pag. 31 ); mais il est clair que ceux-ci n'ont pu former l'opercule, puisqu'ils existent indépendamment de lui, et qu'il est parfaitement continu avec la partie inférieure du calice. Si l'on veut absolument expliquer par des soudures la forme singulière du calice des Calyptranthes, il serait plus naturel, ce me semble, de l'attribuer à l'union intime des divisions calicinales ; cependant comment se ferait-il , dans ce caslà même, comme dans l'hypothèse d'une soudure de deux bractées avec le calice, comment se ferait-il, dis-je, que le déchirement s'opérât transversalement au lieu de s'opérer en longueur entre les parties soudées, point où la résistance doit nécessairement être moindre?

$\$$ III. Corolle. Tous les auteurs ont avancé que la corolle n'existait pas dans le Calyptranthes. En examinant sur le frais mes espèces brasiliennes, je me suis convaincu que leurs fleurs étaient pourvues de pétales ; mais ceux-ci peu- 
vent facilement échapper à l'observateur, bien moins à cause de leur petitesse que parce qu'ils tombent, comme je l'ai dit, lors du déchirement du calice, ou restent attachés à l'opercule.

\section{EXPLICATION DE LA FIGURE.}

I. Fleur grossie : on y voit les deux pétales attachés à l'opercule. - 2. id. sans les étamines pour faire voir le style. - 3. Une étamine. - 4. Coupe de l'ovaire.

$N . B$, Les feuilles ont été réduites à moitié. 
PL. XIV

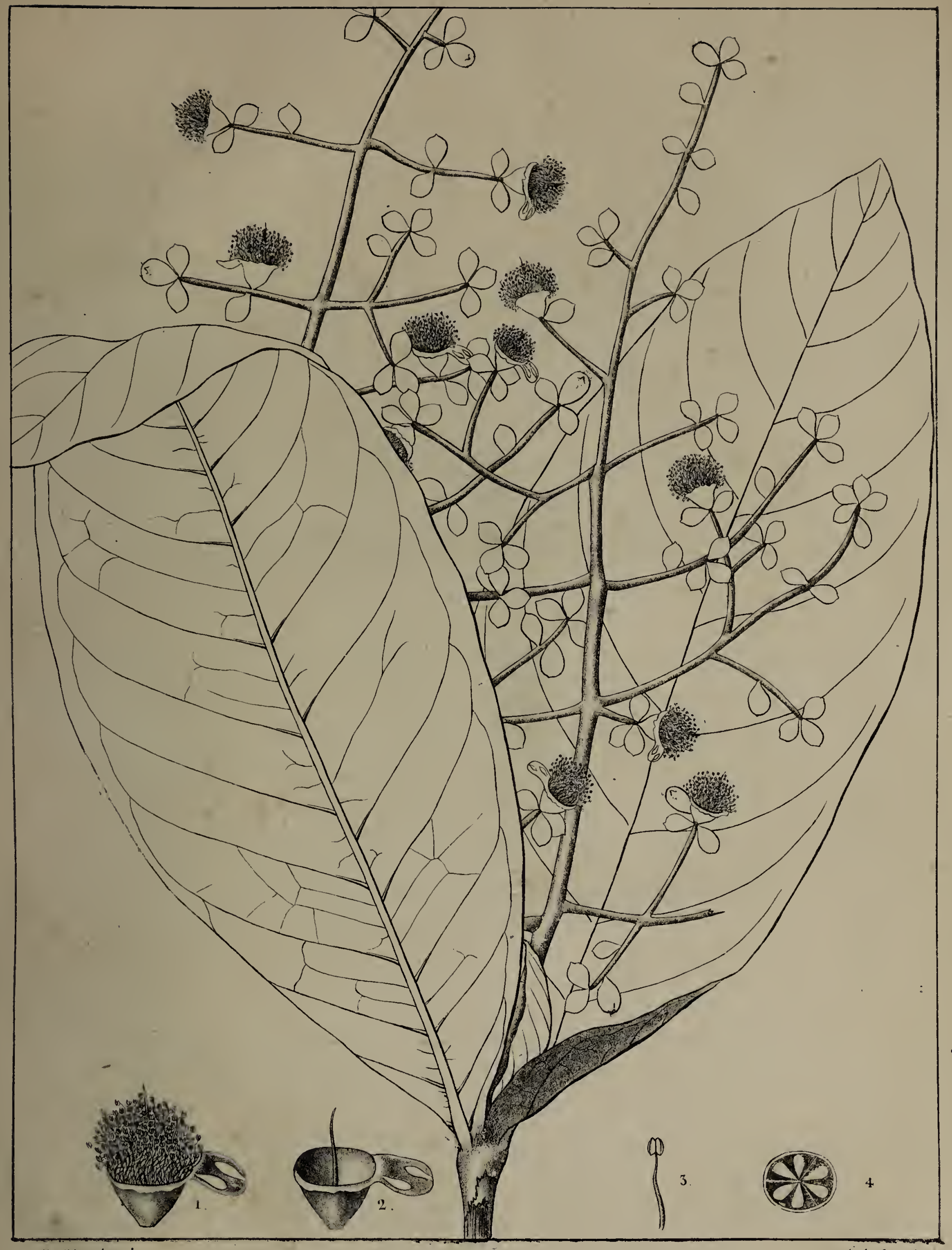

R. Blunctiard

CALIPTRANTHES AROMATICA. 



\section{DROSERA COMMUNIS.}

ROSSOLIS COMMUN.

D ROSÉRACÉS.

D. foliis radicalibus, spathulatis ; laminâ obovatâ, obtusissimâ, suprà marginibusque ciliato-glanduliferâ, subtùs nudiusculá; stipulis capillaceo-multipartitis ; scapis subascendentibus, rachi foliisque multoties longioribus, glabris vel basi subvillosis ; calycibus 5-partitis, glanduloso-puberulis.

Description. Plante herbacée fort variable, principalement dans ses dimensions. Feuilues radicales, nombreuses, disposées en rosette, munies de stipules, ayant avec leurs pétioles une longueur de 6 à I 2 lignes, et la forme d'une spatule : lame obovée, trèsobtuse, presque nue en-dessous, chargée, sur les bords et à la surface supérieure, de cils glanduleux : pétiole aplati, canaliculé, un peu velu ou glabre, à peu près deux fois plus long que la lame. Strpules naissant à la face supérieure de la base des pétioles, divisées en lanières capillaires, et ayant une couleur fauve. Hampes solitaires ou au nombre de deux à trois, un peu ascendantes à leur base, glabres ou quelquefois un peu velues, longues de 5 à 8 pouces, chargées de 3 à 8 fleurs. Fleurs en grappe terminale, tournées du même côté, pédicellées, roses ou couleur de chair : axe de la grappe beaucoup plus court que la hampe, et à peine chargé de quelques petits poils glanduleux : bractées linéaires, étroites, attachées à l'axe le plus souvent au-dessous de la base de chacun des pédicelles, et quelquefois placé entre eux; il n'y a point de bractées au-dessous de la fleur inférieure. CALIce turbiné, 5-partite, un peu inégal, chargé de petits poils glanduleux, persistant : divisions du calice linéaires, un peu aiguës. PÉt ALEs au nombre de cinq, hypogynes, ovales, très-obtus, rétrécis en onglet, très-glabres, persistans. Е́т amines au nombre de cinq, hypogynes, alternes avec les pétales, très-glabres, persistantes : filets aplatis : anthères orbiculaires-elliptiques, jaunes, $\mathrm{N}^{\circ} \mathrm{XV}$. 
2

attachées par la base, immobiles, 2-loculaires, ayant la face tournée en dehors, et s'ouvrant longitudinalement. STyLE unique, profondément 3-partite, glabre, persistant; à divisions profondément 2-fides et ascendantes. Stigmates au nombre de 6 (autant qu'il y a de divisions au style), terminaux, à peu près en massue. Ovarre oblong, obtus, glabre, I-loculaire, polysperme : ovules nombreux, attachés à trois placentas pariétaux. Ca PSUlE entourée du calice, des pétales et des étamines desséchés, obtuse, glabre, à 3 valves : valves portant les semences dans leur milieu. D'après les semences que j’ai vues dans des fruits qui n'étaient pas encore mûrs, je pense que le tégument propre extérieur est membraneux comme dans les Drosera Anglica et rotondifolia, et beaucoup plus long que l'amande.

Localités. Cette plante croît dans les marais des provinces de Saint-Paul, et Minas-Geraes. Elle fleurit de février en mars.

Qualités. Il ne suffit pas de connaître les plantes utiles; il est nécessaire encore de savoir distinguer celles qui sont nuisibles, pour pouvoir prévenir le mal qu'elles peuvent causer. C'est ce qui m'a déterminé à décrire et à faire figurer l'espèce dont il s'agit ici.

Il est peu de pays qui offrent des pâturages meilleurs et aussi vastes que le Brésil; il en est peu qui soient aussi favorables à l'éducation des bêtes à laine que les parties élevées des provinces de Minas, Goyaz et Saint-Paul; et quelques essais, qui pourtant n'ont été tentés que par des hommes ignorans et sans expérience, tendent à prouver qu'on pourrait fabriquer avec la laine de certains cantons des tissus aussi fins que ceux des manufactures les plus renommées de France et d'Angleterre. L'état de la population ne permet pas encore que l'on forme au Brésil de grands établissemens de ce genre; mais on devrait déjà s'y préparer, en cherchant à multiplier les bêtes à laine, en faisant venir d'Europe des béliers de bonne race, en essayant des croisemens, et en donnant quelques soins aux troupeaux. Dans la province de Rio-Grande, on en confie la garde tout entière à des chiens châtrés, auxquels on a fait 
sucer le lait des brebis, et qui, élevés au milieu d'elles, ne les quittent plus, et deviennent leurs défenseurs. Mais dans les provinces de Minas, Goyaz, Saint-Paul, etc., où cette pratique est ignorée, les troupeaux sont nuit et jour abandonnés à eux-mêmes , et la seule précaution que l'on ait coutume de prendre consiste à les placer dans un lieu peu éloigné de l'habitation, et d'où ils ne puissent pas s'éloigner facilement. Les Brasiliens n'arriveront sans doute qu'avec le temps à une méthode systématique de soigner les bêtes à laine; mais dès aujourd'hui les cultivateurs qui se plaignent sans cesse de voir chaque jour diminuer leurs troupeaux, pourraient choisir avec plus d'attention les lieux où ils les placent; ils devraient éviter les endroits humides qui sont généralement si funestes aux moutons, et surtout les marais où croissent des Drosera. Celles des espèces de ce genre qui se trouvent en Europe, sont considérées par un si grand nombre de cultivateurs comme dangereuses pour les bêtes à laine, qu'il est difficile de ne pas croire à la réalité des qualités nuisibles qui sont attribuées à ces plantes, et les espèces brasiliennes diffèrent trop peu de celles d'Europe, pour ne point participer à leurs propriétés délétères. J'ai décrit ici l'espèce la plus commune du Brésil, et comme les autres, qui sont au nombre de douze environ, présentent à peu près le même aspect, on les distinguera facilement quand on connaîtra l'une d'elle (I).

Observations botaniques. \$. I. Caractères génériques. - Le genre Drosera se distingue de la manière suivante : CAIIICE profondément 5-fide, ou plus rarement 5-partite, le plus souvent un peu irrégulier. PétaLes au nombre de 5 , hypogynes ou insérés au fond du calice, alternes avec ses divisions, un peu onguiculés, ovales, très-obtus, glabres. ÉTaMrnes insérées comme les pétales, alternes avec eux, plus longues que l'ovaire, glabres: filets aplatis : anthères obtuses, attachées par la base, immobiles, ayant la face tournée en dehors, et deux loges qui s'ouvrent longitudinalement. STrLe unique, terminal, profondément 3-5-partite, dont les branches sont siniples ou plus souvent profondément 2-fides, quelquefois divisées en lanières, dont la réunion ressemble à un pinceau. Ovarre

(1) Ces douze espèces se trouvent décrites dans la $6^{\mathrm{e}}$ livraison de mes Plantes les plus remarquables du Brésil et du Paraguay. 
libre, ses sile, à peu prés globuleux, 3-lobé, glabre, uniloculaire, polysperme: ovules nombreux, attachés à 3 placentas pariétaux, semi-cylindriques. C $\mathrm{C}_{\mathrm{A} P U \mathrm{LE}}$ obtuse, glabre, 3-valve, entourée du calice, des pétales et des étamines qui tous persistent : valves portant les semences dans leur milieu. Semences nombreuses, fort petites, oblongues. TÉGUMEnT Propre , tantốt simple et crustacé, tantốt double, l'extérieur beaucoup plus grand que l'intérieur. OMrilic terminal. Eмrryon extrêmement petit, placé tout-à-fait à la base du périsperme, tantốt entièrement recouvert par la substance de ce corps, tantốt simplement ap. pliqué contre lui par sa partie supéricure : cotylédons épais et tronqués : radicule obtuse, atteignant l'ombilic, quand l'embryon est placé hors du périsperme, et ne l'atteignant pas tout-à-fait, lorsque le périsperme environne l'embryon (1).

§ II. Affinités spécifiques. - Le Drosera communis a des rapports avec les D. Anglica Huds. capillaris Mich. et intermedia Hayne; mais il differe principalement de l'Anglica par la lame des feuilles beaucoup plus courte, obovée et non oblongue, par ses pétioles qui souvent portent des poils, et par ses stipules divisées en lanières capillair es et profondes ; il se distingue du capillaris par ses feuilles qui ne sont point cunéiformes-arrondies, et des deux espèces enfin par ses calices qui ne sont nullement glabres, mais chargés de petits poils glanduleux. On ne peut non pl us confondre le $D$. communis a vec le $D$. intermedia, à cause de ses pétioles souvent un peu velues, et de ses hampes moins évidemment ascendantes, bien des fois plus longues que les grappes; à cause de ses fleurs moins nombreuses et de ses calices chargés de quelques petits poils glanduleux.

\section{EXPLICATION DE LA FIGURE.}

Elle représente deux individus de dimensions différentes.

(1) Cette description du genre Drosera differe en plusieurs points de celle des auteurs. On verra sur quoi je me fonde dans la 6 e livraison des Plantes les plus remarquables du Brésil et du Paraguay. 


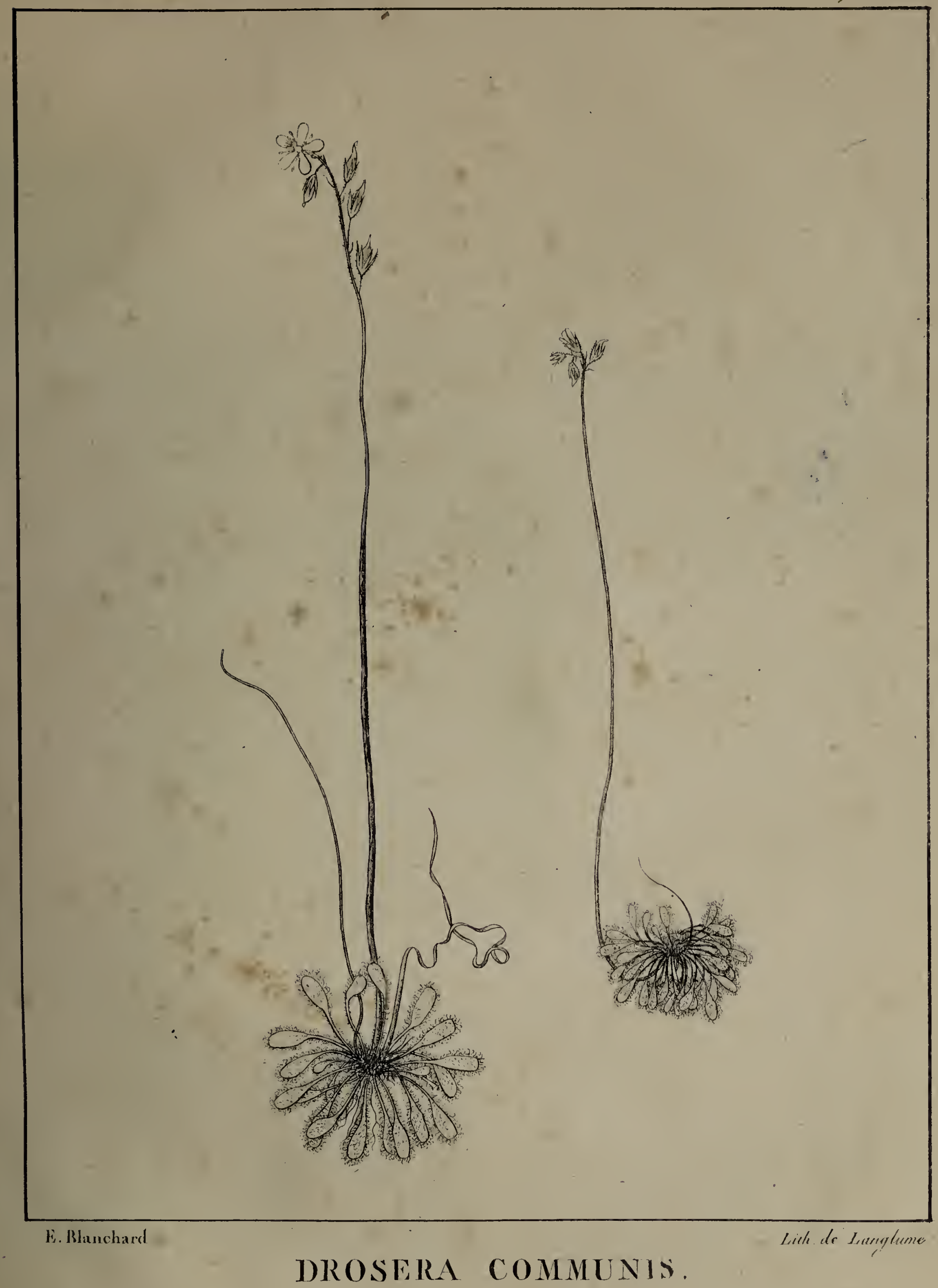








